\title{
ipen
}

AUTARQUIA ASSOCIADA À UNIVERSIDADE DE SÃO PAULO

EFEITOS DA RADIAÇÃO GAMA (COBALTO-60) NAS PRINCIPAIS PROPRIEDADES FÍSICAS E QUÍMICAS DE EMBALAGENS COMPOSTAS POR PAPEL GRAU CIRÚRGICO

E FILME PLÁSTICO LAMINADO, DESTINADAS À ESTERILIZAÇÃO DE PRODUTOS PARA SAÚDE

Karina Meschini Batista Geribello Porto

Dissertação apresentada como parte dos requisitos para obtenção do Grau de Mestre em Ciências na Área de Tecnologia Nuclear - Aplicações

Orientadora:

Profa. Dra. Sueli Ivone Borrely 


\title{
INSTITUTO DE PESQUISAS ENERGÉTICAS E NUCLEARES
}

Autarquia associada à Universidade de São Paulo

\section{EFEITOS DA RADIAÇÃO GAMA (COBALTO-60) NAS PRINCIPAIS PROPRIEDADES FÍSICAS E QUÍMICAS DE EMBALAGENS COMPOSTAS POR PAPEL GRAU CIRÚRGICO E FILME PLÁSTICO LAMINADO, DESTINADAS À ESTERILIZAÇÃO DE PRODUTOS PARA SAÚDE}

Karina Meschini Batista Geribello Porto

\author{
Dissertação apresentada como parte dos \\ requisitos para obtenção do Grau de \\ Mestre em Ciências na Área de Tecnologia \\ Nuclear - Aplicações \\ Orientadora: \\ Profa. Dra. Sueli Ivone Borrely
}

Versão Corrigida

Versão Original disponível no IPEN

São Paulo

2013 


\section{DEDICATÓRIA}

Ao meu marido Fernão, pela dedicação, companheirismo, apoio e ajuda concreta na realização deste trabalho. Aos meus filhos

Sofia, Frederico e João Francisco, pela paciência e carinho, especialmente ao Frederico que desde a barriga me acompanhou neste trabalho e que com certeza continua me acompanhando do céu. Aos meus pais, Ira e Valter, por terem contribuído para eu ser quem sou e pelas constantes orações. Por fim a Deus, que apesar de ter levado meu filho para junto Dele, continuou me dando forças para que eu conseguisse seguir em frente. 


\section{AGRADECIMENTOS}

À minha orientadora Profa. Dra. Sueli Ivone Borrely, pela dedicação, orientação e apoio durante todo o desenvolvimento deste trabalho.

À Dra. Maria Luiza Otero D’Almeida, chefe do Laboratório de Papel e Celulose do IPT, pela oportunidade, orientações, colaboração e constante incentivo.

À Mariza Eiko Tsukuda Koga, pela realização das imagens realizadas no MEV e no microscópio óptico, pelas análises das fibras e análises por EDS, pela amizade e incentivo durante este trabalho.

À Vilma Tavares Teves Varalta, pela valiosa colaboração com as referências bibliográficas e editoração e pela amizade.

À Edna Gubitoso, pela ajuda constante na busca de artigos técnicos, pela prontidão e pela valiosa amizade.

A todos os meus amigos do Laboratório de Papel e Celulose do IPT: Marcela, Patrícia, Márcia, Daniela Colevati, Caroline, Renato, Regina, Denise e Priscila, pelo incentivo, apoio e amizade, em especial ao Antônio (Toninho), Daniela de Paula, Arlete e Érica, pela colaboração na realização dos ensaios.

Ao Laboratório de Corrosão e Proteção do IPT e seus colaboradores Taeko e Marcelo, pelas tentativas de realização das imagens no MEV/FEG e FIB.

Ao Laboratório de Análises Químicas do IPT e seus colaboradores Shoko, pelas análises por espectroscopia no infravermelho; Rosana, Almir e Leandro, pelas análises de difração de raios $X$.

À MSc. Célia e demais colaboradores do Laboratório de Dosimetria em Processos de Irradiação da Divisão de Pesquisa e Desenvolvimento do Centro de Tecnologia das Radiações (CTR) do IPEN, pelas discussões, fornecimento de material e medidas realizadas durante a dosimetria.

Aos Engenheiros Elizabeth e Carlos Gaia do Laboratório de Fontes Intensas de Radiação do Centro de Tecnologia das Radiações (CTR) responsáveis, pela irradiação dos materiais estudados, pela dedicação e pronto atendimento nos momentos solicitados. 
Ao Instituto de Pesquisas Energéticas e Nucleares, pela infraestrutura dos Cursos de Pós-graduação, disponibilidade em disciplinas, e pela oportunidade.

A toda minha família, pai, mãe, Talita, Naila, Lucas, Anna, Pérsio, Ana Helena, Peco e Rô, tios/as, primos/as, pela torcida e constante incentivo.

Às minhas amigas que me acompanharam e me apoiaram psicológica e espiritualmente durante este período, especialmente a Klesi, Nives, Ethel, Aline, Carla, Pati Drago (PD), Karina Pompeu, Raquel Aguiar, Maria Cristina (Cris) e Christina (Chris).

A todos aqueles que de alguma maneira me acompanharam e me encorajaram durante esta etapa de minha vida e carreira demonstrando amizade e apoio. 


\title{
EFEITOS DA RADIAÇÃO GAMA $\left({ }^{60} \mathrm{Co}\right)$ NAS PRINCIPAIS PROPRIEDADES FÍSICAS E QUÍMICAS DA EMBALAGEM COMPOSTA POR PAPEL GRAU CIRÚRGICO E FILME PLÁSTICO LAMINADO, DESTINADA À ESTERILIZAÇÃO DE PRODUTOS PARA SAÚDE
}

\author{
Karina Meschini Batista Geribello Porto
}

RESUMO

A radiação gama é uma das tecnologias aplicadas para a esterilização de sistemas de embalagens contendo produtos para a saúde. No processo de esterilização, é fundamental que as propriedades das embalagens sejam mantidas. Neste estudo, duas amostras de embalagens comerciais, no formato de envelope compostas por papel grau cirúrgico de um dos lados e filme plástico laminado do outro, foram irradiadas com raios gama com doses de $25 \mathrm{kGy}$ (taxa de dose de $1,57 \mathrm{kGy} / \mathrm{h}$ ) e $50 \mathrm{kGy}$ (taxa de dose de 1,48 kGy/h). Uma das amostras de embalagem era constituída por papel de fibras de coníferas e filme plástico laminado de poli(tereftalato de etileno) (PET)/polietileno (PE) e a outra por papel de fibras de coníferas e de folhosas e filme plástico laminado de poli(tereftalato de etileno) (PET)/polipropileno (PP). Os efeitos da radiação nas propriedades físicas e químicas dos papéis e dos filmes plásticos, assim como nas propriedades da embalagem foram estudados. $O$ papel foi o material mais sensível à radiação, sendo a alvura, $\mathrm{o} \mathrm{pH}$ e as resistências ao rasgo, ao arrebentamento e à tração os parâmetros nos quais foram observadas maiores modificações, em ambas as amostras. Todavia, dos dois tipos de papel, o efeito foi mais pronunciado para a amostra com fibras de conifera e de folhosas. A porosidade dos papéis foi alterada com $50 \mathrm{kGy}$. No caso dos filmes plásticos, a propriedade com maior modificação foi a resistência à tração, em ambas as amostras. No caso das embalagens, a irradiação diminuiu a resistência da selagem. Os efeitos observados para a dose de $50 \mathrm{kGy}$ foram em média mais pronunciados quando comparados com as modificações nos valores das amostras tratadas com $25 \mathrm{kGy}$, que é a dose usualmente empregada para esterilização de produtos para a saúde. A dosimetria deste estudo foi realizada nos materiais irradiados com $25 \mathrm{kGy}, 40 \mathrm{kGy}$ e $50 \mathrm{kGy}$, demonstrando sua importância à medida que a variação média para as três doses estudadas foi de $20 \%$.

Palavras-chave: embalagem; esterilização por raios gama; filme plástico laminado; papel. 


\title{
EFFECTS OF GAMMA RADIATION $\left({ }^{60} \mathrm{Co}\right)$ ON THE MAIN PHYSICAL AND CHEMICAL PROPERTIES OF HEALTH CARE PACKAGING AND THEIR COMPOUNDS PAPER AND MULTILAYER PLASTIC FILM, USED FOR HEALTH PRODUCTS STERILIZATION
}

\author{
Karina Meschini Batista Geribello Porto
}

\begin{abstract}
Gamma radiation is one of the technologies applied for the sterilization of packaging systems containing products for health. During sterilization process it is critical that the properties of packages are maintained. In this study two samples of commercial pouch packaging comprised of surgical grade paper on one side and the other side multilayer plastic film were irradiated with gamma rays. The following doses were applied $25 \mathrm{kGy}(1,57 \mathrm{kGy} / \mathrm{h})$ and $50 \mathrm{kGy}(1,48 \mathrm{kG} / \mathrm{h})$. One packaging sample was paper formed by softwood fibers and multilayer plastic film based on poly(ethylene terephthalate) (PET)/polyethylene (PE). The second type of paper sample was made by a mixture of softwood and hardwood fibers and multilayer plastic film based on polyethylene terephthalate (ethylene) (PET)/polypropylene (PP). The effects of radiation on the physical and chemical properties of papers and multilayer plastic films, as well as the properties of the package were studied. The paper was the more radiation sensitive among the studied materials and radiation effects were more pronounced at brightness, $\mathrm{pH}$, tearing resistance, bursting strength and tensile strength. Nonetheless, worst comparatively effects were noted on the sample made by a mixture of softwood and hardwood fibers. The porosity of paper was enhanced by $50 \mathrm{kGy}$. In the case of plastic films, radiation effects on tensile strength was the most pronounced property for both samples. In the case of the packaging the sealing resistance decreased with radiation. The effects observed for the treatment at $50 \mathrm{kGy}$ were more pronounced when compared to $25 \mathrm{kGy}$. This last is the dose which is usually applied to sterilize health products. A dosimetry study was performed during irradiation at $25 \mathrm{kGy}, 40 \mathrm{kGy}$ and $50 \mathrm{kGy}$ and its importance may be reported by the average dose variation $20 \%$.
\end{abstract}

Keywords: packaging, paper, plastic film laminate; sterilization with gamma rays. 


\section{SUMÁRIO}

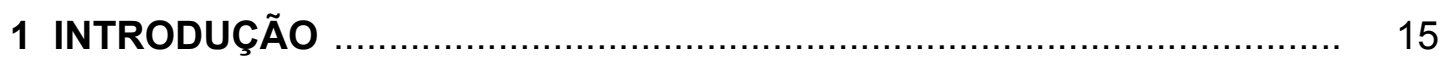

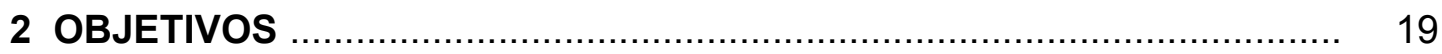

3 CONSIDERAÇÕES TEÓRICAS E REVISÃO BIBLIOGRÁFICA .................. 20

3.1 Embalagens destinadas à esterilização por radiação ionizante ............... 20

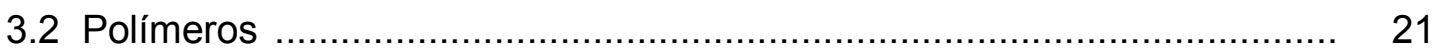

3.2.1 Polietileno (PE), Polipropileno (PP) e Poli(tereftalato de etileno) (PET) ... 22

3.2.1.1 Classificação dos polímeros PE, PP e PET ................................... 23

3.2.1.2 Propriedades dos polímeros PE, PP e PET ................................. 26

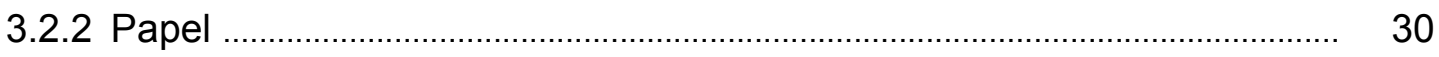

3.3 Esterilização por radiação ionizante (radiação gama de ${ }^{60} \mathrm{Co}$ ) ................. 33

3.3.1 Radiação ionizante ................................................................... 33

3.3.2 Irradiadores .................................................................. 34

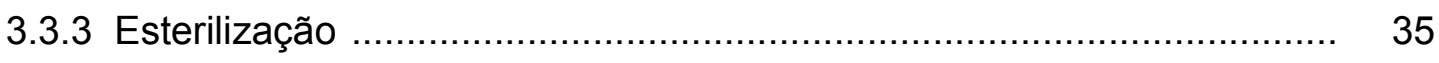

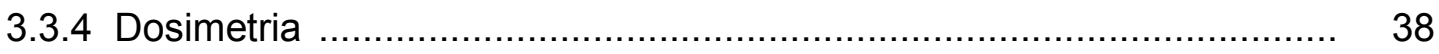

3.3.5 Efeitos da radiação ionizante em polímeros …….................................. 38

3.3.6 Efeitos da radiação ionizante sob papel, celulose e outros materiais ... 42

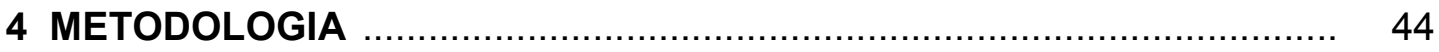

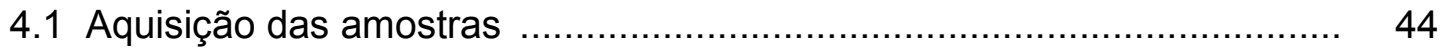

4.2 Caracterização geral das amostras ..................................................... 45

4.3 Irradiação das amostras com dose de $25 \mathrm{kGy}$..................................... 48

4.3.1 Descrição dos ensaios realizados nos papéis das amostras de embalagem ............................................................ 52

4.3.2 Descrição dos ensaios realizados nos filmes plásticos das amostras

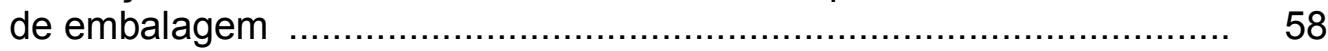

4.3.3 Descrição dos ensaios realizados nas embalagens (envelopes) .......... 60

4.4 Irradiação das amostras com dose de 50 kGy ....................................... 61

4.5 Estudo da variação da dose absorvida no material com uso da dosimetria .. 61

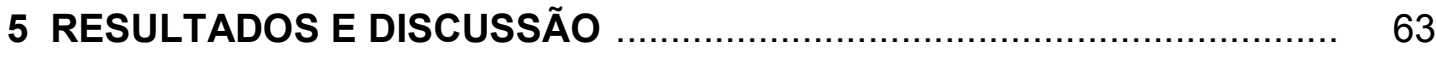

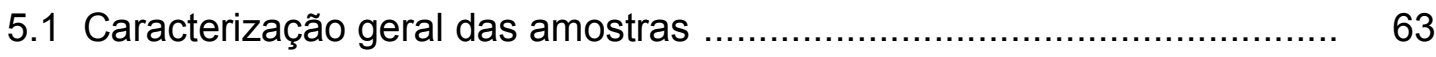

5.2 Irradiação das amostras com dose de 25 kGy ........................................ 71 
5.2.1 Análise dos resultados obtidos para os parâmetros relacionados aos papéis das Amostras 1 e 2

5.2.2 Análise dos resultados obtidos para os parâmetros relacionados aos filmes plásticos das Amostras 1 e 2

5.2.3 Análise dos resultados obtidos para os parâmetros relacionados às Amostras de Embalagem 1 e 2

5.3 Irradiação das amostras com dose de 50 kGy

5.3.1 Análise dos resultados obtidos para os parâmetros relacionados aos papéis das Amostras 1 e 2

5.3.2 Análise dos resultados obtidos para os parâmetros relacionados aos filmes plásticos das Amostras 1 e 2

5.3.3 Análise dos resultados obtidos para os parâmetros relacionados às Amostras de Embalagem 1 e 2

5.4 Estudo da variação da dose absorvida no material com uso da dosimetria

5.5 Atendimento das amostras aos requisitos da norma ABNT NBR 14990. 108

6 CONCLUSÕES 110

7 TRABALHOS FUTUROS 112

ANEXO A - Cópia do certificado de dosimetria 113 


\section{LISTA DE TABELAS}

Tabela 1 - Métodos empregados para a análise do papel e requisitos de desempenho solicitados pela norma ABNT NBR 14990 - Parte 3 .

Tabela 2 - Métodos empregados para a análise do filme plástico e da embalagem e requisitos de desempenho solicitados pela norma ABNT NBR 14990 - Parte 8

Tabela 3 - Controle das datas de irradiação, dose e taxa de dose

Tabela 4 - Resultados das análises por espectroscopia por energia dispersiva para os papéis das Amostras 1 e 2 estudadas, em concentração em massa dos elementos analisados

Tabela 5 - Efeitos da radiação (25 kGy) nas propriedades dos papéis das amostras de embalagem 1 e 2

Tabela 6 - Grau de cristalinidade do papel da Amostra 1 e da Amostra 2 não irradiadas e irradiadas com $25 \mathrm{kGy}$

Tabela 7 - Efeitos da radiação (25 kGy) nas propriedades dos filmes plásticos das amostras de embalagem 1 e 2

Tabela 8 - Efeitos da irradiação (25 kGy) nas propriedades das amostras de embalagem (envelope) 1 e 2

Tabela 9 - Efeitos da radiação (50 kGy) nas propriedades dos papéis das amostras de embalagem 1 e 2

Tabela 10 -Grau de cristalinidade do papel das amostras 1 e 2 não irradiadas e irradiadas com $50 \mathrm{kGy}$

Tabela 11 - Efeitos da radiação (50 kGy) nas propriedades dos filmes plásticos das amostras de embalagem 1 e 2

Tabela 12 - Efeitos da radiação (50 kGy) nas propriedades das amostras de embalagem (envelope) 1 e 2

Tabela 13 - Efeitos da radiação (25, 40 e 50 kGy) nas propriedades dos materiais das amostras de embalagem 1 e 2 para estudo da 


\section{LISTA DE FIGURAS}

Figura 1 - Embalagens compostas por papel grau cirúrgico e filme plástico .. 17

Figura 2 - Representação das estruturas do polietileno e do polipropileno ..... 23

Figura 3 - Representação da estrutura do poli(tereftalato de etileno) - PET ... 24

Figura 4 - Estrutura da celulose a partir da $\beta$-D-glicose destacando a unidade repetitiva (celobiose) e extremidade redutora e não redutora ......... 30

Figura 5 - Estrutura molar da celulose ................................................... 31

Figura 6 - Representação esquemática dos constituintes da suspensão

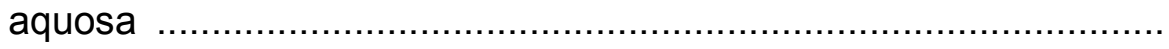

Figura 7 - Superfície de um papel com hifas de fungos sobre as fibras ......... 33

Figura 8 - Irradiador multipropósito de cobalto-60 tipo compacto do IPEN/CTR: a) caixas que contém os lotes de materiais a serem processados adentrando o irradiador; b) piscina do irradiador com a fonte de ${ }^{60} \mathrm{Co}$ exposta

Figura 9 - Fotos das amostras das embalagens utilizadas neste estudo ........ 45

Figura 10 - Irradiador Gammacell 220 série no 142 (12kCi; 8,5 kGy/h) .......... 48

Figura 11 - Preparação dos corpos de prova da Amostra 1 para as análises . 49

Figura 12 - Porosímetro para determinação do diâmetro de poros, construído pelo IPT e ilustração do modo de realização do ensaio

Figura 13 - (a) Exposição das amostras a serem dosimetradas e colocadas no recipiente que é colocado no interior do irradiador; (b) localização de alguns dos dosímetros nas amostras; (c) recipiente que é colocado dentro do irradiador já contendo as amostras

Figura 14 - Fotomicrografias do papel da Amostra 1 da embalagem em estudo

Figura 15 - Fotomicrografias do papel da Amostra 2 da embalagem em estudo

Figura 16 - Imagens obtidas por MEV do papel da Amostra 1 para aumentos de 100x, 500x e 2000x

Figura 17 - Imagens obtidas por MEV do papel da Amostra 2 para aumentos de 100x, 500x e 2 000x

Figura 18 - Espectro de EDS da superfície do papel da Amostra 1

Figura 19 - Espectro de EDS da superfície do papel da Amostra 2

Figura 20 - Representação da porcentagem em massa dos elementos químicos presentes nos papéis das amostras 1 e 2

Figura 21 - Espectro de infravermelho do papel da Amostra 1

Figura 22 - Espectros de infravermelho da frente (a) e do verso (b) do filme plástico laminado da Amostra 1

Figura 23 - Espectro de infravermelho do papel da Amostra 2

Figura 24 - Espectros de infravermelho da frente (a) e do verso (b) do filme plástico laminado da Amostra 2 
Figura 25 - Comparação do espectro total (a) do filme plástico laminado da Amostra 1 com os espectros da frente (b) e do verso (c)

Figura 26 - Comparação do espectro total (a) do filme plástico laminado da Amostra 2 com os espectros da frente (b) e do verso (c)

Figura 27 - Variações em porcentagem dos valores obtidos para o parâmetro de resistência ao rasgo nos papéis das amostras 1 e 2 não irradiadas e irradiadas com $25 \mathrm{kGy}$

Figura 28 - Variações em porcentagem dos valores obtidos para o parâmetro de resistência à tração nos papéis das amostras 1 e 2 não irradiadas e irradiadas com $25 \mathrm{kGy}$

Figura 29 - Variações em porcentagem dos valores obtidos para o parâmetro de resistência ao arrebentamento nos papéis das amostras 1 e 2 não irradiadas e irradiadas com 25 kGy

Figura 30 - Variações em porcentagem dos valores obtidos para os parâmetros de permeância ao ar e diâmetro dos poros nos papéis das amostras 1 e 2 não irradiadas e irradiadas com 25 kGy

Figura 31 - Variações em porcentagem dos valores obtidos para os parâmetros de $\mathrm{pH}$ e alvura nos papéis das amostras 1 e 2 não irradiadas e irradiadas com $25 \mathrm{kGy}$

Figura 32 - Espectros de infravermelho do papel da Amostra 1 não irradiada e irradiada com $25 \mathrm{kGy}$, respectivamente

Figura 33 - Espectros de infravermelho do papel da Amostra 2 não irradiada e irradiada com $25 \mathrm{kGy}$, respectivamente

Figura 34 - Difratogramas do papel da Amostra 1 não irradiada e irradiada com $25 \mathrm{kGy}$

Figura 35 - Difratogramas do papel da Amostra 2 não irradiada e irradiada com $25 \mathrm{kGy}$

Figura 36 - Variações em porcentagem dos valores obtidos para o parâmetro de resistência à tração dos filmes plásticos das amostras 1 e 2 não irradiadas e irradiadas com 25 kGy

Figura 37 - Espectros de infravermelho da frente (a) e do verso (b) do filme plástico da Amostra 1 não irradiada e irradiada com 25 kGy, respectivamente

Figura 38 - Espectros de infravermelho da frente (a) e do verso (b) do filme plástico da Amostra 2 não irradiada e irradiada com 25 kGy, respectivamente

Figura 39 - Fotos e identificação dos lados das amostras de embalagem 1 e 2 utilizadas para o estudo

Figura 40 - Variações em porcentagem dos valores obtidos para o parâmetro de resistência da selagem das amostras 1 e 2 não irradiadas e irradiadas com $25 \mathrm{kGy}$

Figura 41 - Variações em porcentagem dos valores obtidos para o parâmetro de resistência ao rasgo nos papéis das amostras 1 e 2 não irradiadas e irradiadas com 50 kGy

Figura 42 - Variações em porcentagem dos valores obtidos para o parâmetro de resistência à tração nos papéis das amostras 1 e 2 não irradiadas e irradiadas com 50 kGy 
Figura 43 - Variações em porcentagem dos valores obtidos para o parâmetro de resistência ao arrebentamento nos papéis das amostras 1 e 2 não irradiadas e irradiadas com 50 kGy

Figura 44 - Variações em porcentagem dos valores obtidos para os parâmetros de permeância ao ar e diâmetro dos poros nos papéis das amostras 1 e 2 não irradiadas e irradiadas com 50 kGy

Figura 45 - Variações em porcentagem dos valores obtidos para os parâmetros de $\mathrm{pH}$ e alvura nos papéis das amostras 1 e 2 não irradiadas e irradiadas com 50 kGy

Figura 46 - Espectros de infravermelho do papel da Amostra 1 não irradiada e irradiada com $50 \mathrm{kGy}$, respectivamente

Figura 47 - Espectros de infravermelho do papel da Amostra 2 não irradiada e irradiada com $50 \mathrm{kGy}$, respectivamente

Figura 48 - Difratogramas do papel da Amostra 1 não irradiada e irradiada com 50 kGy

Figura 49 - Difratogramas do papel da Amostra 2 não irradiada e irradiada com 50 kGy

Figura 50 - Variações em porcentagem dos valores obtidos para o parâmetro de resistência à tração dos filmes plásticos das amostras 1 e 2 não irradiadas e irradiadas com 50 kGy

Figura 51 - Espectros de infravermelho da frente (a) e do verso (b) do filme plástico da Amostra 1 não irradiada e irradiada com 50 kGy, respectivamente

Figura 52 - Espectros de infravermelho da frente (a) e do verso (b) do filme plástico da Amostra 2 não irradiada e irradiada com 50 kGy, respectivamente

Figura 53 - Variações em porcentagem dos valores obtidos para o parâmetro de resistência da selagem das amostras 1 e 2 não irradiadas e irradiadas com $50 \mathrm{kGy}$

Figura 54 - Comparação entre as variações em porcentagem para os parâmetros mais alterados dos papéis das amostras 1 e 2 não irradiadas e irradiadas com 25 e 50 kGy

Figura 55 - Comparação entre as variações em porcentagem dos valores obtidos para o parâmetro resistência à tração dos filmes plásticos das amostras 1 e 2 não irradiadas e irradiadas com 25 e 50 kGy

Figura 56 - Comparação entre as variações em porcentagem dos valores obtidos para o parâmetro resistência da selagem das amostras de embalagem 1 e 2 não irradiadas e irradiadas com 25 e 50 kGy .....

Figura 57 - Variações em porcentagem dos valores obtidos no estudo da dosimetria para as amostras 1 e 2 não irradiadas e irradiadas com 25, 40 e 50 kGy 


\section{LISTA DE ABREVIATURAS E SIGLAS}

$\begin{array}{ll}\text { ABNT } & \text { Associação Brasileira de Normas Técnicas } \\ \text { AIEA } & \text { Agência Internacional de Energia Atômica } \\ \text { ASTM } & \text { American Society for Testing and Materials } \\ \text { ATR } & \text { Attenuated Total Reflectance } \\ \text { BS } & \text { British Standards } \\ \text { BSE } & \text { Backscattered Electrons } \\ \text { BV } & \text { Borracha vulcanizada } \\ \text { CGEM } & \text { Cromatografia gasosa acoplada a espectrometría de massas } \\ \text { CMQ-LAQ-PE-QI } & \text { Centro de Metrologia Química-Laboratório de Análises } \\ & \text { Químicas-Procedimento de ensaio-Química Inorgânica } \\ \text { CMQ-LAQ-PE-QO } & \text { Centro de Metrologia Química-Laboratório de Análises } \\ \text { CNEN } & \text { Químicas-Procedimento de ensaio-Química Orgânica } \\ \text { CTR } & \text { Comissão Nacional de Energia Nuclear } \\ \text { DLR } & \text { Centro de Tecnologia das Radiações } \\ \text { DNA } & \text { Taxa de dose limite } \\ \text { EDS } & \text { Deoxyribonucleic acid } \\ \text { EN } & \text { Energy Dispersive X-Ray Spectroscopy } \\ \text { EVA } & \text { European Standard } \\ \text { EVOH } & \text { Etileno vinil acetato } \\ \text { FAO } & \text { Etileno vinil álcool } \\ \text { FDA } & \text { Food and Agriculture Organization } \\ \text { FEG } & \text { Food and Drug Administration } \\ \text { FIB } & \text { Field Emission Gun } \\ \text { FT-IR } & \text { Focused lon Beam } \\ \text { GLP } & \text { Fourier Transform Infrared Spectroscopy } \\ \text { HDPE } & \text { Gás liquefeito de petróleo } \\ \text { HPLC } & \text { Pigh-density polyethylene (polietileno de alta densidade - } \\ \text { IAEA } & \text { High Performance/Pressure Liquide Chromatography } \\ \text { INMETRO } & \text { Instituto Nacional de Metrologia, Qualidade e Tecnologia } \\ & \end{array}$




\begin{tabular}{|c|c|}
\hline IPEN & Instituto de Pesquisas Energéticas e Nucleares \\
\hline IPT & Instituto de Pesquisas Tecnológicas do Estado de São Paulo \\
\hline ISO & International Organization for Standardization \\
\hline IR & Infrared \\
\hline LDPE & $\begin{array}{l}\text { Low-density polyethylene (polietileno de baixa densidade - } \\
\text { PEBD) }\end{array}$ \\
\hline LLDPE & $\begin{array}{l}\text { Linear low-density polyethylene (polietileno linear de baixa } \\
\text { densidade - PELBD) }\end{array}$ \\
\hline LPC & Laboratório de Papel e Celulose \\
\hline MDPE & $\begin{array}{l}\text { Medium-density polyethylene (polietileno de média densidade } \\
\text { - PEMD) }\end{array}$ \\
\hline MEV & Microscópio Eletrônico de Varredura \\
\hline NBR & Norma Brasileira \\
\hline OECD & $\begin{array}{l}\text { Organisation de Coopération et de Développement } \\
\text { Économiques }\end{array}$ \\
\hline PA & Poliamida \\
\hline PAN & Poliacrilonitrila \\
\hline PC & Policarbonato \\
\hline PE & Polietileno \\
\hline PET & Poli(tereftalato de etileno) \\
\hline PP & Polipropileno \\
\hline PS & Polystyrene (poliestireno) \\
\hline PVC & Poly(vinil chloride) (poli(cloreto de vinila) \\
\hline PVDC & Poly(vinylidene chloride) (poli(cloreto de vinilideno) \\
\hline $\mathrm{RBC}$ & Rede Brasileira de Calibração \\
\hline REMESP & Rede Metrológica do Estado de São Paulo \\
\hline SAL & Sterility Assurance Level \\
\hline SE & Secondary Electrons \\
\hline TE & Termoplásticos de engenharia \\
\hline $\mathrm{T}_{\mathrm{m}}$ & Temperatura de fusão cristalina \\
\hline $\mathrm{T}_{\mathrm{g}}$ & Temperatura de transição vítrea \\
\hline UHMWPE & $\begin{array}{l}\text { Ultra-high-molar-weight polyethylene (polietileno de ultra alto } \\
\text { peso molar - PEUAPM) }\end{array}$ \\
\hline UV & Ultravioleta \\
\hline UV/VIS & Ultravioleta visível \\
\hline WHO & World Health Organization \\
\hline
\end{tabular}




\section{INTRODUÇÃO}

A industrialização de produtos descartáveis avançou para atender a demanda crescente por produtos que tanto na área de alimentação quanto na saúde são considerados prioridades e cujas tecnologias de produção e de preservação são indispensáveis, muito em função do acentuado crescimento da população mundial e respectivas demandas.

O controle de microrganismos na área da saúde, por exemplo, é de fundamental importância e dentre as tecnologias mais empregadas para esse controle encontram-se o calor seco, o calor úmido (autoclaves com vapor), o óxido de etileno e as radiações ionizantes, além de outros processos químicos.

No final da década de 1950, houve importante revolução na área da saúde, por ocasião da oferta de produtos descartáveis para uso médico. Com isso, muitos profissionais passam a dedicar mais tempo ao paciente e procedimentos médicos do que aos processos de higienização de produtos antes e após seu uso (Mukherjee, 1975).

As radiações ionizantes tornaram-se um processo de esterilização comercial no início da década de 1950, sendo que na década anterior muitos estudos foram realizados para garantir esse desenvolvimento. A fonte de cobalto-60 foi o irradiador aplicado. Em 1957, as empresas Johnson \& Johnson criaram a "J\&J Ethicon Division", que expandiu o uso da radiação para esterilização de suturas, cateteres, bandagens, coletores de sangue e materiais biológicos, entre tantos outros produtos (Chmielewski e Berejka, 2008). Desse modo, todo produto que necessita da condição estéril até seu uso irá depender de embalagens seguras e que possam ser processadas pela mesma tecnologia do item de interesse.

Na publicação "Trends in Radiation Sterilization of Health Care Products" (2008), foram feitas considerações sobre os tipos de irradiadores possíveis para essa aplicação da radiação, sobre os processos de validação e documentação, aspectos microbiológicos, bem como para a utilização da radiação para o tratamento de tecidos biológicos que farão parte do banco de tecidos para utilização em pacientes 
queimados, por exemplo. O efeito da radiação gama em polímeros que compõem itens para a saúde também foram abordados nesse documento.

Embalagens empregadas na área da saúde e na comercialização de alimentos exigem compatibilidade com o produto que devem conservar, ocorrendo hoje uma verdadeira revolução no mercado e tecnologia de embalagens. $\mathrm{Na}$ indústria farmacêutica, aproximadamente $50 \%$ dos produtos farmacêuticos sólidos (comprimidos, cápsulas ou pó) são embalados em materiais flexíveis (Brody e Marsch, 1997). Mais de $90 \%$ destas embalagens estão sob a forma de embalagens de blister utilizando camadas múltiplas, por exemplo, poli(cloreto de vinila) (PVC)/ poli(cloreto de vinilideno) (PVDC)/polietileno (PE) (Goulas et al., 2003). Outras estruturas multicamadas flexíveis são utilizadas em cosméticos e embalagens de produtos para saúde. A Agência Internacional de Energia Atômica (AIEA) recomenda para embalagens de dispositivos médicos alguns polímeros, tais como polietileno (PE), poliéster (PET), polipropileno (PP), nylon, poli(cloreto de vinila) (PVC), para uso da radiação ionizante (Fengmei, 2000; IAEA,1987; Jeon, 2004).

Essas embalagens têm por finalidade: a) proteger o conteúdo durante o transporte, a armazenagem e o manuseio; b) possibilitar a identificação perfeita do conteúdo; c) garantir a esterilidade do conteúdo até o momento do uso, ou seja, funcionar como barreira antimicrobiana; d) apresentar resistência à violação, ser flexível e impermeável a partículas microscópicas e nutrientes microbianos; e) permitir abertura asséptica, facilitando ao usuário o acesso ao produto; f) não interagir com o produto causando reação que o prejudique (Pinter, 2000; ABNT NBR 14990-8, 2004). Convém ressaltar que estas características devem ser mantidas após a embalagem com o material embalado passarem pelo processo de esterilização.

Embalagens utilizadas para aplicações farmacêuticas e alimentares podem ser esterilizadas utilizando calor, produtos químicos ou irradiação gama. As vantagens inerentes da irradiação gama são: (a) esterilização em ambiente completamente selado e produtos processados sem manuseio, embalagens impermeáveis que excluem qualquer possibilidade de recontaminação; (b) capacidade de penetração nos lugares mais inacessíveis; (c) grande confiabilidade (seguro para esterilização e redução de carga bacteriana) e controle de processo simples, sendo o tempo de exposição a única variável; e (d) 
a produção de calor desprezível, dispensando a quarentena uma vez que não há resíduos (Demertzis et al., 1999). Segundo Woo et al. (1988), a radiação é um processo comum para a esterilização de dispositivos médicos, porque é conveniente economicamente e mais eficiente do que os processos de vapor saturado e esterilização com óxido de etileno.

Cada vez mais, embalagens assépticas para utilização nas modernas linhas de processamento de alimentos, farmacêuticas e indústrias de cosméticos são esterilizadas por radiação ionizante (Demertzis et al., 1999). A qualidade e a segurança do processo de esterilização por radiação gama são homologados por diversas organizações nacionais e internacionais de prestígio, tanto governamentais quanto não governamentais que apoiam a utilização de energia das radiações ionizantes (ISO, FAO, OECD, WHO, etc.).

Devido ao tratamento de produtos com radiação gama e/ou feixe de elétrons ser um processo comum principalmente para a esterilização de produtos relacionados à saúde, é fundamental para a engenharia de embalagens compreender os efeitos da radiação sobre estes materiais, que carecem de mais investigação para garantir a proteção de embalagens e produtos, bem como sobre a integridade do plástico, e de polímeros naturais ou sintéticos, utilizados no processamento asséptico de alimentos e produtos farmacêuticos (Haji-Saeid, 2007).

Algumas embalagens destinadas à esterilização de produtos para saúde apresentam-se nos formatos envelope e tubular, tendo em um dos lados papel e do outro filme plástico laminado, coextrusado ou não, formado por mais de uma camada de diferentes polímeros, cuja transparência permite visualizar o produto contido na embalagem como é mostrado na FIG. 1.

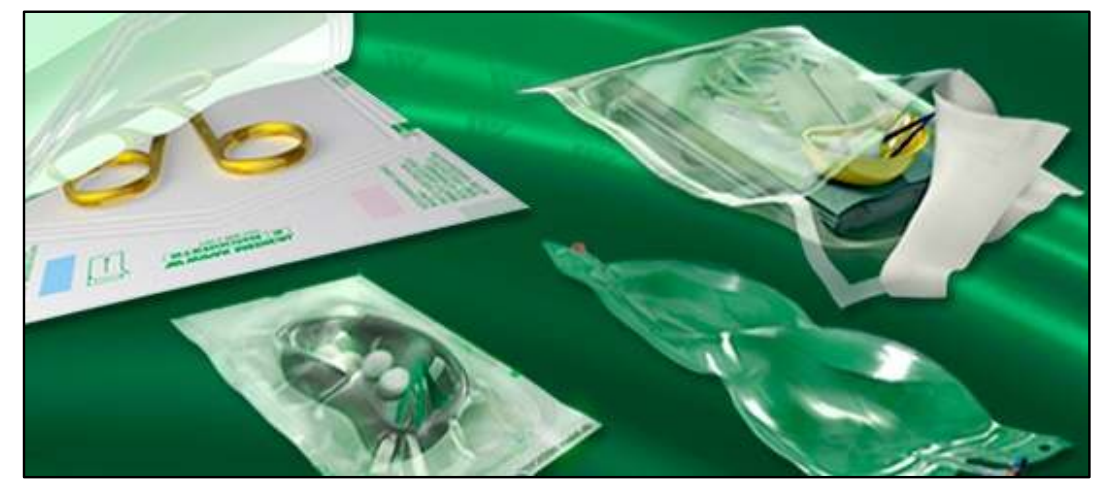

Figura 1 - Embalagens compostas por papel grau cirúrgico e filme plástico (WINPAK, 2013) 
As propriedades essenciais das embalagens para esterilização de produtos para saúde estão agrupadas na norma ABNT NBR 14990 - Sistemas e materiais de embalagem para esterilização de produtos para saúde, a qual é largamente empregada no controle e análise das conformidades dessas embalagens no Brasil. Existem ainda outras normas internacionais que são utilizadas para a análise de embalagens para esterilização de produtos para saúde como: ISO 11607 Packaging for terminally sterilized medical devices e EN 868 - Packaging materials and systems for medical devices which are to be sterilized. Sendo que a norma brasileira ABNT NBR 14990 é baseada na norma EN 868.

Os efeitos da radiação ionizante sobre embalagens destinadas à esterilização de produtos para saúde no formato de envelopes, tendo em um dos lados papel e no outro filme plástico laminado formado pela combinação dos polímeros poli(tereftalato de etileno)/polietileno (PET/PE) e poli(tereftalato de etileno)/polipropileno (PET/PP) foram objeto deste estudo. 


\section{OBJETIVOS}

Os objetivos deste trabalho foram: estudar os efeitos da radiação gama nas principais propriedades físicas e químicas do papel grau cirúrgico e dos filmes plásticos laminados, formados pela combinação dos polímeros poli(tereftalato de etileno)/polietileno (PET/PE) e poli(tereftalato de etileno)/polipropileno (PET/PP), empregados na confecção de embalagens destinadas à esterilização de produtos para saúde; avaliar os efeitos do tratamento por radiação em algumas propriedades das embalagens (envelope); e determinar a variação da dose absorvida (25 kGy, 40 kGy e 50 kGy) no material com uso da dosimetria. 


\title{
3 CONSIDERAÇÕES TEÓRICAS E REVISÃO BIBLIOGRÁFICA
}

\author{
Este capítulo será iniciado com algumas considerações sobre \\ embalagens que devem conter produtos para saúde e deverão passar pelo \\ processo de esterilização por radiação ionizante.
}

\subsection{Embalagens destinadas à esterilização por radiação ionizante}

A FDA (Food and Drug Administration) regulamentou o uso de radiação ionizante em embalagens de materiais plásticos de camada única quase 20 anos atrás, enquanto hoje materiais multicamadas (laminado ou coextrusado) são quase exclusivamente utilizados em aplicações de embalagens alimentares avançadas (Reinke, 1989). Há relativamente pouca informação na literatura sobre irradiação em substratos, tais como embalagens de materiais plásticos multicamada e/ou laminado coextrusado (Killoran, 1974; Hama e Hirade, 1991; Buchalla et al., 1993; Deschênes et al., 1995). Para Berejka e Kaluska (2008), os materiais considerados adequados para uso em dispositivos médicos são também adequados para utilização como materiais de embalagem. Plásticos tolerantes à radiação, tais como os PET e PC (policarbonato), podem ser usados para estruturas rígidas e transparentes de embalagens de blister. Materiais de poliolefinas, como vários tipos de PEs, podem ser usados para embalagens simples de um único produto.

Existem muitos tipos de embalagens destinadas a produtos para saúde, formadas por diferentes polímeros, as quais são submetidas ao processo de esterilização por radiação ionizante. Neste estudo, como já discutido, serão tratadas as embalagens no formato de envelope formadas por papel de um dos lados da embalagem e filmes plásticos multicamadas ou laminados constituídos por poli(tereftalato de etileno)/polietileno (PET/PE) e poli(tereftalato de etileno)/polipropileno (PET/PP) do outro lado da embalagem. O processo de junção destes polímeros para formar um único filme plástico multicamada é chamado de coextrusão. A coextrusão caracteriza-se pela extrusão simultânea de 
dois ou mais termoplásticos com características próprias para formar um filme laminado de características diferenciadas, ou seja, um produto final com propriedades normalmente impossíveis de se obter com uma só matéria-prima. A diversidade de aplicações de embalagens flexíveis requer laminados com propriedades que atendam às exigências dos produtos acondicionados e estas propriedades são muitas e distintas, sendo assim, pela coextrusão pode-se alcançar um número maior de propriedades.

Para uma melhor compreensão sobre cada um dos materiais que compõem estas embalagens, será apresentada uma breve explanação sobre polímeros em geral e posteriormente sobre os materiais presentes nas embalagens estudadas, ou seja, o papel, formado por um polímero natural (celulose) e os polímeros sintéticos PE, PP e PET. Apesar das embalagens em questão serem formadas por filmes plásticos multicamadas, ou seja, por mais de um tipo de polímero, será discutido sobre cada um dos polímeros que formam os filmes separadamente.

\subsection{Polímeros}

A palavra polímero origina-se do grego poli (muitos) e mero (unidade de repetição). Assim, um polímero é uma macromolécula composta por dezenas de milhares de unidades de repetição denominadas meros, ligados por ligação covalente. A ligação covalente consiste no compartilhamento de dois elétrons entre os átomos. Estas ligações envolvem normalmente curtas distâncias e altas energias. A ligação $\mathrm{C}-\mathrm{C}$ é a ligação covalente mais comum, na maioria dos polímeros. O polietileno tem sua cadeia principal formada exclusivamente por esse tipo de ligação. Dependendo do tipo de monômero (estrutura química), do número médio de meros por cadeia e do tipo de ligação covalente, pode-se dividir os polímeros em três grandes classes: Plásticos, Borrachas e Fibras (Canevarolo, 2002).

Muitas propriedades físicas são dependentes do comprimento da molécula, ou seja, de sua massa molar. Uma grande variação nas propriedades dos polímeros ocorre, pois estes envolvem uma larga faixa de valores de massa molar. Quando uma molécula é pequena, alterações em seu tamanho provocam 
grandes mudanças em suas propriedades físicas, porém, essas alterações tendem a ser menores com o aumento do tamanho da molécula (Canevarolo, 2002).

O custo de um polímero depende basicamente de seu processo de polimerização e disponibilidade do monômero. Os principais fornecedores de matérias-primas, segundo Canevarolo (2002), para a produção de monômeros (e depois polímeros) podem ser divididos em três grupos: Produtos naturais; Hulha ou Carvão Mineral e Petróleo.

\subsubsection{Polietileno (PE), Polipropileno (PP) e Poli(tereftalato de etileno) (PET)}

Além das macromoléculas encontradas na natureza, como a celulose, muitos produtos químicos obtidos por via sintética podem apresentar cadeias longas. Neste caso, são denominados, geralmente, polímeros sintéticos. As propriedades dos polímeros dependem bastante dos materiais de partida, ou seja, dos monômeros, do tipo de reação empregada na sua obtenção e da técnica de preparação (Mano, 1991).

A hulha ou carvão mineral é um dos grupos de fornecedores de matérias-primas para produção de monômeros e posterior formação de polímero. A hulha, ao ser submetida a uma destilação seca, pode produzir gases de hulha, amônia, alcatrão da hulha e coque (resíduo). Do gás de hulha é possível separar etileno para produção de polietileno e do coque obtém-se o acetileno (via reação com óxido de cálcio $(\mathrm{CaO})$ e a seguir com a água) que por hidrogenação produz também etileno (Canevarolo, 2002).

Para Canevarolo (2002), de todos os produtos naturais, o petróleo é a fonte mais importante de matérias-primas para a produção de monômeros. Várias frações podem ser obtidas com a destilação fracionada do óleo cru: GLP, nafta, gasolina, querosene, óleo diesel, graxas, óleos lubrificantes e piche, mas, a fração de interesse para os polímeros é o nafta. O nafta gera várias frações gasosas contendo moléculas saturadas e insaturadas após um craqueamento térmico apropriado (pirólise a altas temperaturas e catálise). Etileno e propileno são moléculas insaturadas as quais são separadas e aproveitadas para a síntese de polímeros. 


\subsubsection{Classificação dos polímeros PE, PP e PET}

Um grande número de polímeros foram gerados até hoje para atender às mais diversas áreas de aplicações. Foi adotado o sistema de classificação proposto por Canevarolo (2002) o qual emprega quatro diferentes classificações: quanto à estrutura química; seu método de preparação, suas características tecnológicas e seu desempenho mecânico. Como os polímeros de interesse neste estudo são: polietileno (PE), polipropileno (PP) e poli(tereftalato de etileno) (PET), pois são os utilizados na confecção dos filmes plásticos das embalagens comerciais utilizadas neste estudo, serão enfatizadas aqui suas classificação e principais propriedades. Segundo Mano (1991), o PE normalmente utilizado em filmes para embalagens em geral é o polietileno de baixa densidade (LDPE). Além disso, sabe-se que este é o polímero mais flexível dentre os PEs; portanto, a partir destas informações, o PE utilizado nas embalagens em estudo foi considerado como sendo o LDPE e para a classificação e as propriedades descritas nos itens 3.2.1.1 e 3.2.1.2, respectivamente, foram consideradas as do LDPE.

Estrutura química: nesta classificação, analisa-se o polímero através da estrutura química do seu mero. Duas subdivisões são possíveis nesta classificação: polímeros de cadeia carbônica e polímeros de cadeia heterogênea.

Como exemplo de cadeia carbônica, têm-se as poliolefinas que são polímeros originários de monômeros de hidrocarboneto alifático insaturado, contendo uma dupla ligação carbono-carbono reativa. Dentro desta classificação, têm-se o polietileno e o polipropileno (FIG. 2).

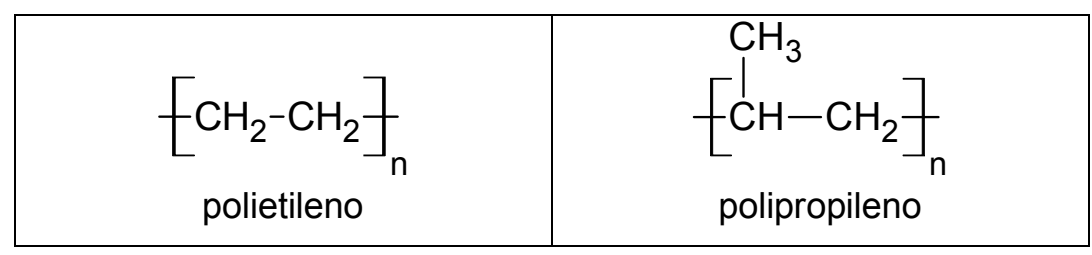

Figura 2 - Representação das estruturas do polietileno e do polipropileno

Para polímeros de cadeia heterogênea, têm-se, como exemplo, os poliésteres, nos quais a ligação característica é a ligação éster -CO-O-, podendo gerar cadeias saturadas (formando termoplásticos de engenharia) ou insaturadas 
(gerando termofixos), dependendo do tipo de material inicial empregado (saturado ou não). Na classe dos termoplásticos, tem-se usado para extrusão e sopro, poli(tereftalato de etileno) (PET) (FIG. 3), muito empregado para a confecção de garrafas descartáveis, filmes e fibras.

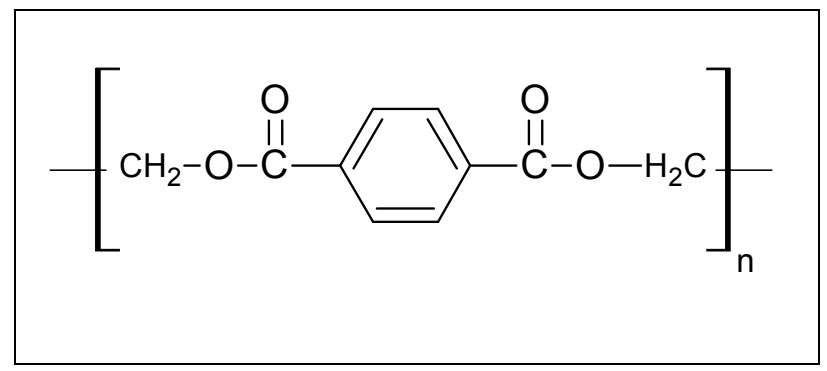

Figura 3 - Representação da estrutura do poli(tereftalato de etileno) - PET

Método de preparação: este tipo de classificação dos polímeros divide os polímeros em duas grandes classes: polímeros de adição e polímeros de condensação.

Polímeros de adição são aqueles que, durante a sua formação, não há perda de massa na forma de compostos de baixa massa molar. Em uma conversão total, o peso de polímero formado é igual ao peso de monômero adicionado. Alguns exemplos destes polímeros são os PE e PP.

Polímeros de condensação são aqueles originários da reação de dois grupos funcionais reativos, com a eliminação de moléculas de baixa massa molar (água, amônio, ácido clorídrico ( $\mathrm{HCl})$, etc.), e o PET é um exemplo.

Comportamento mecânico: os polímeros podem ser classificados em: Plásticos, Elastômeros e Fibras.

Plásticos: são materiais poliméricos sólidos na temperatura ambiente e podem ser subdivididos em: Termoplásticos e Termorrígidos. Os termoplásticos são polímeros que, sob o efeito da temperatura e pressão, amolecem e fluem, podendo ser moldados nestas condições. Novas aplicações de temperatura e pressão reiniciam o processo e, portanto, são recicláveis. Estes polímeros são solúveis e possuem cadeia linear ou ramificada. Exemplos são PE, PP, PVC, etc. 
Os termorrígidos são polímeros que, quando sujeitos a aplicações de temperatura e pressão, amolecem e fluem adquirindo a forma do molde, reagem quimicamente formando ligações cruzadas entre cadeias e se solidificam. Após se solidificarem, tornam-se materiais insolúveis, infusíveis e não-recicláveis. Alguns exemplos são: baquelite, epóxi, etc.

Elastômeros: polímeros que podem se deformar no mínimo duas vezes o seu comprimento inicial em temperatura ambiente, retornando ao comprimento original logo após retirado o esforço. Normalmente, possuem cadeias flexíveis amarradas umas às outras, com uma baixa densidade de ligação cruzada. $O$ principal exemplo é a borracha vulcanizada (BV).

Fibras: um termoplástico orientado (com um sentido longitudinal dito eixo principal da fibra), satisfazendo a condição geométrica de L/D>=100. A orientação das cadeias e dos cristais, feita de modo forçado durante a fiação, aumenta a resistência mecânica dessa classe de materiais, tornando-os possíveis de serem usados na forma de fios finos. Exemplos são poliacrilonitrila (PAN), nylons, poliéster (PET), etc.

Desempenho mecânico: esta classificação leva em conta o desempenho mecânico do polímero quando usado em um material.

Termoplásticos convencionais (commodities): são polímeros de baixo custo, baixo nível de exigência mecânica, alta produção, facilidade de processamento, etc. A produção destes termoplásticos somados corresponde a aproximadamente $90 \%$ da produção total de polímeros no mundo. Como exemplos, têm-se as poliolefinas (LDPE, HDPE, PP), o poliestireno (PS) e o poli(cloreto de vinila) (PVC).

Termoplásticos de engenharia (TE): a confecção de peças de bom desempenho para aplicações em dispositivos mecânicos (engrenagens, peças técnicas para a indústria eletroeletrônica e automobilística, etc.) exige do polímero principalmente boa resistência mecânica (rigidez), tenacidade e estabilidade dimensional. Alguns exemplos são poliamidas (nylons em geral), poliésteres termoplásticos (PET), etc.

Os polímeros industriais obtidos através de rotas sintéticas podem ser utilizados como materiais de engenharia, tanto individualmente, sistemas poliméricos simples, quanto em sistemas mistos, mais complexos. Os polímeros PE, PP e PET 
fazem parte dos sistemas poliméricos simples e são, em geral, aditivados com corantes, pigmentos, plastificantes, cargas, estabilizadores, antioxidantes e agentes de reticulação, em pequenas quantidades, ingredientes estes que lhes conferem características, como cor, flexibilidade, resistência mecânica, resistência às intempéries, etc., adequadas ao que se pretende fabricar (Mano, 1991).

\subsubsection{Propriedades dos polímeros PE, PP e PET}

A seguir, será feita uma breve descrição de algumas propriedades que considerou-se serem as mais relevantes para os polímeros PE, PP e PET que compõem as embalagens utilizadas neste estudo. As propriedades aqui apresentadas foram determinadas, discutidas e apresentadas por Mano (1991). Apesar de apresentar as características de cada um dos polímeros que compõem as embalagens estudadas de forma separada, não se pode esquecer que estas embalagens são formadas por filmes plásticos multicamadas, ou seja, por mais de um polímero. Neste caso, os filmes são formados por PET/PE e PET/PP, ou seja, o PET é o polímero em comum para os dois filmes. Além disso, como já descrito anteriormente (item 3.2.1.1), serão consideradas as propriedades do PE como sendo as do LDPE. Os valores determinados por Mano (1991) e apresentados a seguir correspondem aos valores aproximados de mínimo e máximo, respectivamente, para cada uma das propriedades dos polímeros aqui tratados, em suas respectivas unidades.

\section{Propriedades físicas}

As propriedades físicas não envolvem qualquer modificação estrutural a nível molar dos materiais. Nelas, incluem-se as propriedades mecânicas, térmicas, elétricas e óticas. Estas características são avaliadas por métodos clássicos, às vezes empíricos, descritos em normas nacionais ou internacionais.

Propriedades mecânicas: propriedades que determinam a resposta dos materiais às influências mecânicas externas; são manifestadas pela capacidade destes materiais desenvolverem deformações reversíveis e irreversíveis e resistirem à fratura. Citamse algumas delas fazendo uma comparação entre os polímeros de interesse: 
- resistência à tração $\left(\mathrm{kgf} / \mathrm{mm}^{2}\right)$ : avaliada pela carga aplicada ao material por unidade de área, no momento da ruptura: PE (de 0 a 2) < PP (de 2 a 9) < PET (de 16 a 90);

- alongamento na ruptura (\%): representa o aumento percentual do comprimento da peça sob tração, no momento da ruptura: PE (de 289 a 882) > PP (de 19 a 289) > PET (de 6 a 47);

- módulo de elasticidade $\left(\mathrm{kgf} / \mathrm{mm}^{2}\right)$ : é medido pela razão entre a tensão e a deformação, dentro do limite elástico, em que a deformação é totalmente reversível e proporcional à tensão: PE (de 15 a 37) < PP (de 119 a 122) < PET (de 393 a 1450). Em geral, os polímeros de alta cristalinidade, ou que apresentam estruturas rígidas aromáticas, ou os polímeros reticulados, revelam módulo de elasticidade mais elevado.

Propriedades térmicas: são observadas quando a energia térmica, isto é, o calor, é fornecido ou removido dos materiais. Polímeros em geral são maus condutores de calor:

- calor específico (cal/g. $\left.{ }^{\circ} \mathrm{C}\right)$ : PE $(0,55)>\operatorname{PP}(0,46)>\operatorname{PET}(0,30)$;

- expansão térmica $\left(10^{-4} /{ }^{\circ} \mathrm{C}\right): \mathrm{PE}($ de 1,3 a 2,2$)>\operatorname{PP}($ de 1,2 a 1,3$)>\operatorname{PET}$ (de $1,2$ a 1,3$)$;

- fusão cristalina (temperatura de fusão cristalina $\left.\left(T_{m}\right),{ }^{\circ} \mathrm{C}\right)$ : nesta temperatura, as regiões ordenadas dos polímeros, isto é, os cristalitos e esferulitos, se desagregam e se fundem. Polímeros de alta cristalinidade possuem uma temperatura de fusão relativamente elevada quando comparada à temperatura de fusão de polímeros predominantemente amorfos. Nos termoplásticos a temperatura máxima de fusão é inferior a $300^{\circ} \mathrm{C}:$ PE (de 109 a 125) > PP (de 165 a 175) > PET (de 250 a 270);

- transição vítrea $\left(\mathrm{T}_{\mathrm{g}}\right),{ }^{\circ} \mathrm{C}$ : está associada à região amorfa dos polímeros. Abaixo da $\mathrm{Tg}$, desaparece a mobilidade das cadeias macromolares e o material torna-se mais rígido: PE (de -30 a -20) > PP (de -12 a 4) > PET (de 70 a 74 ). 
Propriedades óticas: estas propriedades podem informar sobre a estrutura e ordenação molares, bem como sobre a existência de tensões ou regiões sob deformação nos polímeros:

- transparência: a transparência a luz visível é apresentada por polímeros amorfos ou com muito baixo grau de cristalinidade. É quantitativamente expressa pela transmitância, que é a razão entre a quantidade de luz que atravessa o meio e a quantidade de luz que incide paralelamente à superfície;

- a densidade $\left(\mathrm{g} / \mathrm{cm}^{3}\right)$ é uma propriedade física que não se enquadra nos grupos anteriores. A densidade de um material reflete a sua estrutura química e a sua organização molar. As regiões cristalinas são mais compactas enquanto as amorfas são mais volumosas. Os materiais poliméricos são todos comparativamente leves em relação a outros materiais: PE (de 0,92 a 0,94) > PP $(0,90)>$ PET (de 1,33 a 1,45).

\section{Propriedades químicas}

Muitas são as propriedades químicas importantes para materiais poliméricos e estas estão diretamente relacionadas às suas aplicações. Neste estudo, será discutido apenas sobre três delas:

1) Resistência à oxidação: é mais encontrada nas macromoléculas saturadas, que contêm apenas ligações simples entre átomos de carbono, como as poliolefinas (polietileno e polipropileno). A presença de átomos de carbono terciário na cadeia, saturada ou insaturada, baixa a resistência à oxidação.

2) Resistência à degradação térmica: a exposição de polímeros ao calor em presença de ar causa a sua maior degradação, dependendo da estrutura do polímero; envolve reações químicas às vezes complexas causadas pela formação de radicais livres na molécula, normalmente com a interveniência do oxigênio, gerando radicais livres pela ruptura das ligações covalentes dos átomos nas cadeias macromolares insaturadas, ou nas cadeias contendo átomos de carbono terciário.

3) Resistência a radiações ultravioletas: as radiações ultravioletas são absorvidas gerando facilmente radicais livres os quais atuam de forma semelhante à resistência à degradação. Este fenômeno ocorre na 
exposição de plásticos à luz solar, por exemplo, quando o polietileno ou o polipropileno são expostos prolongadamente à luz do dia ocorre formação de fissuras, rachaduras e fragmentações.

\section{Propriedades físico-químicas}

A permeabilidade a gases e vapores é uma das propriedades físicoquímicas mais importantes dos polímeros, principalmente os destinados a embalagens. Os polímeros são pouco permeáveis a gases e vapores, cujo transporte ocorre ou intersticialmente, através de poros permanentes ou transitórios da membrana, ou por um processo de sorção ou dissolução, em um lado da barreira, seguido de difusão através dela e posterior dessorção ou evaporação, no outro lado. A permeação de moléculas pequenas através de materiais poliméricos se dá nas regiões amorfas, onde as cadeias macromolares estão mais afastadas. A presença de domínios cristalinos diminui bastante a permeabilidade:

- permeabilidade a nitrogênio $\left(\left(10^{-10} \cdot \mathrm{cm}^{2}\right)(\mathrm{s} . \mathrm{cm} . \mathrm{Hg})\right)$ : PE (de 1,2 a 2,1) > PP (de 0,2 a 0,5) > PET (de 0,04 a 0,08);

- permeabilidade a dióxido de carbono $\left(\left(10^{-10} . \mathrm{cm}^{2}\right)(\mathrm{s} . \mathrm{cm} \cdot \mathrm{Hg})\right)$ : PE (de 17,0 a $35,0)>$ PP (de 1,2 a 9,0 > PET (de 0,1 a 0,1);

- permeabilidade a vapor d'água $\left(\left(10^{-10} \cdot \mathrm{g}\right)(\mathrm{cm} . \mathrm{s} . \mathrm{cm} . \mathrm{Hg})\right)$ : $P E($ de 0,08 a 0,23) $>$ PP $($ de 0,08 a 0,11) > PET (de 0,08 a 0,15).

Segundo Demertzis et al. (1999), o PET é um dos polímeros mais adequados para ser utilizado como material de embalagem que será submetido à irradiação quando preenchido com alimentos, produtos farmacêuticos ou dispositivos médicos. Para Ekman et al. (1993), o polipropileno tem boas propriedades mecânicas e alta transparência, o que o torna um dos polímeros mais comuns na fabricação de dispositivos médicos.

Para Berejka e Kaluska (2008), filmes plásticos oclusivos podem ser produzidos a partir de PE e copolímeros de etileno e PET que além de oclusivos são resistentes, porém, ao considerar a esterilização por radiação, os filmes de PP devem ser evitados, uma vez que sem um aditivo adequado poderá ocorrer cisão de cadeia. 


\subsubsection{Papel}

Dentre os diversos materiais que podem ser utilizados na fabricação de papel, encontram-se fibras celulósicas virgens e ou recicladas provenientes de madeira, de algodão, ou de outros vegetais. Além destas, fibras sintéticas, minerais ou animais podem ser incorporadas ao papel dependendo de sua finalidade. A maior fonte de fibras para a produção de papel é, sem dúvida, a pasta celulósica proveniente de fibras de madeira (Yasumura, 2011). A celulose é o principal material estrutural da fibra, é um carboidrato que está presente em quase todos os vegetais e pertence ao grupo dos produtos naturais (Canevarolo, 2002). "A celulose é um polissacarídeo formado por unidades do monossacarídeo $\beta$-D-glicose, que se ligam entre si através dos carbonos 1 e 4 , dando origem a um polímero linear" (D’Almeida, 1988).

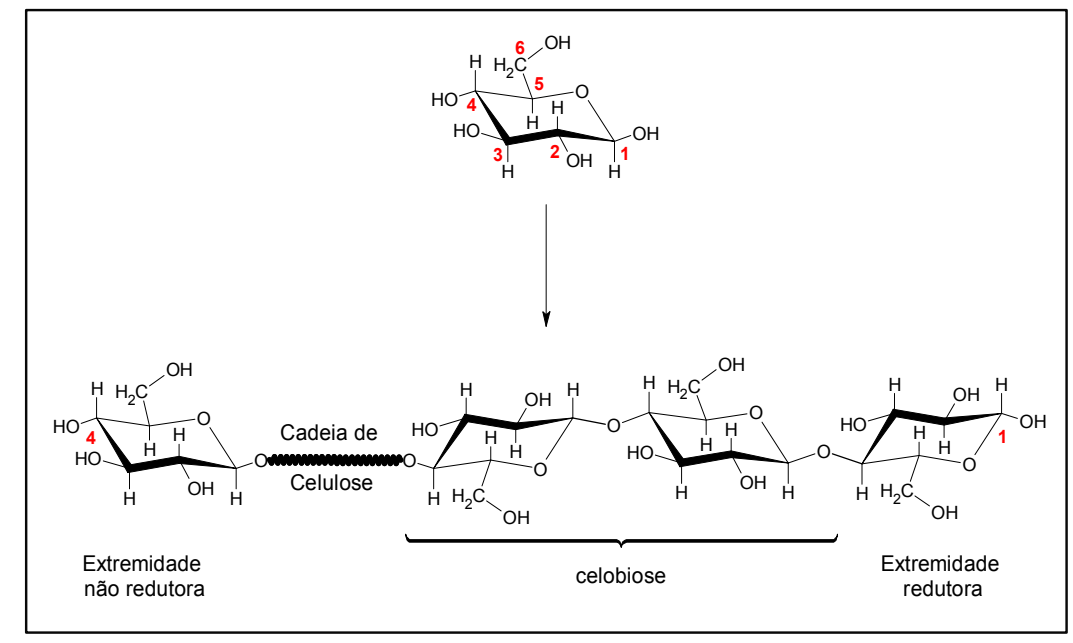

Figura 4 - Estrutura da celulose a partir da $\beta$-D-glicose destacando a unidade repetitiva (celobiose) e extremidade redutora e não redutora (Fengel e Wegener, 1989)

Os grupos terminais da cadeia polimérica diferem entre si quanto à reatividade, o grupo $\mathrm{C}(1)-\mathrm{OH}$ apresenta uma estrutura hemiacetal e, portanto, características redutoras e a outra extremidade $\mathrm{C}(4)-\mathrm{OH}$ consiste em um álcool, portanto, não redutor (FIG. 4) (Fengel e Wegener, 1989). Os grupos hidroxilas presentes na cadeia polimérica da celulose são capazes de interagir entre si por meio de ligações de hidrogênio de dois tipos: intramolares (entre hidroxilas de uma mesma cadeia), que conferem certa rigidez às cadeias poliméricas, e intermolares (entre hidroxilas de cadeias distintas), formando a fibra vegetal pelo 
alinhamento das moléculas de celulose. Estas formam as microfibrilas, que se agregam em fibrilas mais espessas (macrofibrilas), que se ordenam para formar as camadas das paredes celulares da fibra (Silva, 2009).

A celulose é importante para as características finais do papel devido à capacidade de atração entre as suas moléculas que é a principal fonte de ligações entre fibras no papel (FIG. 5). As fibras longas, provenientes de coníferas e, as fibras curtas, de folhosas, diferem em suas dimensões, como largura e comprimento, e em outras características estruturais. As fibras longas possuem um maior comprimento em relação às fibras curtas; além disso, as fibras longas possuem largura maior que as fibras curtas. Outra diferença é a função da fibra, pois as fibras longas desempenham ambas as funções de reforço estrutural e condução de fluidos; já as fibras curtas possuem função estrutural, porém os fluidos são conduzidos por outros elementos, denominados elementos de vaso (Yasumura, 2011).

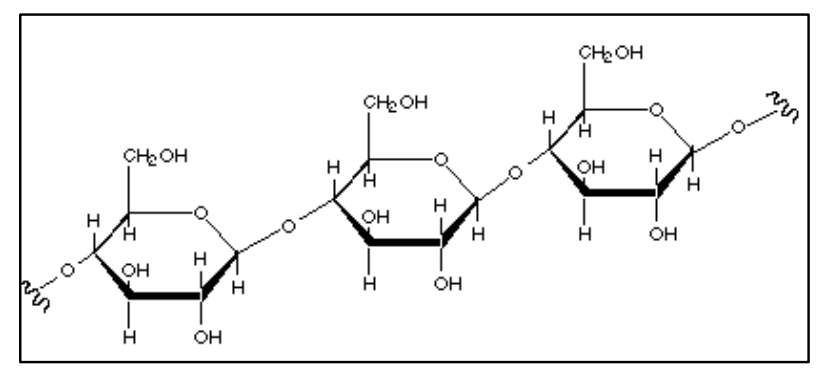

Figura 5 - Estrutura molar da celulose

A escolha da fibra na produção de um papel dependerá do seu uso final. As fibras longas, em geral, são utilizadas na fabricação de papéis que demandam maior resistência, como em embalagens. As fibras curtas são mais utilizadas em papéis absorventes e em papéis para imprimir e escrever (Yasumura, 2011).

A química da fabricação do papel envolve interações entre as superfícies e os coloides que constituem a suspensão da pasta celulósica: eletrólitos dissolvidos, fibras, finos, partículas de cargas minerais, moléculas com atividade superficial (detergentes, dispersantes, extrativos da madeira, antiespumantes, etc.), polímeros e polieletrólitos dissolvidos (poliacrilamidas, resinas de resistência a úmido e a seco, etc.) conforme representação na FIG. 6 (Rojas, 2003). Todos estes componentes da suspensão aquosa que formará o papel apresentam diferentes características no que se refere ao tamanho, forma, 
superfície específica, rugosidade de superfície e carga elétrica. Estes componentes depositam-se de modo aleatório na mesa de formação resultando numa distribuição não uniforme de partículas.

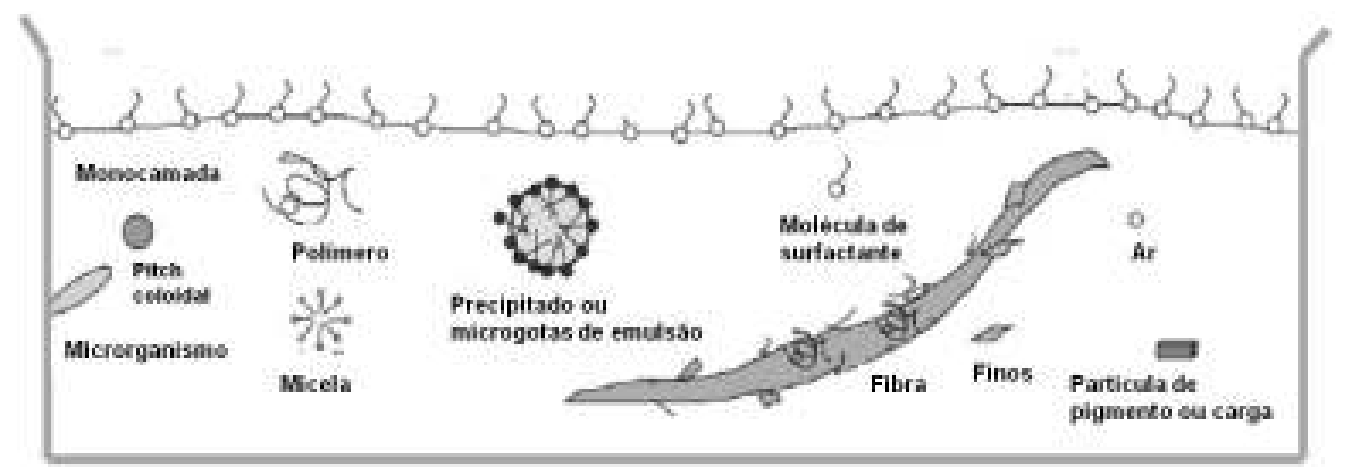

Figura 6 - Representação esquemática dos constituintes da suspensão aquosa (Rojas, 2003)

Webb (1998) definiu o papel como uma mistura não uniforme de partículas, ou seja, fibras, fragmentos de fibras, cargas minerais e aditivos químicos. Segundo Webb, a complexidade no processo de formação do papel atinge o máximo na faixa de partículas entre $100 \mathrm{~nm}$ a $10 \mu \mathrm{m}$, com polímeros competindo pela absorção nas superfícies de finos e cargas, aglomerando partículas e levando à formação de flocos estáveis. Também podem ocorrer interações entre substâncias dissolvidas e à formação de compostos indesejáveis.

Os papéis podem ser afetados por agentes biológicos, químicos e físicos, dentre os quais os insetos, microrganismos (fungos, bactérias, actinomicetos), acidez, lignina residual, poluição atmosférica $\left(\mathrm{NO}_{2}, \mathrm{SO}_{2}\right)$, tintas de impressão, luz, temperatura, umidade e outros fatores relacionados que contribuem para a redução de sua vida útil e até causam sua destruição (FIG. 7). Esta degradação do papel pode ser reduzida a valores tão baixos quanto possíveis através de medidas preventivas ou curativas (Tomazello, 1994). 


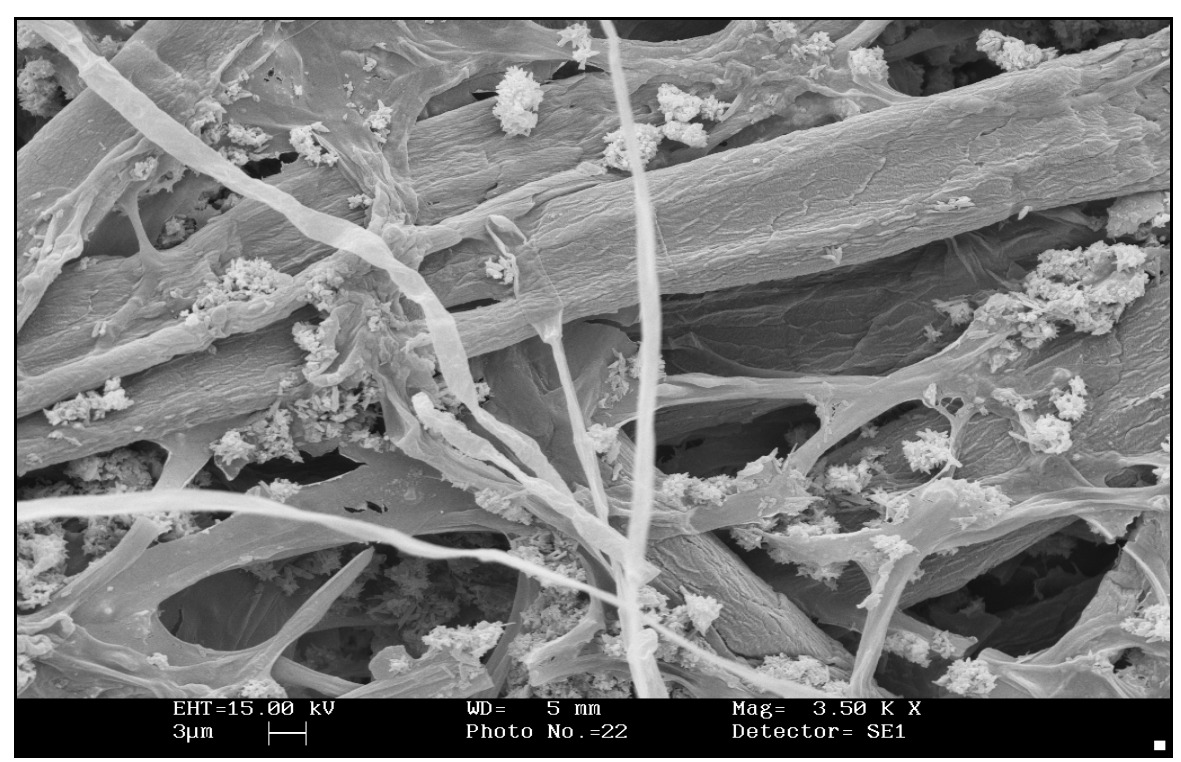

Figura 7 - Superfície de um papel com hifas de fungos sobre as fibras (acervo do IPT)

O papel utilizado na manufatura das embalagens para esterilização é denominado de "grau cirúrgico". Este papel possui requisitos a serem atendidos para que a embalagem confeccionada a partir dele apresente desempenho adequado. Estes requisitos estão presentes na norma brasileira ABNT NBR 14990-3:2010.

Para compreender melhor o processo de esterilização pelo qual passam as embalagens de produtos para saúde tratadas neste estudo, serão feitas algumas considerações teóricas sobre este processo.

\subsection{Esterilização por radiação ionizante (radiação gama de ${ }^{60} \mathrm{Co}$ )}

Para uma melhor compreensão sobre a esterilização por radiação ionizante, é importante discorrer sobre a radiação gama.

\subsubsection{Radiação ionizante}

Os raios gama são radiações eletromagnéticas, com propriedades básicas de absorção representadas pela diminuição exponencial nas intensidades das radiações que, ao passarem pela matéria, propiciam alto poder de penetração, efetivamente utilizadas no processamento industrial de materiais. Em 
todos os tipos de radiação ionizante, a penetração é inversamente proporcional à densidade dos materiais processados. Sendo assim, a densidade dos produtos e as dimensões das embalagens são fatores determinantes nas aplicações dos raios gama. Os raios gama provenientes do ${ }^{60} \mathrm{Co}$ possuem energia média de 1,25 $\mathrm{MeV}$ e poder de penetração superior a $50 \mathrm{~cm}$, porém possuem uma taxa de dose baixa, ideais no processamento de produtos diversificados, espessos e de alta densidade (Calvo, 2005).

\subsubsection{Irradiadores}

As tecnologias de processamento de materiais por raios gama estão mundialmente consolidadas. A indústria de processamento de radiação ganhou impulso significativo com o advento dos reatores nucleares, que têm a capacidade de produzir radioisótopos, tais como cobalto-60. Estes emissores de raios gama tornaram-se fontes de radiação populares para aplicações médicas e industriais (Mehta, 2008). Atualmente, são computados mais de 160 irradiadores gama industriais em operação no mundo. A tendência mundial na construção de irradiadores industriais de cobalto-60 segue duas linhas, uma de irradiadores de grande porte e outra de irradiadores compactos ou dedicados. Os de grande porte representam cerca de 20 \% dos irradiadores gama em operação. Nas plantas de irradiação, 86 \% utilizam racks de fontes retangulares e $90 \%$ armazenam as fontes de cobalto-60 em piscina, com água deionizada (Calvo, 2005).

Os irradiadores gama são classificados, sob o aspecto de segurança, pela Agência Internacional de Energia Atômica - AIEA, nas categorias I, II, II e IV, de acordo com o design da instalação, a acessibilidade e a blindagem das fontes radioativas (Mehta, 2008).

Este trabalho foi desenvolvido utilizando um irradiador de categoria I pela IAEA, onde a fonte selada é completamente encapsulada e blindada em um contêiner seco, construído de materiais sólidos. O acesso à fonte radioativa selada ou à região de irradiação não é fisicamente possível, em função da sua configuração. Comercialmente, este tipo de irradiador é conhecido como Gammacell (Mehta, 2008). 
O irradiador multipropósito de cobalto-60 tipo compacto que foi projetado e instalado no Instituto de Pesquisas Energéticas e Nucleares IPEN/SP (FIG. 8) é classificado pela Comissão Nacional de Energia Nuclear CNEN como sendo do grupo I e pela IAEA (2008) um irradiador gama categoria IV. Este irradiador possui sistemas de porta giratória e irradiação de produtos inéditos (Calvo, 2005).

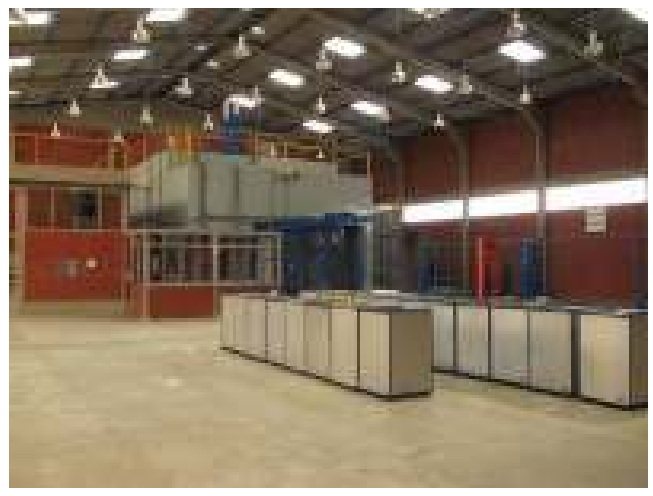

(a)

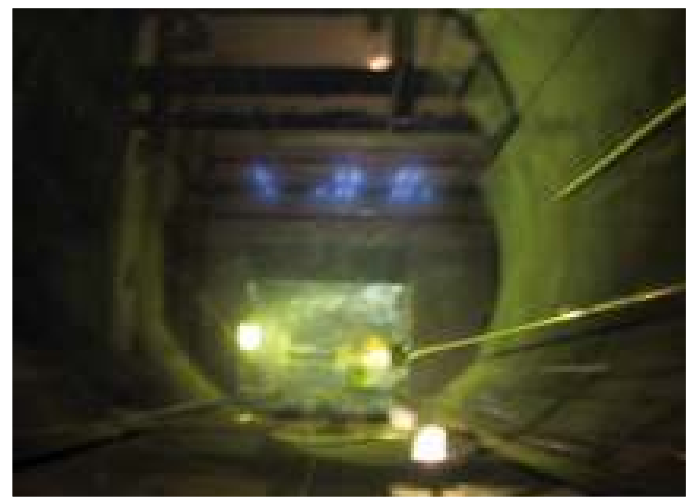

(b)

Figura 8 - Irradiador multipropósito de cobalto-60 tipo compacto do IPEN/CTR: a) caixas que contêm os lotes de materiais a serem processados adentrando o irradiador; b) piscina do irradiador com a fonte de ${ }^{60} \mathrm{Co}$ exposta

\subsubsection{Esterilização}

O processo de esterilização por radiação ionizante é estudado e desenvolvido desde o início do século XX. Em geral, a esterilidade de um determinado produto está associada à ausência de microrganismos viáveis (com capacidade de se reproduzir). Entretanto, como a inativação de microrganismos é uma função exponencial, teoricamente é improvável atingir essa condição. Desse modo, uma boa definição para radioesterilização estará sempre associada ao nível de segurança de esterilidade, quando um produto é submetido ao processo de irradiação (Mukherjee, 1975). Atualmente, esse processamento por radiação pode ser obtido em fontes gama proveniente de cobalto-60 ou em aceleradores de elétrons, cujo feixe de elétrons transfere a energia ionizante ao material de interesse.

Vários tipos de microrganismos, principalmente bactérias e fungos, têm sido encontrados em dispositivos médicos e produtos farmacêuticos. O processo de esterilização deve ser validado para verificar se é eficaz e viável. É importante 
lembrar que a exposição a um processo de esterilização validado e controlado com precisão não é o único fator associado com a garantia de que o produto está estéril e adequado para o seu uso (Hammad, 2008).

A radiação gama reduz a carga de microrganismos por ação direta e indireta da radiação. Da ação direta da radiação resultam danos nas estruturas das células até efeitos no material genético, como, por exemplo, a ruptura da estrutura do DNA. Ações indiretas da radiação nos sistemas biológicos correspondem às alterações sofridas pela célula em decorrência das espécies reativas geradas nos fluidos da célula, principalmente pela radiólise da água (Sonntag, 1987). A quantidade de energia de radiação absorvida necessária para inativar microrganismos em um produto (médico, farmacêutico) dependerá da resistência destes à radiação (Hammad, 2008).

O processo de determinação da dose de esterilização destina-se a estabelecer a dose mínima necessária para atingir a esterilidade ou desejado nível de garantia. As normas internacionais se reportam a esse nível de segurança microbiológica como SAL (Sterility Assurance Level) que é derivado matematicamente e define a probabilidade de um microrganismo viável estar presente numa unidade de produto individual, após a esterilização, e deve ser de $10^{-6}$ para produtos médicos (Hammad, 2008; Kowalski, 2002). O tipo e o nível de contaminação de um determinado produto estão relacionados com a origem do material bruto que o compõe, bem como com o seu processo de manufatura. Por exemplo, num produto cuja origem é o solo, a presença de coliformes é bastante provável. A partir dessas informações parte-se para a determinação da sensibilidade das espécies presentes à radiação. Essas informações são essenciais para definir a dose de radiação para os produtos a serem processados por radiação.

A dose de radiação pode ser definida como a quantidade de energia absorvida pelo material em função de sua massa. A dose absorvida é usualmente medida em joules por quilograma (J/kg), também denominada Gray (Gy), medida atual aplicada para processamento por radiações ionizantes (McLaughlin, et al., 1989).

A atividade total do irradiador definirá a taxa de dose de radiação no momento do processamento. Essa taxa de dose corresponde à quantidade de 
energia absorvida pelo material em processamento, ou seja, à variação da dose, no tempo. A taxa de dose é usualmente expressa em grays por hora $(\mathrm{Gy} / \mathrm{h})$. A energia absorvida pelo lote do material deve ser mensurada com ajuda da dosimetria adequada, precedida por sistemática de calibrações (McLaughlin, et al., 1989).

Na década de 1980, o processo de esterilização por radiação foi admitido para alguns medicamentos, incluindo antibióticos, esteroides e alcaloides, alguns produtos vegetais crus e ervas medicinais, bem como medicamentos veterinários, no Reino Unido, Noruega, Índia, Indonésia, Israel e Austrália. De acordo com Marciniec (2008), a contribuição da esterilização por radiação na produção mundial de dispositivos médicos em 1980 já estava perto de $13 \%$ e seu uso generalizado foi antecipado, o que levou à introdução de algumas normas internacionais. Existem dois principais documentos que regulam o uso de esterilização por radiação atualmente em vigor:

1) A norma europeia (EN 522 - Sterilization of Medical Devices) para o uso de raios gama e de feixes de elétrons de energia $\leq 10 \mathrm{MeV}$ (de aceleradores) em uma dose mínima de 25 kGy, garantindo o nível de garantia de esterilidade $(\mathrm{SAL})$ de $10^{-6}$ em dispositivos médicos.

2) A norma da Organização Internacional de Normalização (ISO 11137 Sterilization of health care products - Radiation) para o uso de raios gama, raios $X$ e feixes de elétrons em diferentes doses, dependendo do tipo e do nível de contaminação microbiológica e a meta do nível de esterilidade, em instrumentos médicos, dispositivos e produtos, incluindo medicamentos, vacinas e produtos para a saúde. Porém, em versões anteriores a esta norma, uma dose mínima de 25 kGy era aplicada rotineiramente para muitos dispositivos médicos, produtos farmacêuticos e tecidos biológicos.

A quarta edição da Farmacopeia Europeia (2002) permite cinco tipos de procedimentos de esterilização incluindo a radiação. Para este método de esterilização, a dose absorvida de referência é 25 kGy e também deve assegurar SAL de $10^{-6}$ ou maior (Marciniec, 2008). 
A radiação gama tem um largo uso em aplicações industriais para controle biológico, tais como: esterilização de material médico cirúrgico, odontológico, de laboratório, frascos, embalagens, fármacos, descontaminação de produtos, cosméticos, matérias-primas, fitoterápicos, chás, processamento de alimentos, especiarias, condimentos, corantes. Indução de modificações em vidros, pedras semipreciosas, melhoria de fibras sintéticas e de polímeros, produção de inoculantes para a agricultura, impregnação de madeiras e outros materiais.

\subsubsection{Dosimetria}

O sistema de qualidade e a utilização de um processo de dosimetria adequado garantem a qualidade dos produtos. O relatório da dosimetria fornece evidências e prova documental de validação de que o processo de esterilização de rotina foi corretamente administrado e que todos os produtos receberam a dose especificada para o processo (Mehta e Abdel-Fattah, 2008).

A dose limite superior é fixada de modo a evitar quaisquer efeitos prejudiciais sobre o produto e sua embalagem. A dose inferior deve alcançar o nível desejado de esterilidade. As doses envolvidas durante o experimento podem variar consideravelmente. É importante assegurar boa uniformidade de dose e mapeamento de dose durante a pesquisa. A relação entre o limite superior e o limite inferior da dose pode ser chamada de "taxa de dose limite" (DLR). No processo de qualificação de desempenho, esta relação é um parâmetro importante (Mehta e Abdel-Fattah, 2008).

\subsubsection{Efeitos da radiação ionizante em polímeros}

Segundo Berejka e Kaluska (2008) e Mukherjee (1975), a área de dispositivos médicos foi beneficiada a partir da disponibilidade de numerosas matérias-primas poliméricas disponíveis comercialmente. Porém, em todos os casos, quando a esterilização por radiação está sendo considerada, os efeitos da radiação sobre os próprios polímeros devem ser levados em conta.

Visando atender às necessidades de mercado para produtos processados por radiação, foram realizados desenvolvimento e caracterização de 
embalagens formadas por diferentes polímeros. Estudos que envolveram efeitos das radiações em polímeros promoveram diversas aplicações possíveis dessas radiações tanto na obtenção de polímeros mais resistentes quanto no uso das radiações para a modificação e degradação deles (Miranda, 1999; Encyclopedia, 1988). A radiação ionizante tem sido aplicada em polímeros para produzir a reticulação ou cura e a esterilização de produtos poliméricos de usos biomédicos (O’Donnell e Sangster, 1970).

Estudos mostraram que quando um determinado polímero ou filme polimérico é submetido à radiação ionizante pode sofrer modificações na sua estrutura física e química induzidas pela interação da radiação com o polímero e pela produção de cátions, ânions, radicais livres e espécies excitadas (Clegg e Collyer, 1991; Goulas et al., 2003; Chapiro, 1969; O'Donnell e Sangster, 1970; Demertzis et al., 1999). As modificações causadas pela radiação ionizante em polímeros dependem das condições específicas de irradiação, isto é, da dose absorvida, da taxa de dose, da atmosfera da irradiação e da presença de oxigênio. As modificações dependem ainda da composição do polímero, ou seja, dos aditivos utilizados, dos solventes e do grau de cristalinidade e homogeneidade do material polimérico que irá absorver a energia (Clegg e Collyer, 1964; Demertzis et al., 1999; Riganakos et al., 1999; Buchalla et al., 1993).

As principais alterações químicas que ocorrem em polímeros devido à radiação ionizante são a cisão das ligações da cadeia principal (degradação) e as ligações químicas entre moléculas poliméricas diferentes (reticulação) (Spinks e Woods, 1990); além disso, ocorrem também a formação de gases, de compostos de baixa massa molar pela radiólise do polímero e a formação de ligações insaturadas (Buchalla et al., 1993). Os processos de degradação e reticulação ocorrem concomitantemente e a predominância de um deles sobre o outro depende da estrutura química do polímero e das condições de irradiação (Wilsky, 1987). Ainda, segundo Schnabel (1981), a produção de radicais livres e íons pela radiação de alta energia podem iniciar a polimerização ou a copolimerização em monômeros.

Geralmente, os polímeros contendo carbonos quaternários na cadeia principal tendem a degradar, enquanto que os demais tendem a reticular (Spinks e Woods, 1990). Polímeros contendo anel benzênico têm uma maior resistência à 
radiação, necessitando de doses de radiação superiores para reticular, em comparação aos demais polímeros. A energia pode ser transferida ao longo da cadeia polimérica pelas ligações $\mathrm{C}-\mathrm{C}$ e $\mathrm{C}-\mathrm{H}$. As ligações $\mathrm{C}-\mathrm{H}$ são as que sofrem mais facilmente a cisão, sendo, portanto, o hidrogênio produzido em abundância. Em polímeros, em pequena escala, ocorrem cisões nas ligações $\mathrm{C}-\mathrm{C}$, com a produção de radicais livres (Dole, 1972), que recombinam-se, principalmente com o hidrogênio formado, produzindo, desta forma, espécies com massa molar menor do que aquelas que lhes deu origem. A presença de oxigênio favorece a degradação, devido, provavelmente, a formação de peróxidos, os quais impedem a recombinação de radicais no final da cadeia (Scott, 1990).

Alguns dos polímeros em que prevalece a cisão são o poli(isobuteno), o poli(metil metacrilato), o poli(tetrafluoroetileno) e a celulose, enquanto que no polietileno prevalece a reticulação. No poliestireno, a degradação é induzida pela irradiação na presença de oxigênio e a reticulação quando é irradiado no vácuo (Schnabel, 1981; Encyclopedia, 1988; Sansgster,1989).

Mizani et al. (2009), relataram diminuições consideráveis nas propriedades mecânicas (tração e alongamento), de um filme laminado de múltiplas camadas, comercialmente usado para embalagens de especiarias, após irradiado. Pesquisadores da Universidade de Torino analisaram também a oxidação de dez componentes protéticos de polietileno (PEs) esterilizados por óxido de etileno e radiação gama e demonstraram que todas as amostras exibiram a oxidação da superfície, ocorrida durante o processamento e a modelagem, relatada pela degradação mecânica. Os PEs esterilizados por radiação gama apresentaram níveis mais elevados de oxidação, que variaram de amostra para amostra, na superfície e no volume. Os diferentes níveis de oxidação e de distribuição podem depender das condições da esterilização gama, em especial, a taxa de dose absorvida (Costa et al., 1998).

Segundo Singson et al. (1983), resultados de esterilização de produtos médicos plásticos mostraram uma maior quantidade de matéria oxidável nas amostras (tubos de alimentação e equipos para infusão) irradiadas e um aumento de matéria oxidável em dose mais elevada. Neste mesmo estudo, verificou-se que não houve mudança na cor das amostras de polietileno (PE), enquanto que 
amostras feitas de poli(cloreto de vinila) (PVC) mostraram ligeira descoloração (amarelecimento) após a irradiação.

Goldman et al. (1996), pesquisadores da Universidade da Califórnia, estudaram os efeitos da esterilização por radiação gama e do envelhecimento sobre a estrutura e a morfologia de um polietileno de ultra alto peso molar (UHMWPE), o polímero mais importante para os dispositivos médicos (tais como próteses). As principais alterações observadas foram a oxidação, o aumento da cristalinidade e, consequentemente, da densidade, sendo que a cisão de cadeia foi a resposta predominante ao efeito da irradiação. A aplicabilidade dos resultados deste estudo é dirigida para avaliar a evolução das propriedades mecânicas e da integridade estrutural do UHMWPE para a substituição total da articulação.

Goulas et al. (2003) estudaram o efeito da radiação gama em uma série de embalagens flexíveis de múltiplas camadas comerciais, em diferentes doses; porém, observaram que foram induzidas diferenças nas propriedades mecânicas (tração e alongamento) e na migração global da maioria dos polímeros estudados apenas na dose de $30 \mathrm{kGy}$.

Outros exemplos de estudos realizados para verificar os efeitos da radiação ionizante são: a irradiação de embalagens destinadas a cosméticos (Saunier et al., 2008); os efeitos da radiação ionizante em polietileno de alto peso molar (Buchalla et al., 1995); estudo da aplicabilidade de filmes plásticos (nylon, sarin, filmes complexos de polietileno, filmes de polietileno de alta e baixa densidade), para embalagens de produtos esterilizados por radiação (Fengmei et al., 2000).

Um outro efeito encontrado por pesquisadores foi a indução, pela radiação ionizante, de odores indesejáveis em polímeros (Demertzis et al., 1999; Riganakos et al., 1999; Azuma et al., 1984a e b). Segundo Riganakos et al. (1999), um grande número de compostos voláteis foram produzidos pela irradiação de três filmes de embalagens alimentares em todas as doses testadas e, em geral, a quantidade de compostos voláteis aumentaram proporcionalmente com o aumento da dose de radiação absorvida. Koszinowski e Pringer (1983) estimaram o limiar de odor e aroma para vários compostos de carbonilo 
insaturados e propuseram que estes compostos eram responsáveis por odores indesejáveis resultantes da irradiação de papel cartão, porém revestido com PE.

\subsubsection{Efeitos da radiação ionizante sob papel, celulose e outros materiais}

Além da utilização das radiações ionizantes para esterilizar materiais e produtos, restauradores de diversos países hoje contam com a irradiação dentre as técnicas disponíveis para controle biológico em materiais submetidos a processos de recuperação. Estudos realizados mostram os efeitos da radiação sobre outros materiais além de polímeros sintéticos, como: papel para documentos, papel de valor histórico, livros, papel filtro e celulose microcristalina. Existem ainda estudos sobre: telas de obras de arte (Rizzo et al., 2002); peças de madeira e múmias que podem ser beneficiadas com esse processo (Pointing et al., 1998); tecidos biológicos, como pele, ossos, cartilagens e sangue e seus derivados (plasma, plaquetas, linfócitos, etc.) para evitar rejeições de materiais biológicos e possíveis doenças associadas a transfusões (Dzidzic-Goclawska, et al., 2008). Serão descritos a seguir os estudos e os resultados obtidos para os efeitos da radiação em alguns destes materiais.

A partir do final da década de 1960, foram conduzidas experiências com métodos físicos visando estudar o efeito das radiações de alta frequência, raios ultravioleta e radiação gama em materiais bibliográficos afetados por fungos e insetos. Concluiu-se que o uso da radiação gama pode trazer excelentes resultados biocidas, sem apresentar resíduos de ordem química e/ou radioatividade, podendo atingir completa penetração do objeto. Além disso, verificou-se que a radiação não provocou alterações significativas perceptíveis na aparência dos materiais tratados. Porém, existe a necessidade de pesquisas do uso da radiação gama, uma vez que, dependendo das doses utilizadas, podem ocorrer danos em materiais que contêm celulose, como o papel (Tomazello, 1994).

D'Almeida et al. (2009) estudaram os efeitos da irradiação na integridade do papel formado em laboratório e observaram a redução de alguns parâmetros; contudo, o estudo não evidenciou efeitos que comprometessem a resistência do papel, nas condições estudadas. Estudo realizado na Argentina por Gonzalez et al. 
(2002) empregou radiação (14,4 kGy) em diferentes tipos de papel contaminados com fungos e apenas uma das amostras de papel (revista) sofreu uma redução significativa nas propriedades mecânicas após a irradiação. Além disso, não observaram nenhuma mudança na cor dos papéis e nenhuma mudança na estrutura das fibras. Outros pesquisadores provaram que não ocorreu nenhum efeito prejudicial em propriedades de resistência mecânica e física de celulose pura e papel (Magaudda, 2004; Flores, 1975-1976).

Quando a celulose e outros polissacarídeos são tratados por radiação ionizante o processo de degradação em uma macromolécula por cisão aleatória sem ligações cruzadas é predominante (Ershov, 1998). Muitos pesquisadores analisaram o grau de polimerização do papel e da celulose após passarem pelo processo de radiação ionizante e observaram a diminuição deste parâmetro, porém, não detectaram alterações significativas em suas propriedades mecânicas (Phillips e Arthur, 1985; Stepanik et al., 1998; Majali et al., 1998; Calvini e Santucci, 1978-1979). 


\section{METODOLOGIA}

O trabalho consistiu em selecionar duas das embalagens que se destinam a produtos estéreis, pesquisar e definir as técnicas físicas e químicas a serem empregadas para o estudo, a fim de verificar se as propriedades das embalagens tratadas por radiação ionizante se mantêm com requisitos de qualidade que não comprometam a esterilidade dos itens embalados. Em seguida, foram decididas as doses de radiação a serem empregadas nas embalagens envolvidas no estudo. $O$ irradiador selecionado e empregado foi a fonte gama de cobalto-60, do tipo Gammacell, a ser descrito no decorrer deste capítulo.

A sequência da metodologia empregada resumiu-se nas seguintes etapas:

Etapa I - Aquisição das amostras.

Etapa II - Caracterização geral das amostras.

Etapa III - Irradiação das amostras com dose de 25 kGy.

Etapa IV - Irradiação das amostras com dose de 50 kGy.

Etapa V - Estudo da variação da dose absorvida no material com uso da dosimetria.

\subsection{Aquisição das amostras}

Nesta etapa, foram adquiridas junto a fornecedores comerciais, dois tipos de embalagens, ambas no formato de envelope, uma delas composta por papel grau cirúrgico e filme plástico multicamada formado pelos polímeros poliéster e polietileno, segundo o fornecedor, denominada Amostra 1. A segunda amostra formada por papel grau cirúrgico e filme plástico multicamada formado pelos polímeros poliéster e polipropileno, segundo o fornecedor, denominada Amostra 2 (FIG. 9). 


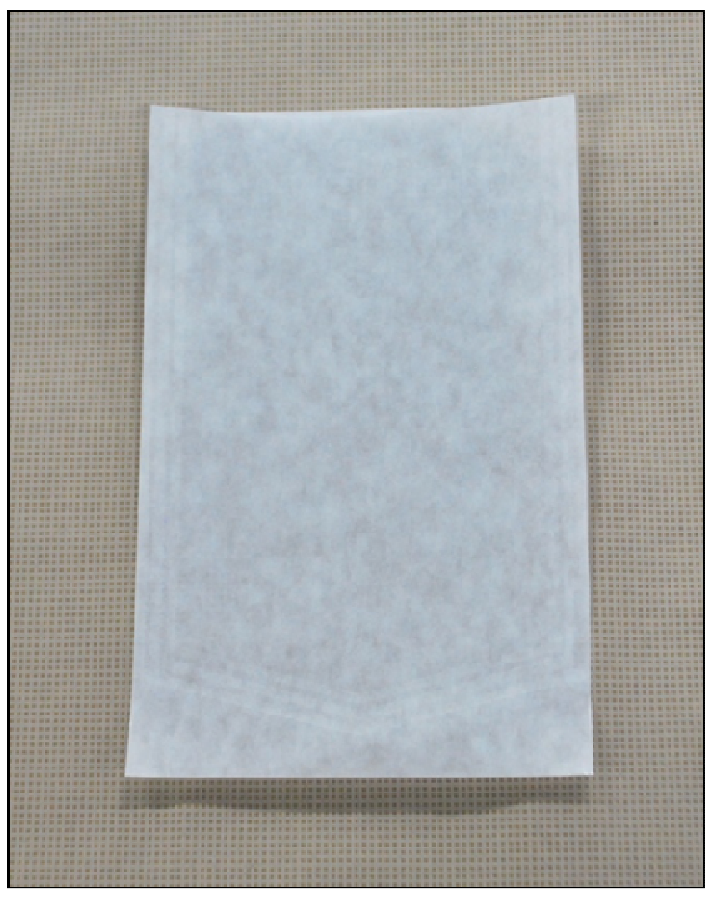

Amostra 1

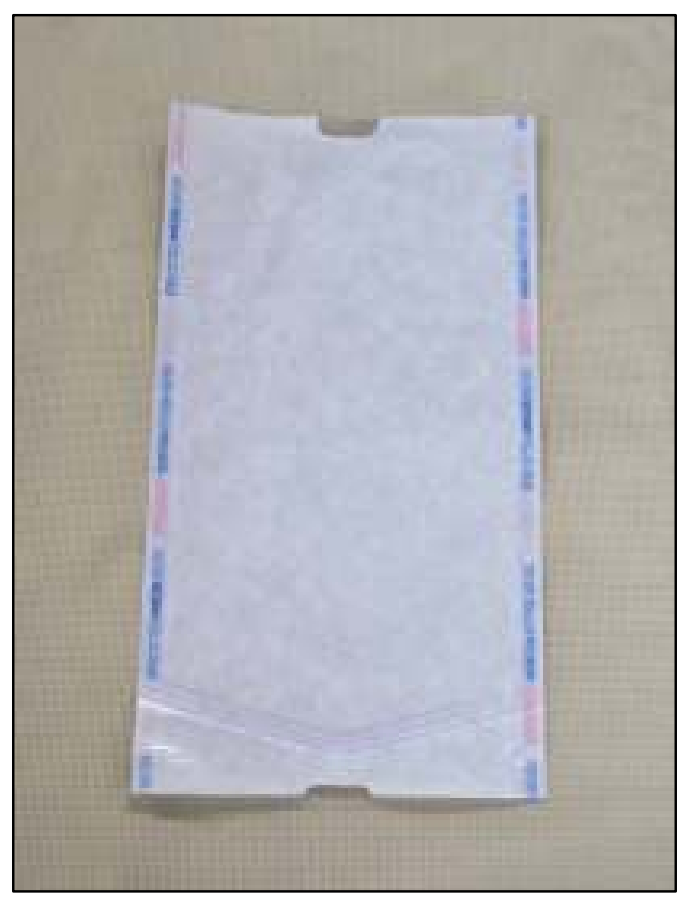

Amostra 2

Figura 9 - Fotos das amostras das embalagens utilizadas neste estudo

\subsection{Caracterização geral das amostras}

A caracterização geral das amostras envolveu: a) análise da composição fibrosa do papel das amostras, para determinação dos tipos de fibras vegetais que compõem este papel e relacionar o tipo de fibra com as características do papel; b) análise em microscópio eletrônico de varredura (MEV), visando obter fotomicrografias da superfície dos papéis das amostras, para verificação da presença de revestimento; c) análise da superfície do papel por espectroscopia por energia dispersiva (EDS), visando obter os elementos presentes; e d) análise por espectroscopia no infravermelho para determinar a natureza química do filme plástico e, no papel, a presença de outros picos além dos referentes à celulose.

\section{a) Análise da composição fibrosa do papel}

A metodologia utilizada para esta análise foi a apresentada na norma ABNT NBR 14129-1:1998 - Papel, cartão e pasta celulósica - Análise de composição fibrosa - Método geral. Este método utiliza o corante Graff "C" e 
também o corante Floroglucinol. Com estes corantes, é possível identificar a maioria das fibras usuais utilizadas na fabricação de papel e seu uso baseia-se nas diferenças de tonalidade e intensidade de cor, quando aplicado nas fibras. Consegue-se diferenciar, também, a origem das fibras dos papéis em: química, semiquímica ou mecânica e de coníferas ou folhosas.

Para a análise das fibras do papel de cada uma das amostras de embalagem, foram feitas fotomicrografias com aumentos de 100 e 200 vezes em um Microscópio Leica - DM 4000 B acoplado com câmera digital DFC 310 FX e software LAS versão 3.8.0.

\section{b) Microscopia eletrônica de varredura}

No microscópio eletrônico de varredura, a coluna do microscópio consiste de uma fonte de elétrons, lentes eletromagnéticas e bobinas de varredura, operando sob vácuo. A fonte de elétrons, normalmente um tipo de filamento de tungstênio, produz um feixe de elétrons por aquecimento do filamento metálico; os elétrons seguem um caminho vertical pela coluna e são focados pelas lentes eletromagnéticas em direção à amostra; os elétrons lançados a partir da amostra são registrados pelo detector e transformados em imagem. As bobinas de varredura têm a função de defletir o feixe e controlar sua varredura sobre a superfície da amostra. A irradiação da amostra com elétrons provoca a emissão de elétrons secundários, elétrons retroespalhados e de raios $X$, além de outros sinais. O microscópio eletrônico de varredura normalmente possui detectores de elétrons secundários (SE) e retroespalhados (BSE) para obtenção de imagens (Gonçalves, 2003).

Foram feitas fotomicrografias do papel das embalagens com aumentos de 100, 500 e 2000 vezes no microscópio eletrônico de varredura de emissão de campo (MEV/FEG), marca FEI, modelo QUANTA 400, com detector INCA PentaFETx3, do Laboratório de Corrosão e Proteção do IPT. Para a realização das análises, foram seguidas as instruções do manual do equipamento. Os corpos de prova utilizados foram introduzidos na câmara do equipamento na forma de quadrados com cerca de $1 \mathrm{~cm}^{2}$. 


\section{c) Espectroscopia por energia dispersiva (EDS)}

Para esta análise, foi utilizado o microscópio eletrônico de varredura de emissão de campo (MEV/FEG), marca FEl, modelo QUANTA 400, com analisador de dispersão de energia de raios X INCA Energy-350 Oxford, com detector INCA PentaFETx3, do Laboratório de Corrosão e Proteção do IPT.

Para o processamento dos espectros, foram utilizadas 4 interações para análise de todos os elementos, não tendo sido omitido qualquer pico. Os espectros foram obtidos nos mesmos corpos de prova utilizados na tomada de imagens por MEV (item b). Para a atribuição dos picos e cálculo de porcentagem em massa, foram utilizados os padrões: $\mathrm{CaCO}_{3}$ para $\mathrm{C}$; $\mathrm{SiO}_{2}$ para O; Albita para $\mathrm{Na}$; $\mathrm{Al}_{2} \mathrm{O}_{3}$ para $\mathrm{Al}$; $\mathrm{SiO}_{2}$ para $\mathrm{Si}$; $\mathrm{FeS}_{2}$ para $\mathrm{S}$; Feldspato $\mathrm{MAD}-10$ para $\mathrm{K}$; Wollastonita para Ca; Ti para Ti e Fe para Fe.

\section{d) Espectroscopia no infravermelho}

A espectroscopia no infravermelho estuda a interação da radiação eletromagnética com a matéria, sendo um dos principais objetivos o estudo dos níveis de energia de átomos ou moléculas. $O$ espectro infravermelho de um composto químico é considerado uma de suas propriedades físico-químicas mais características. $\mathrm{O}$ espectro de absorção no infravermelho tem origem quando a radiação eletromagnética incidente tem um componente com frequência correspondente a uma transição entre dois níveis vibracionais (Skoog, 1992; Costa Filho, 1998).

A região do espectro eletromagnético correspondente ao infravermelho se estende de aproximadamente $0,75 \mu \mathrm{m}$ até quase $1 \mathrm{~mm}$, mas o segmento mais frequentemente utilizado pelos químicos está situado entre 2,5 e $25 \mu \mathrm{m}$ (4000 e 400 $\mathrm{cm}^{-1}$ ), conhecido como região fundamental ou infravermelho médio (Luz, 2003).

Os aparelhos usados para se obter o espectro de infravermelho (IR) são de dois tipos: espectrofotômetro dispersivo e espectrômetro por transformada de Fourier (FTIR). Um espectrômetro de grande sensibilidade é o FTIR, que emprega um interferômetro de Michelson como princípio de funcionamento, sendo mais rápido, preciso, reprodutível e mais acessível. O interferograma é um gráfico de 
resposta do detector versus diferença de caminho óptico. O espectrômetro FTIR obtém o interferograma e, a partir deste, pela operação de transformada de Fourier feita pelo computador, obtém-se o espectro IR natural, que é o perfil espectral de intensidade versus número de ondas $\mathrm{em} \mathrm{cm}^{-1}$ (Kawano, 2003).

Para as análises qualitativas das amostras por espectroscopia no infravermelho, seguiu-se o procedimento interno IPT, CMQ-LAQ-PE-QO-067, utilizando um Microscópio (610IR) acoplado ao espectrofotômetro no infravermelho com transformada de Fourier (660IR); marca Agilent; modelo 610IR e 660IR. Estas análises foram realizadas no Laboratório de Análises Químicas do IPT.

\subsection{Irradiação das amostras com dose de 25 kGy}

Nesta etapa, os corpos de prova das embalagens foram analisados antes e depois de serem submetidos à irradiação. A dose de radiação usada nesta etapa foi de $25 \mathrm{kGy}$, sendo utilizado o irradiador com fontes de cobalto-60 do tipo Gammacell 220 série $n^{\circ} 142$ (FIG. 10), o qual se encontra no Centro de Tecnologia das Radiações (CTR-IPEN).

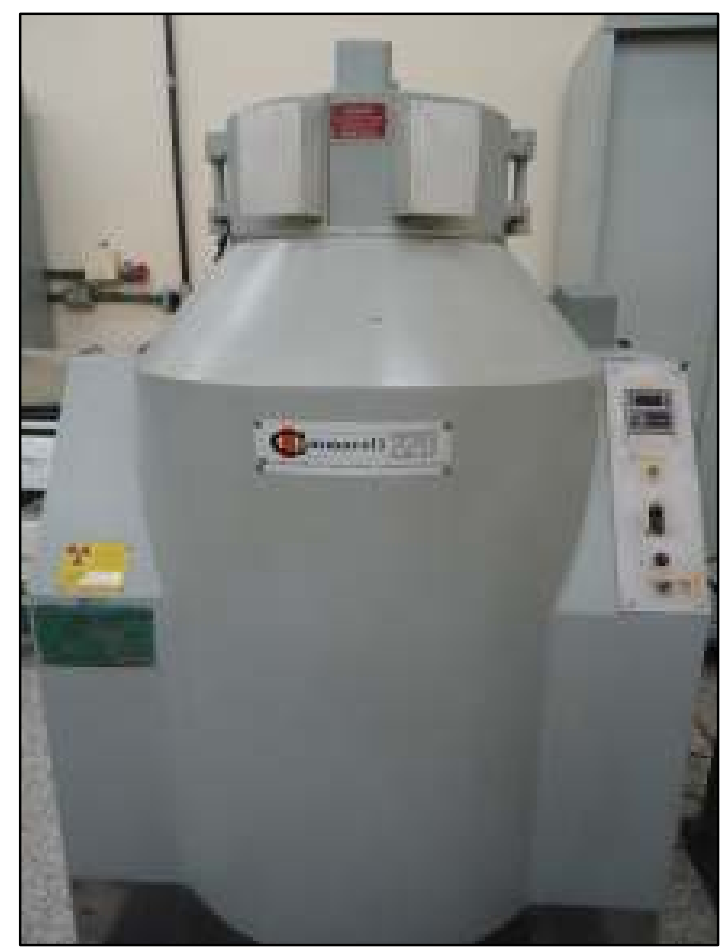

Figura 10 - Irradiador Gammacell 220 série nº 142 (12kCi; 8,5 kGy/h) 
Os corpos de prova das embalagens foram extraídos de uma mesma região, sendo um deles submetido à irradiação e o outro não. Na FIG. 11, é exemplificada a técnica empregada.

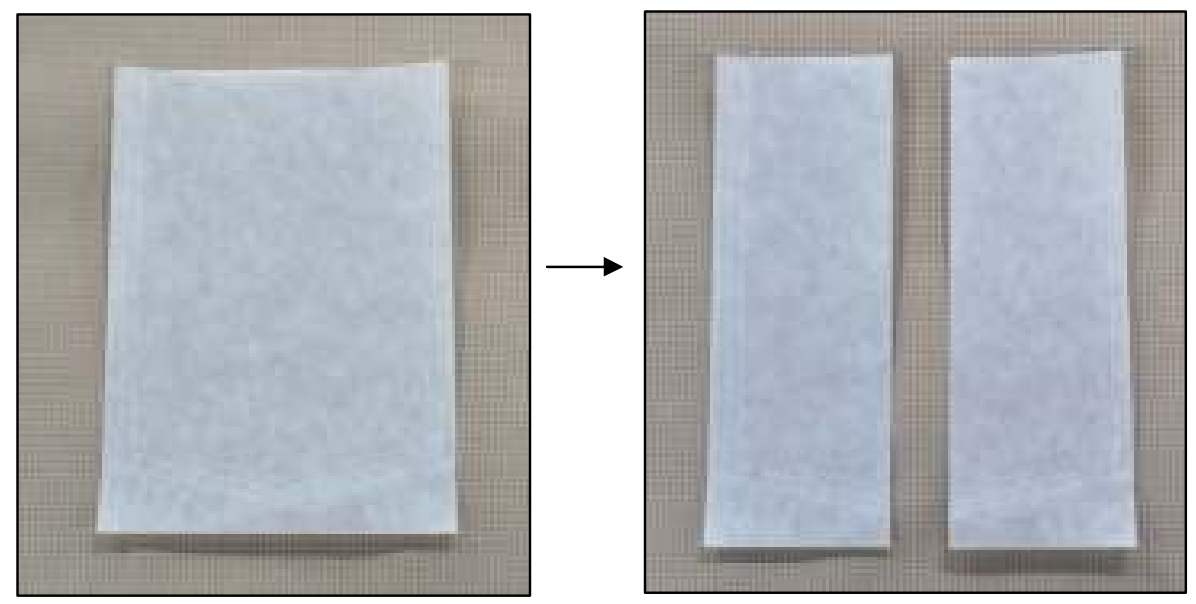

Figura 11 - Preparação dos corpos de prova da Amostra 1 para as análises

Nos corpos de prova não irradiados e irradiados, foram realizados os ensaios relacionados nas TAB. 1 e 2. Estes ensaios são os utilizados para a verificação da conformidade dos papéis grau cirúrgico com relação aos requisitos de desempenho constantes na norma ABNT NBR 14990-3, e da conformidade dos filmes plásticos e das embalagens constantes na norma ABNT NBR 14990-8. A conformidade com as normas citadas aprovam as embalagens para uso.

A caracterização das amostras apoiou-se especialmente em normas porque nelas estão contidas as principais características que o papel, a embalagem e o filme plástico, respectivamente, devem atender para poderem ser utilizados para a finalidade de esterilização por radiação gama. Qualquer modificação induzida pela radiação não deve afetar a qualidade dos materiais a ponto de comprometer tais especificações. O objetivo destas normas é aumentar os níveis de qualidade, segurança, confiabilidade, eficiência e intercâmbio de informações.

No caso do papel, além dos parâmetros indicados nas TAB. 1 e 2, foi determinado o índice de cristalinidade antes e após a irradiação, para verificar se este exerce alguma influência nas celas cristalinas da celulose. Para isto, empregou-se a técnica de difração de raios $X$. 
As análises por espectroscopia no infravermelho foram realizadas também para a verificação de uma possível modificação nos espectros obtidos devido à influência da radiação nas estruturas tanto dos papéis quanto dos filmes plásticos, não irradiados e irradiados com 25 kGy e 50 kGy.

Tabela 1 - Métodos empregados para a análise do papel e requisitos de desempenho solicitados pela norma ABNT NBR 14990 - Parte 3

\begin{tabular}{|c|c|c|}
\hline \multicolumn{3}{|c|}{ PAPEL - NORMA ABNT NBR 14990 PARTE 3:2010 } \\
\hline ENSAIO & MÉTODO & $\begin{array}{l}\text { REQUISITOS DE } \\
\text { DESEMPENHO }\end{array}$ \\
\hline Residual de corantes & $\begin{array}{l}\text { Item } 7.2 \text { da norma } \\
\text { ABNT NBR NM-ISO } 6588 \text { - Parte } 2\end{array}$ & ausente \\
\hline Gramatura & ABNT NBR NM-ISO 536 & $\begin{array}{l}\text { variar no máximo } 5 \% \text { em } \\
\text { relação ao valor nominal }\end{array}$ \\
\hline Espessura & ABNT NBR ISO 534 & |-------------- \\
\hline $\begin{array}{l}\mathrm{pH} \text { do extrato aquoso obtido } \\
\text { a quente }\end{array}$ & ABNT NBR NM-ISO 6588-2 & mínimo 5 / máximo 8 \\
\hline Fluorescência & $\begin{array}{c}\text { Anexo A da norma } \\
\text { ABNT NBR 14990-3:2010 }\end{array}$ & $\begin{array}{l}\text { - aumento em alvura }<1 \% \\
\text { - máximo de } 5 \text { pontos } \\
\text { fluorescentes com eixo } \\
\text { maior que } 1 \mathrm{~mm} \text { por } 0,01 \mathrm{~m}^{2}\end{array}$ \\
\hline $\begin{array}{l}\text { Permeância ao ar Bendtsen, } \\
\text { em } \mu \mathrm{m} / \text { Pa.s }\end{array}$ & ABNT NBR NM-ISO 14255 & mínimo 0,2 \\
\hline Diâmetro dos poros, em $\mu \mathrm{m}$ & $\begin{array}{c}\text { Anexo C da norma } \\
\text { ABNT NBR 14990-3:2010 }\end{array}$ & $\begin{array}{l}\text { máximo para média } 20 \mu \mathrm{m} \\
\text { máximo individual } 30 \mu \mathrm{m}\end{array}$ \\
\hline $\begin{array}{l}\text { Resistência ao rasgo, em mN } \\
\text { - direção de fabricação } \\
\text { - direção transversal }\end{array}$ & ABNT NBR NM-ISO 1974 & $\begin{array}{l}\text { mínimo } 300 \\
\text { mínimo } 300\end{array}$ \\
\hline $\begin{array}{l}\text { Resistência ao arrebentamento } \\
\text { a seco, em } \mathrm{kPa}\end{array}$ & ABNT NBR NM-ISO 2758 & mínimo 200 \\
\hline $\begin{array}{l}\text { Resistência à tração a seco, } \\
\text { em kN/m } \\
\text { - direção de fabricação } \\
\text { - direção transversal }\end{array}$ & ABNT NBR NM-ISO 1924-2 & $\begin{array}{l}\text { mínimo } 4,0 \\
\text { mínimo } 2,0\end{array}$ \\
\hline
\end{tabular}


Tabela 2 - Métodos empregados para a análise do filme plástico e da embalagem e requisitos de desempenho solicitados pela norma ABNT NBR 14990 - Parte 8

\begin{tabular}{|c|c|c|}
\hline \multicolumn{3}{|c|}{ FILME PLÁSTICO - NORMA ABNT NBR 14990 PARTE 8:2004 } \\
\hline ENSAIO & MÉTODO & $\begin{array}{l}\text { REQUISITOS DE } \\
\text { DESEMPENHO }\end{array}$ \\
\hline $\begin{array}{l}\text { Exame visual - furos, rasgos } \\
\text { ou orifícios, polímero e o } \\
\text { copolímero delaminados }\end{array}$ & ABNT NBR 14990-8 - item 4.1 & ausentes \\
\hline Gramatura & ABNT NBR NM-ISO 536 & $\begin{array}{l}\text { variação máxima de } 7 \% \text { do } \\
\text { valor nominal }\end{array}$ \\
\hline Espessura & ABNT NBR ISO 534 & $\begin{array}{l}\text { variação máxima de } 7 \% \text { do } \\
\text { valor nominal }\end{array}$ \\
\hline $\begin{array}{l}\text { Determinação de microfuros } \\
\text { em filme laminado }\end{array}$ & ABNT NBR 14990-8 - Anexo B & $\begin{array}{l}\text { não passagem da solução } \\
\text { corante para o papel } \\
\text { absorvente }\end{array}$ \\
\hline $\begin{array}{l}\text { Determinação da resistência } \\
\text { à tração de plásticos, em } \mathrm{N}\end{array}$ & ASTM D 882-02, Método A & mínimo 20 \\
\hline \multicolumn{3}{|c|}{ EMBALAGEM - NORMA ABNT NBR 14990 PARTE 8:2004 } \\
\hline ENSAIO & MÉTODO & $\begin{array}{l}\text { REQUISITOS DE } \\
\text { DESEMPENHO }\end{array}$ \\
\hline $\begin{array}{l}\text { Determinação da resistência } \\
\text { da selagem }\end{array}$ & ABNT NBR 14990-8 - item 7.2 & mínimo $1,5 \mathrm{~N} / 15 \mathrm{~mm}$ \\
\hline Impurezas & ABNT NBR 8259 & $\begin{array}{l}\text { não deve conter impurezas e } \\
\text { sujeiras removíveis ou não, } \\
\text { cuja soma resulte em área } \\
\text { total maior que } 10 \mathrm{~mm}^{2} / \mathrm{m}^{2} \text { de } \\
\text { amostra analisada }\end{array}$ \\
\hline Integridade da selagem & $\begin{array}{c}\text { ABNT NBR } 14990-8- \\
\text { item } 7.3\end{array}$ & $\begin{array}{l}\text { selagem íntegra: não permitir } \\
\text { a passagem da solução } \\
\text { corante pela área de selagem }\end{array}$ \\
\hline
\end{tabular}

Para a determinação dos parâmetros indicados nas TAB. 1 e 2, exceto $\mathrm{pH}$, residual de corantes, exame visual, microfuros e integridade da selagem, os corpos de prova foram condicionados e ensaiados em atmosfera normalizada a $23 \pm 1^{\circ} \mathrm{C}$ e $50 \pm 2 \%$ de umidade relativa do ar, sendo o tempo de condicionamento dos corpos de prova de no mínimo 24 horas. Todos os equipamentos utilizados nas análises foram calibrados por laboratórios de calibração acreditados pela Rede Brasileira de Calibração (RBC). 
Os ensaios indicados nas TAB. 1 e 2 foram realizados no Laboratório de Papel e Celulose (LPC). O LPC faz parte do Centro de Tecnologia de Recursos Florestais do Instituto de Pesquisas Tecnológicas. Este laboratório realiza ensaios e serviços especializados para três segmentos principais: fabricantes de papel e celulose, usuários e convertedores de papel e fabricantes de insumos e equipamentos para papel e celulose. Possui atuação especial no apoio à qualidade $e$ sistemas de controle de produtos para o setor público. Na área de metrologia, tem atuação marcante por meio do gerenciamento de Programas Interlaboratoriais para ensaios em papel, chapas de papelão ondulado e pasta celulósica com participantes nacionais e estrangeiros. Os Programas Interlaboratoriais, desenhados e operados para garantir o desempenho de laboratórios, são ferramentas necessárias para assegurar a qualidade de dados laboratoriais, sendo uma forma de um laboratório demonstrar sua proficiência ou a compatibilidade de seus resultados. A maioria dos ensaios que este laboratório realiza são acreditados pelo INMETRO e reconhecidos pela REMESP. Este laboratório possui ainda acreditação na ISO 9001.

\subsubsection{Descrição dos ensaios realizados nos papéis das amostras de embalagem}

\section{Gramatura}

A gramatura é descrita como a massa do papel expressa em gramas pela unidade de área do papel. O procedimento para determinação da gramatura consiste em pesar corpos de prova de área conhecida em balança analítica e expressar a massa obtida em gramas por metro quadrado $\left(\mathrm{g} / \mathrm{m}^{2}\right)$. O equipamento utilizado para este ensaio foi uma balança analítica marca Quimis modelo Q500L210C.

\section{Espessura}

A determinação da espessura é feita por meio de um micrômetro padronizado que possui dois discos de pressão, paralelos, entre os quais se coloca o corpo de prova a ser medido. A espessura é definida como a distância perpendicular entre as duas faces do papel.

O equipamento utilizado para a determinação da espessura foi um micrômetro da marca TMI modelo 549. 
$\mathrm{pH}$ e residual de corantes

A medida de $\mathrm{pH}$ indica a presença de grupos ácidos ou básicos no papel. Para a determinação do $\mathrm{pH}$ no papel, se extraiu, com água quente, durante uma hora, uma massa de $2 \mathrm{~g}$ do papel e em seguida mediu-se o $\mathrm{pH}$ do extrato aquoso obtido através de um pHmetro da marca Metrohm modelo 827 com um eletrodo de vidro combinado. Para o controle do tempo de extração, utilizou-se um cronômetro digital da marca Technos. Para a pesagem da massa de papel das amostras, foi utilizada uma balança analítica da marca Mettler modelo AB 204-S/FACT. Para o controle da temperatura do extrato aquoso, foi utilizado um termômetro.

O ensaio de residual de corantes consiste em observar a coloração do extrato aquoso obtido a quente na determinação do $\mathrm{pH}$.

\section{Fluorescência}

A determinação da fluorescência empregou dois métodos:

1) Método I: calcular o aumento da alvura em \%, em virtude do branqueador óptico, a partir das medições dos fatores de refletância difusa com filtro de corte (UV calibrado) ou sem filtro de corte (UV excluído) em corpos de prova de $100 \mathrm{~mm}$ x $100 \mathrm{~mm}$, usando a seguinte fórmula: (UV calibrado UV excluído)/UV calibrado.

A alvura é o fator de reflectância de papéis brancos, ou quase brancos, medido em um único comprimento de onda, $457 \mathrm{~nm}$. A determinação da alvura foi empregada inicialmente para avaliar o branqueamento de pastas celulósicas, sendo escolhido o comprimento de onda de $457 \mathrm{~nm}$ por ser na região do azul, 400-500 nm, que a refletividade das pastas celulósicas apresentavam maior mudança devido ao branqueamento. Neste ensaio, a alvura foi medida em um equipamento que tem uma geometria de $\mathrm{d} / 0^{\circ}$, ou seja, a incidência da luz é difusa e a leitura é feita a $0^{\circ}$, em um equipamento denominado Refletômetro Elrepho 3000 da marca Datacolor.

2) Método II: determinar em um corpo de prova de $100 \mathrm{~mm} \times 100 \mathrm{~mm}$ o número de pontos fluorescentes, cada um com eixo maior que $1 \mathrm{~mm}$ por 0,01 $\mathrm{m}^{2}$, utilizando uma fonte de radiação UV (lâmpada ultravioleta) com comprimento de onda de $315 \mathrm{~nm}$ a $380 \mathrm{~nm}$. 
Permeância ao ar, método Bendtsen

A permeância ao ar é o fluxo médio de ar, sob condições específicas, que passa através de uma unidade de área do papel, em uma dada unidade de diferença de pressão e em certa unidade de tempo. A permeância ao ar é uma propriedade estrutural do papel que depende do número, tamanho, formato e distribuição dos poros no papel.

No método Bendtsen, o corpo de prova é fixado entre uma superfície plana e um anel metálico circular e o ar é suprido a uma pressão normalizada de $1,47 \mathrm{kPa}$ na área interna do anel e, a seguir, é medida a velocidade do fluxo de ar que passa entre o anel e o corpo de prova, em $\mathrm{mL} / \mathrm{min}$.

O equipamento utilizado para esta análise foi o Aparelho Bendtsen de marca Andersson e Sorensen Copenhagen, modelo $6 n^{\circ} 12746$.

\section{Diâmetro dos poros}

O princípio deste método se resume na determinação da pressão exercida para forçar a passagem de uma bolha de ar através dos interstícios do papel umedecido por um líquido e tendo um filme do mesmo líquido sobre sua superfície. O conhecimento desta pressão e da tensão superficial do líquido permite calcular o tamanho dos interstícios do papel por meio da seguinte fórmula:

$$
r=\frac{2 T \times 10^{6}}{\rho P g}
$$

ou simplificada

$$
r=\frac{204 x T}{P}
$$

em que:

$T$ = tensão superficial do líquido de ensaio à temperatura de ensaio, em $\mathrm{mN} / \mathrm{m}$;

$g=$ aceleração devido à gravidade, em $\mathrm{mm} / \mathrm{s}^{2}$;

$\rho=$ densidade da água a temperatura de ensaio, em $\mathrm{mg} / \mathrm{mm}^{3}$;

$P=$ pressão da bolha, em milímetro de coluna d'água.

O equipamento utilizado para este ensaio é denominado porosímetro, e a parte mais importante deste equipamento é o manômetro de coluna d'água o qual é calibrado. O líquido utilizado para este ensaio foi o etanol. Para o controle 
do tempo de subida da água na coluna d'água, para posterior cálculo da velocidade de subida que deve ser controlada conforme solicitado pela norma, utilizou-se um cronômetro digital da marca Technos.

O porosímetro foi confeccionado pelo Laboratório de Metrologia Mecânica do IPT, seguindo procedimento descrito na norma ABNT NBR 14990, a qual está sendo utilizada neste estudo.

O equipamento e sua forma de funcionamento são apresentados na FIG. 12, pois este equipamento é muito pouco conhecido e não é comercializado.
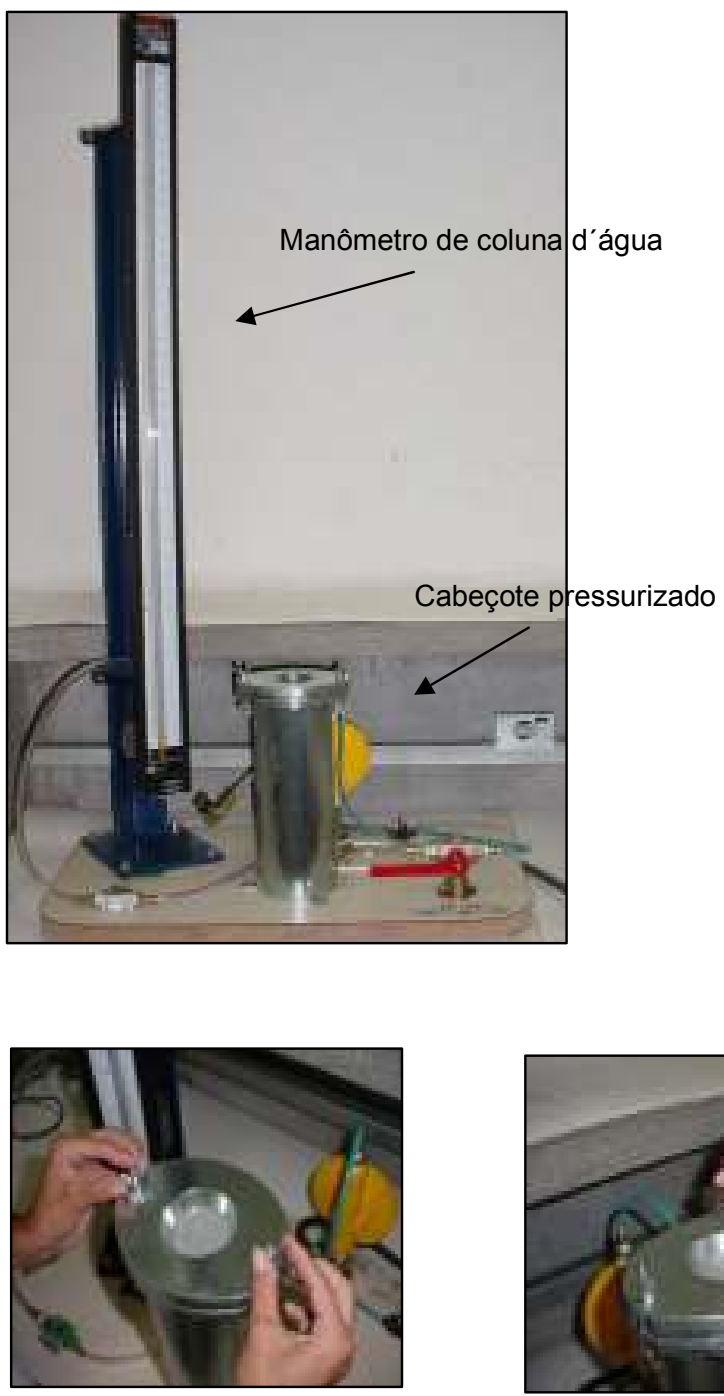

Adição do etanol sob o papel e formação de bolha pela pressão do ar.

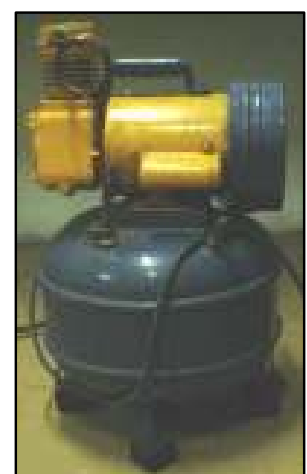

Compressor de ar

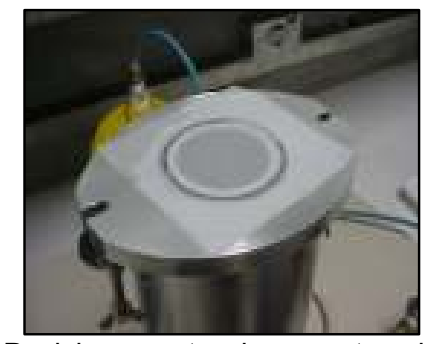

Posicionamento da amostra de papel, umedecido em etanol, no cabeçote pressurizado.

Figura 12 - Porosímetro para determinação do diâmetro de poros, construído pelo IPT e ilustração do modo de realização do ensaio 
$\underline{\text { Resistência ao rasgo }}$

A resistência ao rasgo é a força média requerida para continuar o rasgo a partir de um corte inicial, em uma única folha de papel. O resultado do rasgo é expresso em milinewton, $\mathrm{mN}$, com três algarismos significativos.

O método Elmendorf foi o empregado neste estudo para determinação da resistência ao rasgo, sendo o princípio deste juntar 4, 8, 16 ou 32 folhas; neste caso, foram utilizadas 8 folhas, que após um corte inicial foram rasgadas a uma distância fixa, usando um pêndulo para aplicar a força do rasgo pelo movimento em um plano perpendicular ao plano inicial.

O trabalho realizado para rasgar o conjunto de folhas é medido pela perda de energia potencial do pêndulo. A escala do equipamento é aferida para indicar a força média de rasgo, trabalho dividido pela força média total de rasgo. A resistência ao rasgo do papel é determinada pela força média de rasgo e pelo número de folhas que compõem o conjunto.

O aparelho utilizado para a realização desta análise foi o Elmendorf Tearing Tester da marca Thwing - Albert Instrument Co.

\section{$\underline{\text { Resistência ao arrebentamento }}$}

A resistência ao arrebentamento é a pressão hidráulica máxima que uma única folha de papel pode suportar sob as condições de ensaio. Esta pressão é distribuída uniformemente e aplicada perpendicularmente à superfície do papel.

O método consiste em colocar um corpo de prova sobre um diafragma elástico circular, com bordas rigidamente presas, mas com sua superfície livre. Um fluido hidráulico é bombardeado a uma velocidade constante expandindo o diafragma até a ruptura do corpo de prova. O equipamento utilizado para a realização deste ensaio foi o Mullen Tester da marca Regmed e modelo MTA 2000P.

\section{$\underline{\text { Resistência à tração }}$}

A propriedade de resistência à tração está relacionada com a capacidade do papel se sustentar sob condições de tensão. Uma tira de papel, 
tendo suas extremidades fixadas por garras ligadas a um dispositivo tracionador e a um dispositivo de medida de carga, é tracionada e deformada (alongada) até ocorrer sua ruptura.

A resistência à tração de um papel é a força máxima por unidade de largura, que ele suporta, sob condições específicas antes de se romper. A unidade da resistência à tração é $\mathrm{kN} / \mathrm{m}$.

Para a maioria dos papéis, a resistência à tração é maior na direção longitudinal à fabricação do papel do que na direção transversal, pois na direção longitudinal as fibras estão alinhadas e exercem uma resistência maior.

Os equipamentos utilizados para este ensaio foram um medidor de tração vertical, Dinamômetro da marca EMIC modelo DL 500, com uma célula de carga de $10 \mathrm{~kg}$. Os corpos de prova consistiram em tiras de $15 \mathrm{~mm}$ de largura.

\section{Difração de raios X}

A difração de raios $X$ é uma técnica para a obtenção de parâmetros estruturais bem como informações da cristalinidade de compostos. Denomina-se raios $X$ a radiação eletromagnética com comprimento de onda, $\lambda$, da ordem de $10^{-}$ ${ }^{10} \mathrm{~m}$. Esta radiação pode ser produzida em laboratório bombardeando um alvo metálico com um feixe de elétrons acelerados por uma diferença de potencial (Atikins, 1998).

O comprimento de onda $(\lambda)$ da radiação raios $X$ é da mesma ordem de grandeza das distâncias interatômicas dos sólidos. As reflexões produzidas pelos planos reticulares formados por arranjos regulares de átomos podem interagir entre si de forma a produzir padrões de interferência que podem ser relacionados a $\lambda$ e a distância interplanar $d$ de acordo com a Lei de Bragg:

$$
n \lambda=2 d_{h k l} \operatorname{sen} \theta_{h k l}
$$

em que, $n$ é a ordem da reflexão, $\lambda$ é o comprimento de onda da radiação empregada, $d$ é a distância interplanar, $\theta$ é o ângulo de incidência, e $h k l$ são os índices de Miller. A difração pode ocorrer por diferentes planos atômicos e estes planos recebem índices (Atikins, 1998). 
As análises qualitativas por difração de raios $X$ foram realizadas seguindo o método BS EN 13925-2:2003: Non-destructive testing - X-ray diffraction from polycrystalline and amorphous materials - Part 2: Procedures e o procedimento interno IPT, CMQ-LAQ-PE-QI-004, utilizando o equipamento Difratômetro de raios X da marca Panalytical e modelo X'Pert PRO MPD. Estas análises foram realizadas no Laboratório de Análises Químicas do IPT.

\section{Espectroscopia no infravermelho}

Esta análise foi realizada conforme já descrito no item 4.2 - d.

\subsubsection{Descrição dos ensaios realizados nos filmes plásticos das amostras de embalagem}

\section{Exame visual}

Esta análise consiste em observar, visualmente, as amostras de embalagens antes e após passarem pelo processo de esterilização, verificando se possuem furos, rasgos ou orifícios, polímero e ou copolímero delaminados.

\section{$\underline{\text { Microfuros }}$}

A presença de microfuros em filmes laminados é verificada pela colocação da superfície interior de um corpo de prova do filme plástico (superfície que entra em contato com o produto embalado) sob um pedaço de papel absorvente de tamanho similar ao corpo de prova na superfície plana de um pedaço de vidro. Sob o corpo de prova, coloca-se uma esponja feita de blocos de celulose com dimensões de $110 \mathrm{~mm} \times 75 \mathrm{~mm} \times 32 \mathrm{~mm}$, a qual foi previamente embebida por 1 minuto em uma solução corante de vermelho aquoso amarante contendo $0,005 \%$ de cetrimida como agente úmido. Sob a esponja, adiciona-se uma placa de aço de dimensões $110 \mathrm{~mm}$ x $75 \mathrm{~mm} \times 32 \mathrm{~mm}$ formando assim um conjunto de esponja mais placa com massa total de $800 \mathrm{~g} \pm 50 \mathrm{~g}$ e este conjunto permanece em contato com o corpo de prova por 2 minutos. Remove-se a esponja e a placa e examina-se a penetração do corante no papel absorvente. 
$\underline{\text { Resistência à tração de plásticos }}$

A determinação da resistência à tração de plástico segue o mesmo princípio e procedimento descrito no item 4.3.1, porém, para este ensaio, o resultado é expresso em $\mathrm{N}$ e a célula de carga utilizada é a de $10 \mathrm{~kg}$.

\section{Espectroscopia no infravermelho}

Para a análise dos filmes plásticos como um todo, utilizou-se a técnica de espectroscopia no infravermelho (IR) descrita no item 4.2 - d. Porém, na análise da frente e do verso dos filmes plásticos utilizou-se para a obtenção dos espectros de infravermelho um acessório acoplado ao espectrômetro FTIR denominado de reflectância total atenuada (ATR).

A técnica de IR com o ATR é frequentemente empregada para evitar interferentes na impressão digital do espectro de filmes finos. É uma análise não destrutiva, dispensa preparação prévia, é rápida e prática. O acessório é montado no compartimento de amostra do espectrômetro, normalmente adaptado à configuração específica de cada espectrômetro comercial. O elemento principal do acessório é o cristal, cujo material deve ser transparente à radiação infravermelho, apresentar alto índice de refração na faixa do infravermelho e um determinado ângulo de incidência da radiação (Kawano, 2003).

Além do cristal, o acessório possui dois espelhos planos, um que orienta o feixe infravermelho de incidência ao cristal e o outro que orienta o feixe que sai do cristal ao detector. O feixe IR incidente no cristal, a um dado ângulo de incidência, atinge a superfície e sofre o fenômeno de reflexão total, devido ao alto índice de refração do cristal em relação ao meio (amostra ou ar). Com isto, o feixe propaga-se ao longo do cristal até sair na extremidade oposta. O cristal funciona como um guia de onda do feixe IR. O feixe IR, ao atingir a superfície do cristal em contato com a amostra, penetra a uma pequena profundidade na superfície da amostra e se a amostra absorver parte da radiação esta fração de energia será detectada. A radiação IR que penetra na amostra e sofre atenuação é denominada onda evanescente. O termo refletância total atenuada advém deste fato (Costa Filho, 1998; Kawano, 2003). 


\subsubsection{Descrição dos ensaios realizados nas embalagens (envelopes)}

\section{$\underline{\text { Resistência da selagem }}$}

O ensaio de resistência da selagem segue o mesmo princípio e procedimento descrito para o ensaio de resistência à tração do papel presente no item 4.3.1; porém, neste caso, a ruptura da selagem das laterais das amostras é registrada pelo equipamento. O resultado deste ensaio é expresso em $\mathrm{N}$ e a célula de carga utilizada é a de $5 \mathrm{~kg}$.

$\underline{\text { Impurezas }}$

A determinação das impurezas é realizada visualmente, sob boa fonte de luz artificial. A embalagem não deve conter impurezas e sujeiras removíveis ou não, cuja soma resulte em área total maior que $10 \mathrm{~mm}$ por metro quadrado de amostra analisada.

Para a análise das áreas das impurezas, utiliza-se um gabarito indicado na norma ABNT NBR 8259. Considera-se como impureza qualquer fragmento da matéria-prima da própria embalagem ou do produto embalado, com tamanho acima de $0,04 \mathrm{~mm}^{2}$, incorporado à embalagem, não alterando suas propriedades, porém, causando uma não uniformidade visual à embalagem, como, por exemplo, fragmentos de papel, filme ou rebarbas do produto embalado.

\section{$\underline{\text { Integridade da selagem }}$}

Este ensaio tem a finalidade de assegurar que as selagens das amostras de embalagens estejam integras. Para isto, é introduzida uma solução corante vermelha através de uma seringa no centro da embalagem pelo lado do filme, injetando a quantidade suficiente de solução para que esta tenha contato com todas as áreas seladas das embalagens. Se houver alguma penetração da solução corante pela área de selagem do corpo de prova, ou seja, da embalagem, esta é considerada como "selagem falha". 


\subsection{Irradiação das amostras com dose de 50 kGy}

Nesta etapa, foram processadas as duas amostras de embalagem as quais foram submetidas à dose de $50 \mathrm{kGy}$. Os ensaios realizados nas amostras não irradiadas e irradiadas foram os mesmos apresentados nas TAB. 1 e 2 do item 4.3 exceto os ensaios de gramatura e espessura dos papéis, pois, como estes parâmetros não foram modificados pela irradiação com 25 kGy para ambas as amostras, não foram considerados na análise das amostras irradiadas com 50 kGy.

\subsection{Estudo da variação da dose absorvida no material com uso da dosimetria}

Nesta etapa, foi verificada a variação das doses de radiação aplicadas nas amostras das etapas III e IV, utilizando sistemas dosimétricos apropriados. Foram preparados três pacotes selados de corpos de prova das duas amostras estudadas tendo em cada pacote quatro dosímetros: um em cada lateral do pacote, um na parte superior do pacote e outro na parte inferior do pacote.

Os pacotes com as amostras foram colocados no irradiador Gammacell. Parte do material foi retirado ao completar o tempo de exposição para atingir $25 \mathrm{kGy}$. O restante do material foi retirado posteriormente em exposição para 40 kGy e 50 kGy, em função da taxa de dose do irradiador. $O$ certificado de dosimetria foi realizado pelo Laboratório de Dosimetria em Processos de Irradiação da Divisão de Pesquisa e Desenvolvimento do Centro de Tecnologia das Radiações (CTR) do IPEN e está apresentado no Anexo A.

O dosímetro utilizado foi o Perspex, Harwell Red, Batch KZ tipo 4034 que é apropriado para irradiações de materiais no intervalo de dose entre 5 e 50 kGy. Na FIG. 13, é mostrada a preparação das amostras para o controle da dosimetria.

Considerando que essa aferição de doses foi realizada no experimento, os corpos de prova empregados nesta etapa foram submetidos aos seguintes ensaios, antes e após a irradiação:

- no papel: resistência ao arrebentamento, resistência à tração e fluorescência método I e método II;

- no filme: determinação de microfuros e de tração;

- na embalagem: resistência da selagem. 
Os procedimentos seguidos nos ensaios foram os mesmos especificados nas TAB. 1 e 2 do item 4.3.

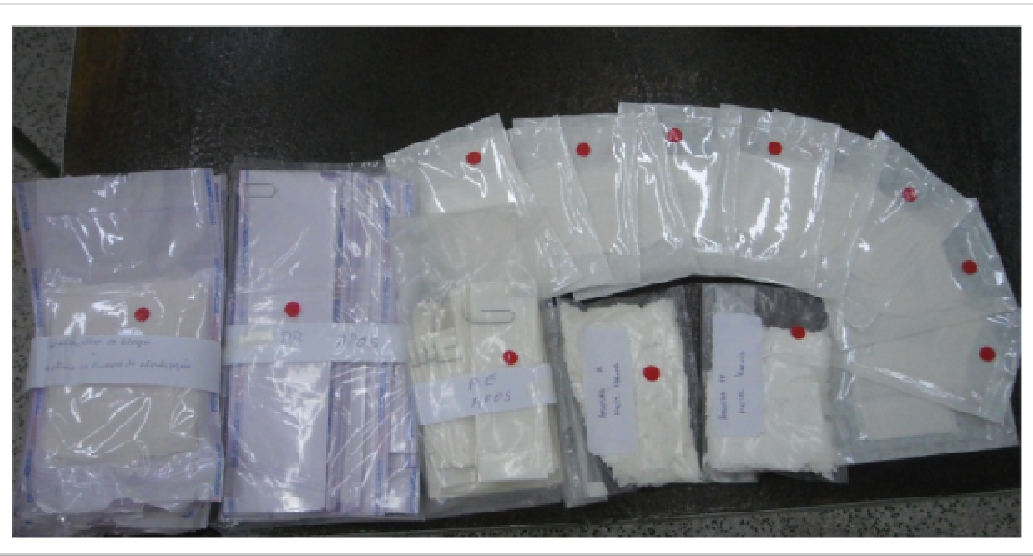

(a)

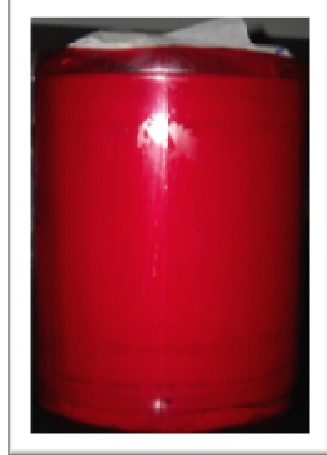

(c)

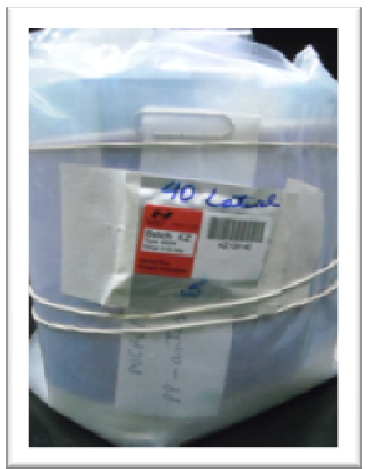

(b)

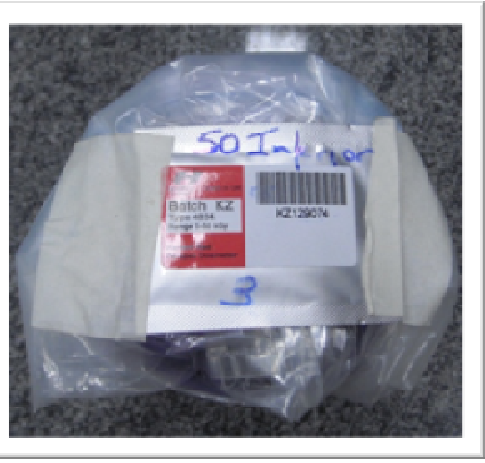

(b)

Figura 13 - (a) Exposição das amostras a serem dosimetradas e colocadas no recipiente que é colocado no interior do irradiador; (b) localização de alguns dos dosímetros nas amostras; (c) recipiente que é colocado dentro do irradiador já contendo as amostras

$\mathrm{Na}$ TAB. 3, estão apresentadas as datas das irradiações, as doses de radiação e as taxas de doses empregadas nas amostras de embalagens utilizadas durante este estudo.

Tabela 3 - Controle das datas de irradiação, dose e taxa de dose

\begin{tabular}{c|c|c|c}
\hline Material irradiado & Data da irradiação & $\begin{array}{c}\text { Dose de radiação } \\
\text { (kGy) }\end{array}$ & $\begin{array}{c}\text { Taxa de dose } \\
\text { (kGy/h) }\end{array}$ \\
\hline Embalagem & $28 / 03 / 2011$ & 25 & 1,71 \\
\hline Embalagem & $24 / 11 / 2011$ & 25 & 1,57 \\
\hline Embalagem & $10 / 04 / 2012$ & 50 & 1,48 \\
\hline Embalagem & $24 / 04 / 2012$ & $25,40,50$ & 1,48 \\
\hline
\end{tabular}




\section{RESULTADOS E DISCUSSÃO}

Neste capítulo, serão discutidos e apresentados os resultados obtidos para os principais parâmetros selecionados para análise dos efeitos da radiação ionizante sobre as duas amostras de embalagem e seus materiais, papel e filme plástico multicamada, aqui tratados.

\subsection{Caracterização geral das amostras}

$\mathrm{Na}$ aquisição das amostras de embalagens para este estudo junto a fornecedores, estes informaram a constituição do filme plástico de cada uma delas, porém, não possuíam informações sobre o papel que as compunham. Fezse necessária a investigação sobre os materiais que compõem as embalagens para assim analisar com mais propriedade os resultados encontrados nas amostras tratadas por radiação bem como no material não irradiado.

Para a caracterização do papel de cada uma das amostras de embalagem, iniciou-se com a análise da composição fibrosa do papel. Analisando as fotomicrografias apresentadas nas FIG. 14 e 15, verificou-se que o papel tanto da Amostra 1 quanto da Amostra 2 foi manufaturado com pasta celulósica química branqueada, procedente do processo sulfato. $O$ processo sulfato é um dos principais processos alcalinos na produção de pastas celulósicas, utilizando, além do hidróxido de sódio, o sulfeto de sódio para a separação das fibras da madeira, sob determinadas condições de temperatura e pressão (Assumpção et al., 1988).

As fibras do papel da Amostra 1 são procedentes de coníferas enquanto as da Amostra 2 são procedentes da mistura de folhosas (árvores de eucalipto) e de coníferas (árvores de pinus).

No caso da Amostra 1, foram encontradas fibras com a presença de pontuação areolada típicas dos traqueídeos das fibras de coníferas (FIG. 14). No caso da Amostra 2, foram encontradas, além de pontuação areolada típicas dos traqueídeos das fibras de coníferas, elementos de vasos que são característicos 
de uma madeira de folhosas (Koga, 1988) (FIG. 15). As fibras de coníferas são longas e têm comprimento médio na faixa de 2 a $5 \mathrm{~mm}$. As fibras de folhosas são curtas e variam, em média de 0,5 a $1,5 \mathrm{~mm}$ (Kuan et al., 1988). Papéis manufaturados com fibras longas apresentam propriedades de resistência melhores do que aquelas dos papéis fabricados com fibras curtas.

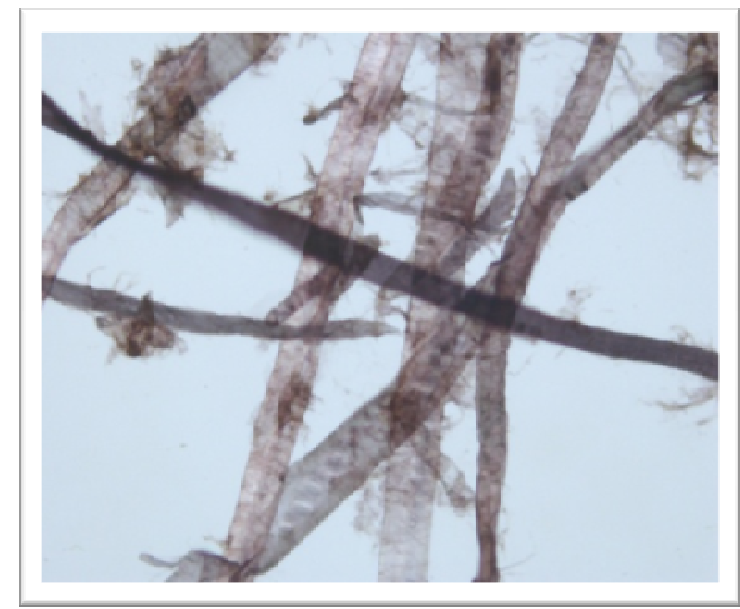

Amostra 1 - Fibras de coníferas (Pinus) - 100X (acervo da autora)

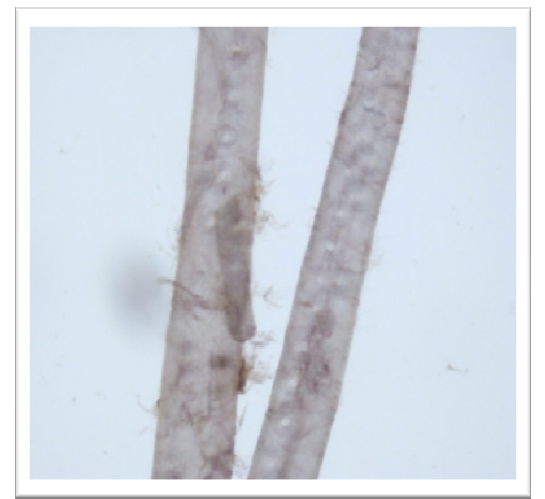

Detalhe da presença de pontuação areolada nos traqueídeos das fibras de coníferas - 200X (acervo da autora)

Figura 14 - Fotomicrografias do papel da Amostra 1 da embalagem em estudo

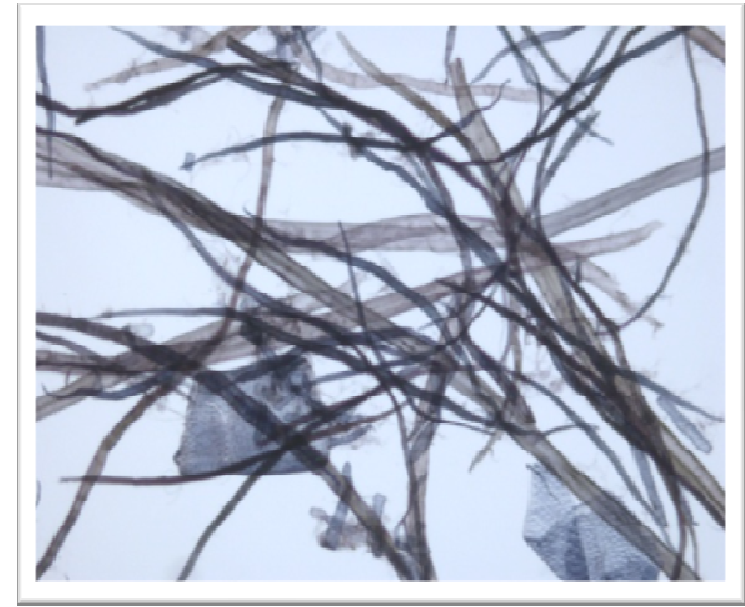

Amostra 2 - Mistura de fibras de folhosas (Eucalipto) e de conífera - $100 \times$ (acervo da autora)
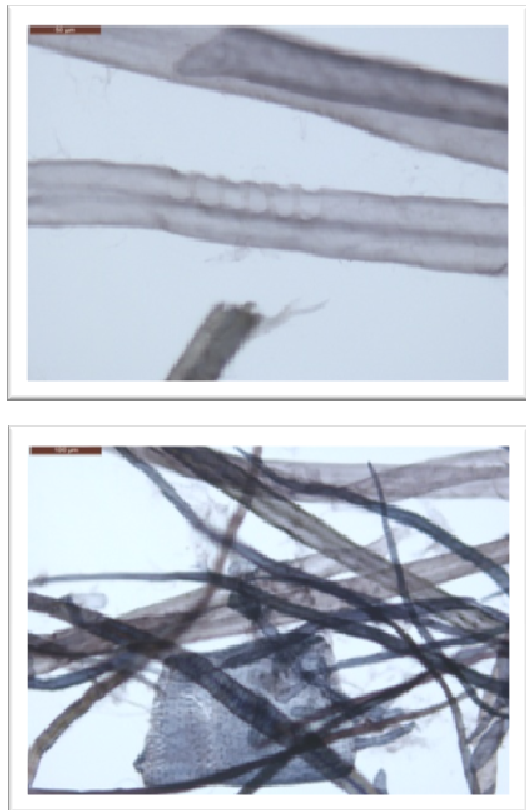

Detalhe da presença de elemento de vaso e pontuação areolada - 200X (acervo da autora)

Figura 15 - Fotomicrografias do papel da Amostra 2 da embalagem em estudo 
Para estudar a superfície dos papéis das amostras, foram realizadas as análises em microscópio eletrônico de varredura (MEV) e por espectroscopia por energia dispersiva (EDS). A partir das fotomicrografias obtidas pelo MEV (FIG. 16 e 17), verifica-se que os papéis não apresentam qualquer tipo de revestimento (não se observa presença de cargas minerais), que têm as superfícies muito semelhantes e, ainda, que as fibras estão bem achatadas, ou seja, foram muito prensadas durante o processo de fabricação do papel.
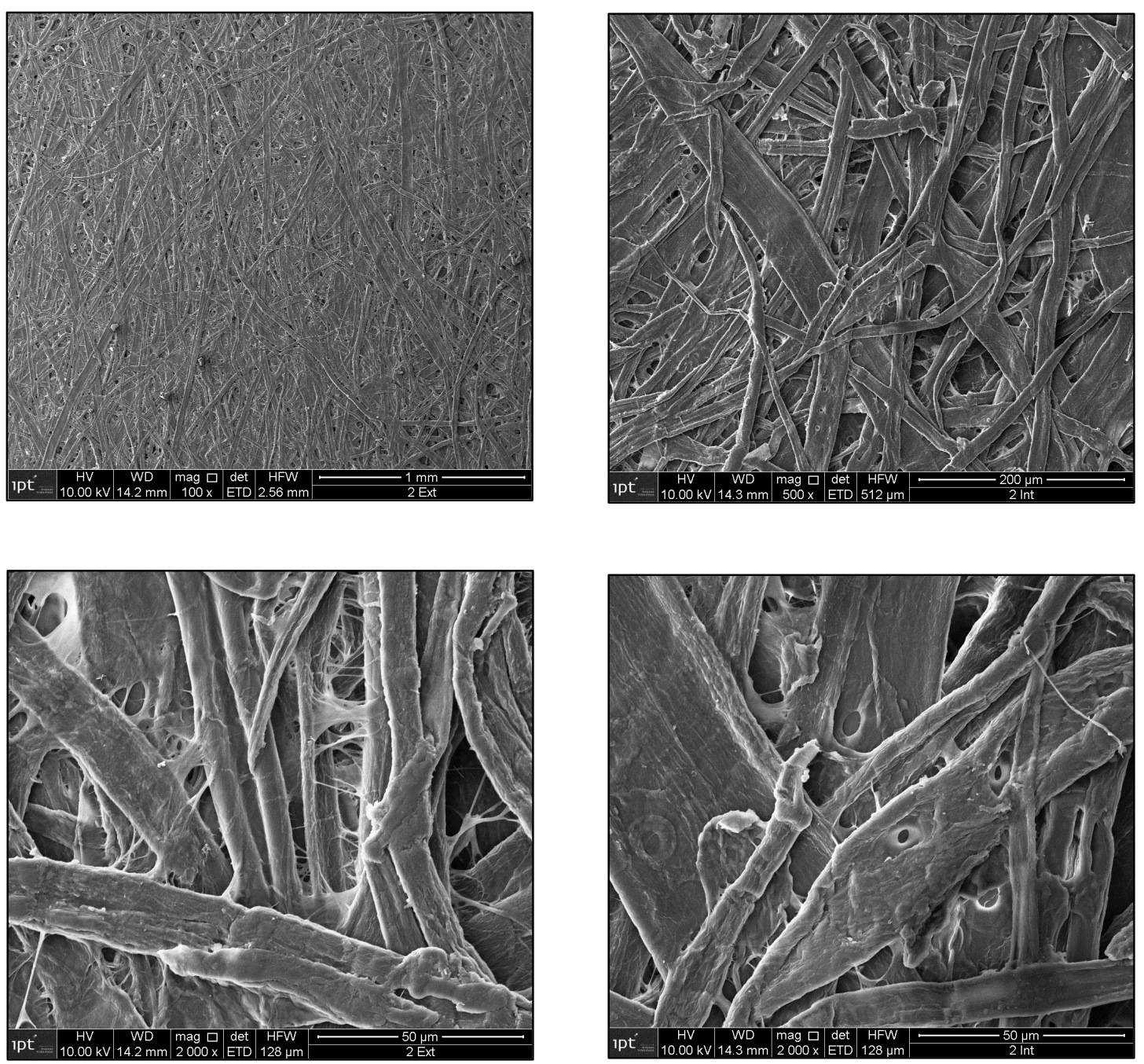

Figura 16 - Imagens obtidas por MEV do papel da Amostra 1 para aumentos de 100x, 500x e 2000x (acervo da autora) 

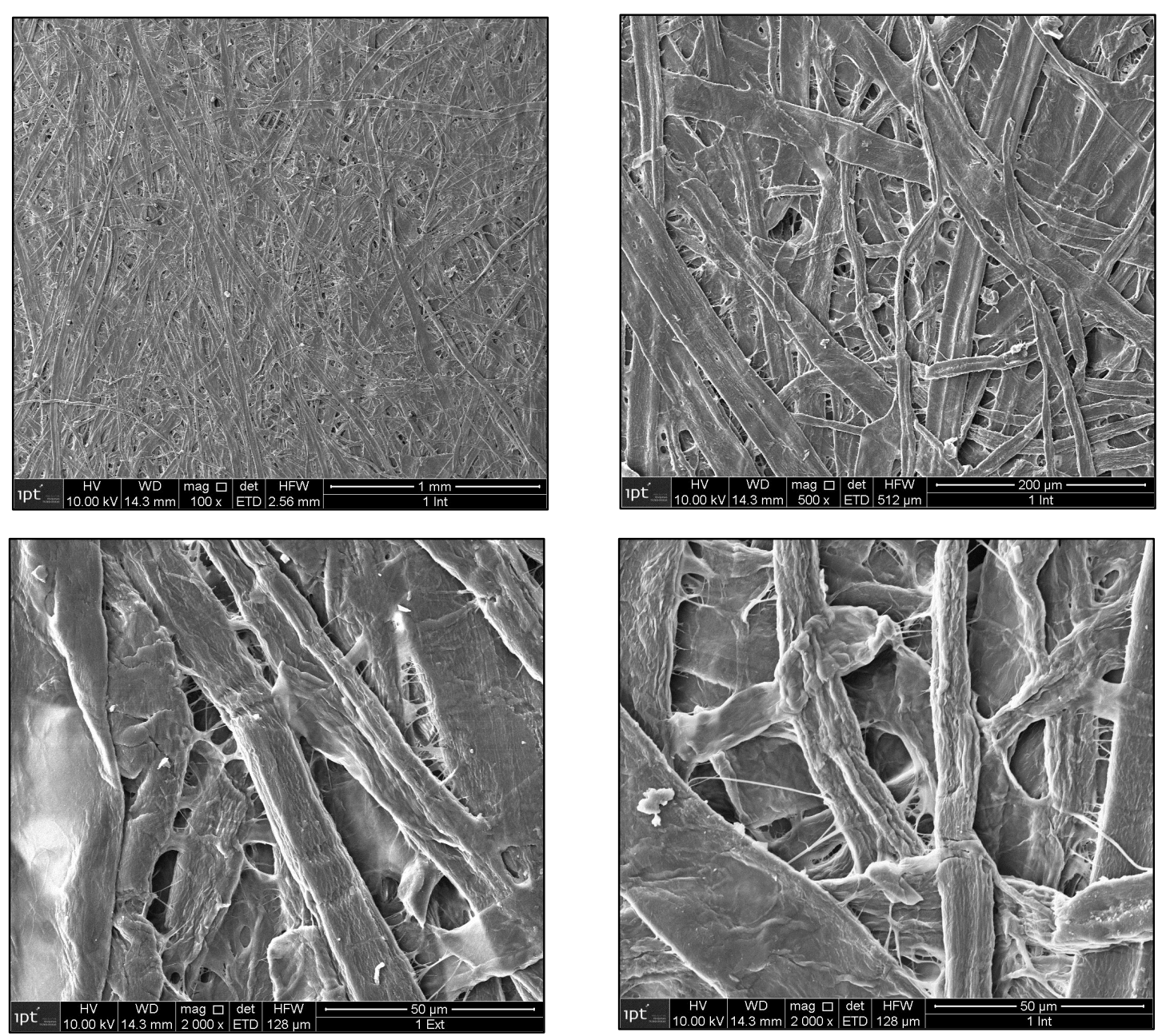

Figura 17 - Imagens obtidas por MEV do papel da Amostra 2 para aumentos de 100x, 500x e 2 000x (acervo da autora)

A análise química elementar da superfície dos papéis das duas amostras foi realizada por EDS e os espectros obtidos para cada uma delas são apresentados nas FIG. 18 e 19. Na TAB. 4, estão apresentados os elementos químicos detectados por essa técnica analítica.

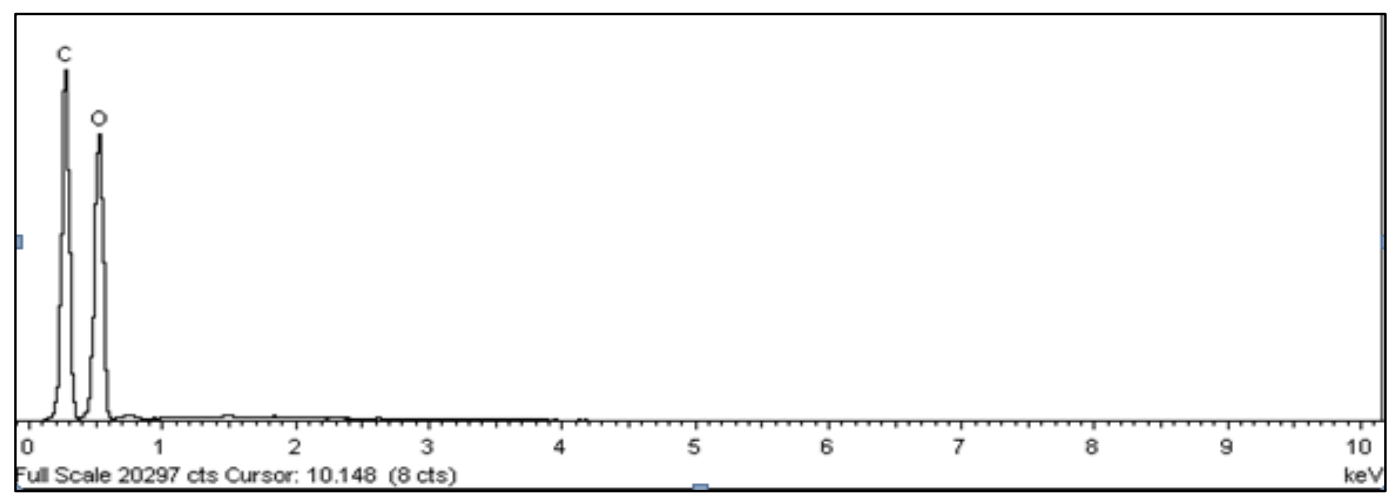

Figura 18 - Espectro de EDS da superfície do papel da Amostra 1 


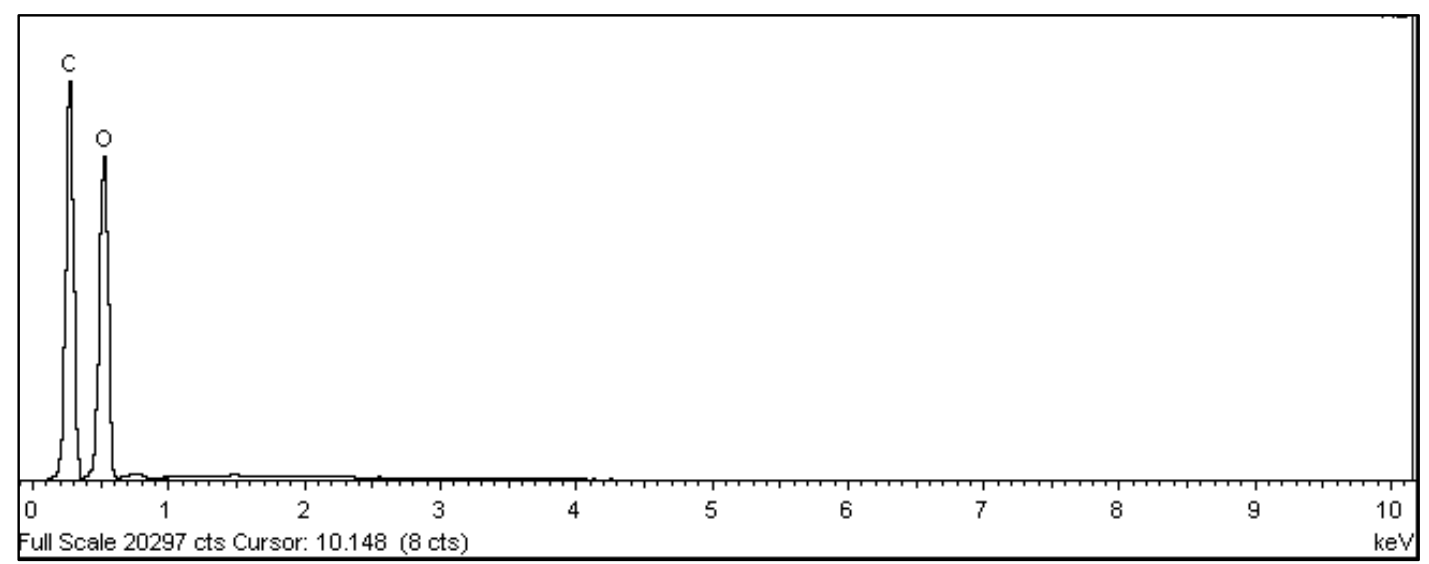

Figura 19 - Espectro de EDS da superfície do papel da Amostra 2

Tabela 4 - Resultados das análises por espectroscopia por energia dispersiva para os papéis das Amostras 1 e 2 estudadas, em concentração em massa dos elementos analisados

\begin{tabular}{c|c|c}
\hline \multirow{2}{*}{ Ensaio } & \multicolumn{2}{|c}{ Concentração em massa do elemento analisado (\%) } \\
\cline { 2 - 3 } & Carbono (C) & Oxigênio (O) \\
\hline Amostra 1 & 48,68 & 51,32 \\
\hline Amostra 2 & 48,77 & 51,23 \\
\hline
\end{tabular}

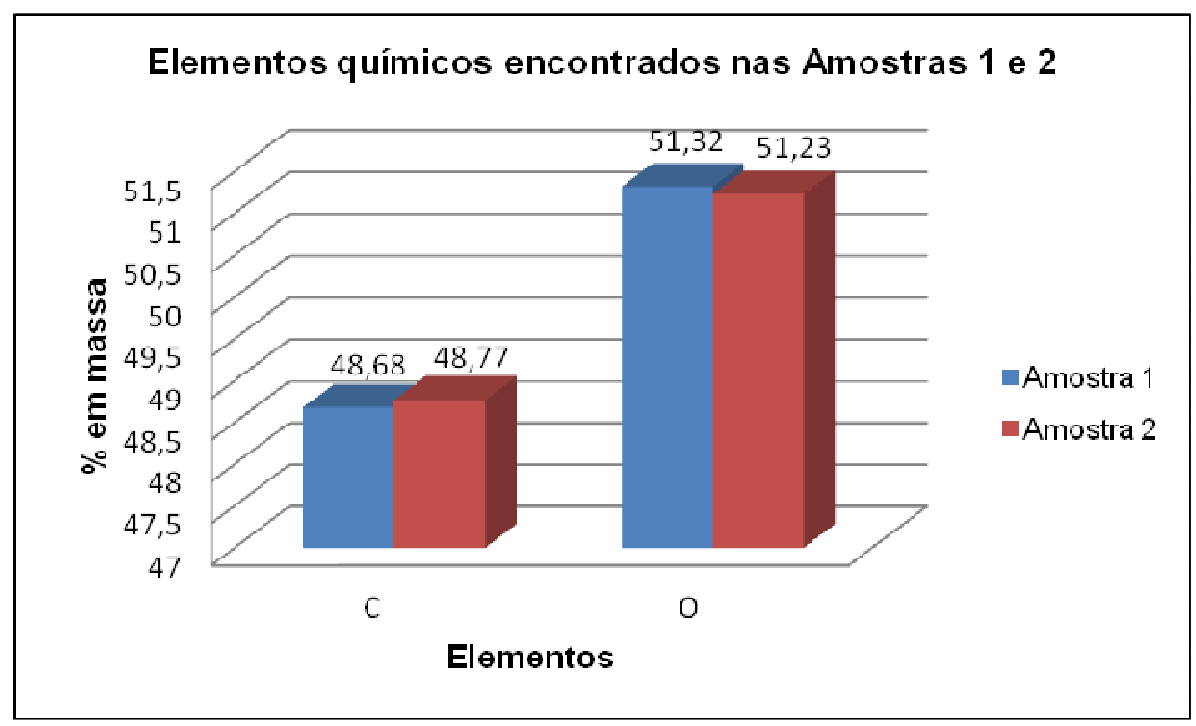

Figura 20 - Representação da porcentagem em massa dos elementos químicos presentes nos papéis das Amostras 1 e 2 
Analisando a TAB. 4 e a FIG. 20, verifica-se que os elementos presentes nos papéis de ambas as amostras são carbono e oxigênio e que os valores de porcentagens destes elementos são muito semelhantes. Isto nos leva a concluir que os papéis de ambas as amostras são papéis sem revestimentos, pois, carbono e oxigênio são os principais constituintes das fibras celulósicas provenientes da madeira.

Nas FIG. 21, 22, 23 e 24, estão apresentados os espectros de infravermelho obtidos para cada uma das amostras e dos materiais que as compõem. Foi considerado como frente do filme plástico o lado do filme que não fica em contato com o produto embalado, ou seja, o lado externo da embalagem $e$ como verso o lado do filme que fica em contato direto com o produto embalado, ou seja, lado interno da embalagem.

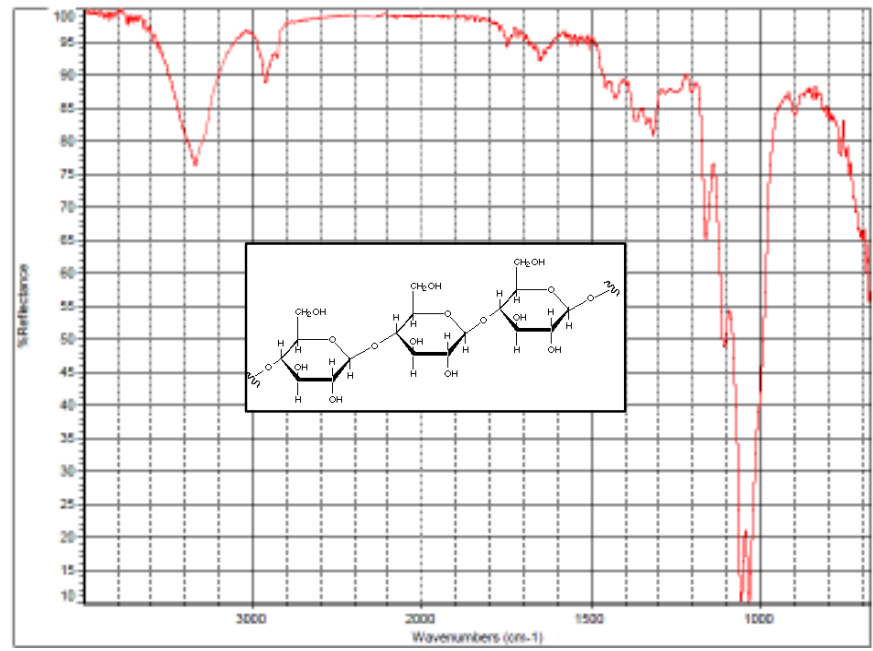

Figura 21 - Espectro de infravermelho do papel da Amostra 1

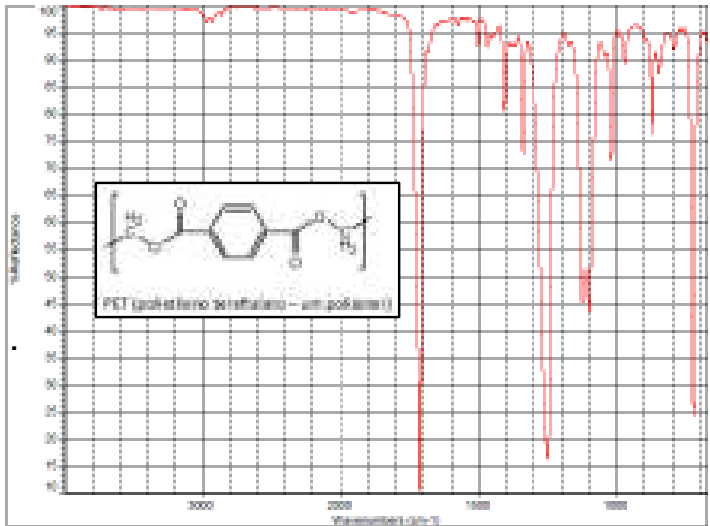

(a)

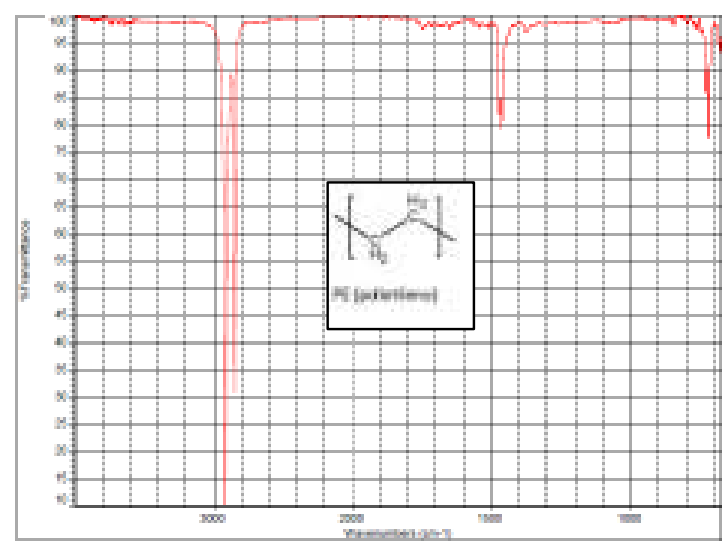

(b)

Figura 22 - Espectros de infravermelho da frente (a) e do verso (b) do filme plástico laminado da Amostra 1 
As análises dos espectros de infravermelho foram realizadas utilizando a bibliografia Hummel e School (1990) que permitiu verificar que o papel da amostra denominada "Amostra 1" (FIG. 21) não tem nenhum revestimento e tampouco verniz aplicado em sua superfície, pois, os picos identificados no espectro de infravermelho do papel são referentes ao composto preponderante que é a celulose.

Os espectros de infravermelho do filme plástico são característicos para poli(tereftalato de etileno) quando analisada a frente do filme plástico e para polietileno quando analisado o verso do filme plástico (FIG. 22). Os espectros de infravermelho obtidos para o papel da amostra denominada "Amostra 2" identificaram que esta também não possui nenhum revestimento ou verniz aplicado em sua superfície, pois o espectro obtido é o característico para celulose (FIG. 23) e os espectros obtidos para o filme plástico mostraram que este é constituído pelos polímeros poli(tereftalato de etileno) (frente) e polipropileno (verso) (FIG. 24).

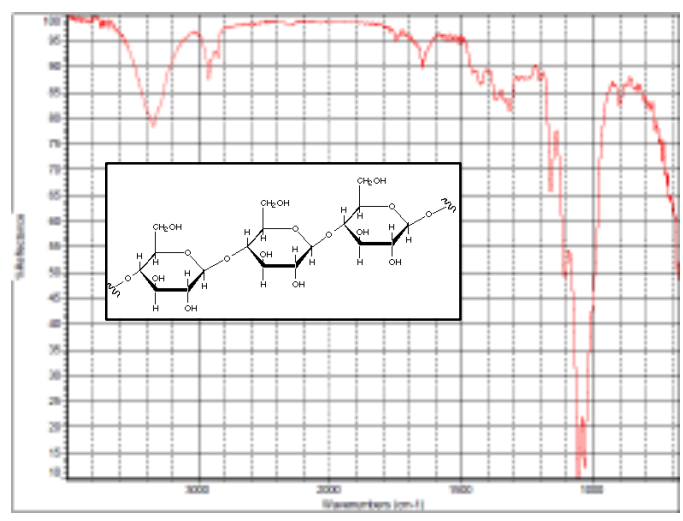

Figura 23 - Espectro de infravermelho do papel da Amostra 2

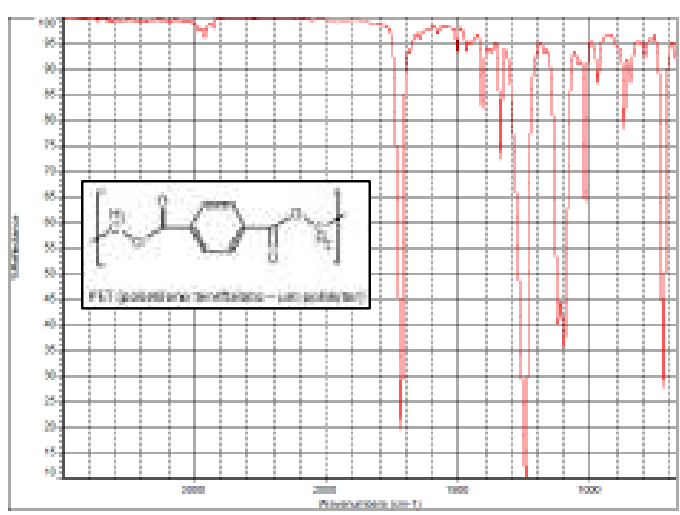

(a)

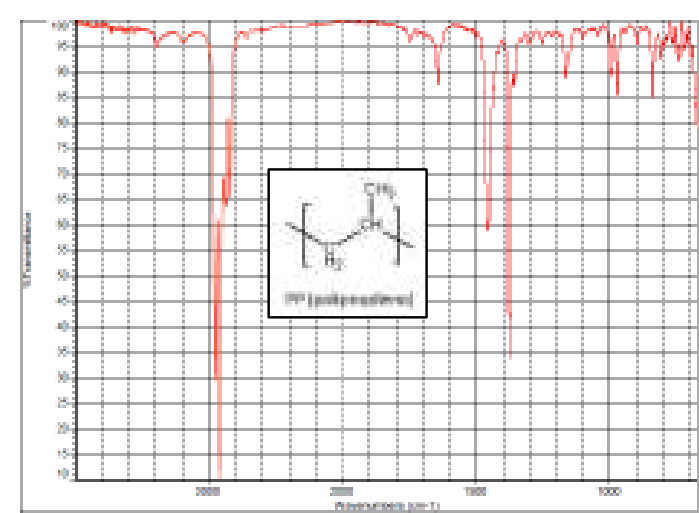

(b)

Figura 24 - Espectros de infravermelho da frente (a) e do verso (b) do filme plástico laminado da Amostra 2 
Para a obtenção dos espectros de infravermelho para a frente e o verso dos filmes plásticos, foi utilizado o acessório ATR, conforme descrito no item 4.3.2. Porém, para verificar a possibilidade das amostras possuírem camadas internas com outros tipos de polímeros além dos encontrados para a frente e o verso dos filmes plásticos, foram obtidos outros espectrogramas dos filmes plásticos o qual chamou-se de "total", conforme descrito nos itens 4.2 - d e 4.3.2, que foi realizado sem o ATR. Ao comparar então os espectros da "frente" e do "verso" do espectro "total" de cada um dos filmes plásticos, foi possível concluir que os filmes não possuem camadas internas com outros tipos de polímeros, além dos já identificados para "frente" e o "verso" destes, pois não foram observados picos diferentes no espectrograma "total" além daqueles já presentes nos espectrogramas da "frente" e do "verso" (FIG. 25 e 26).

(a)

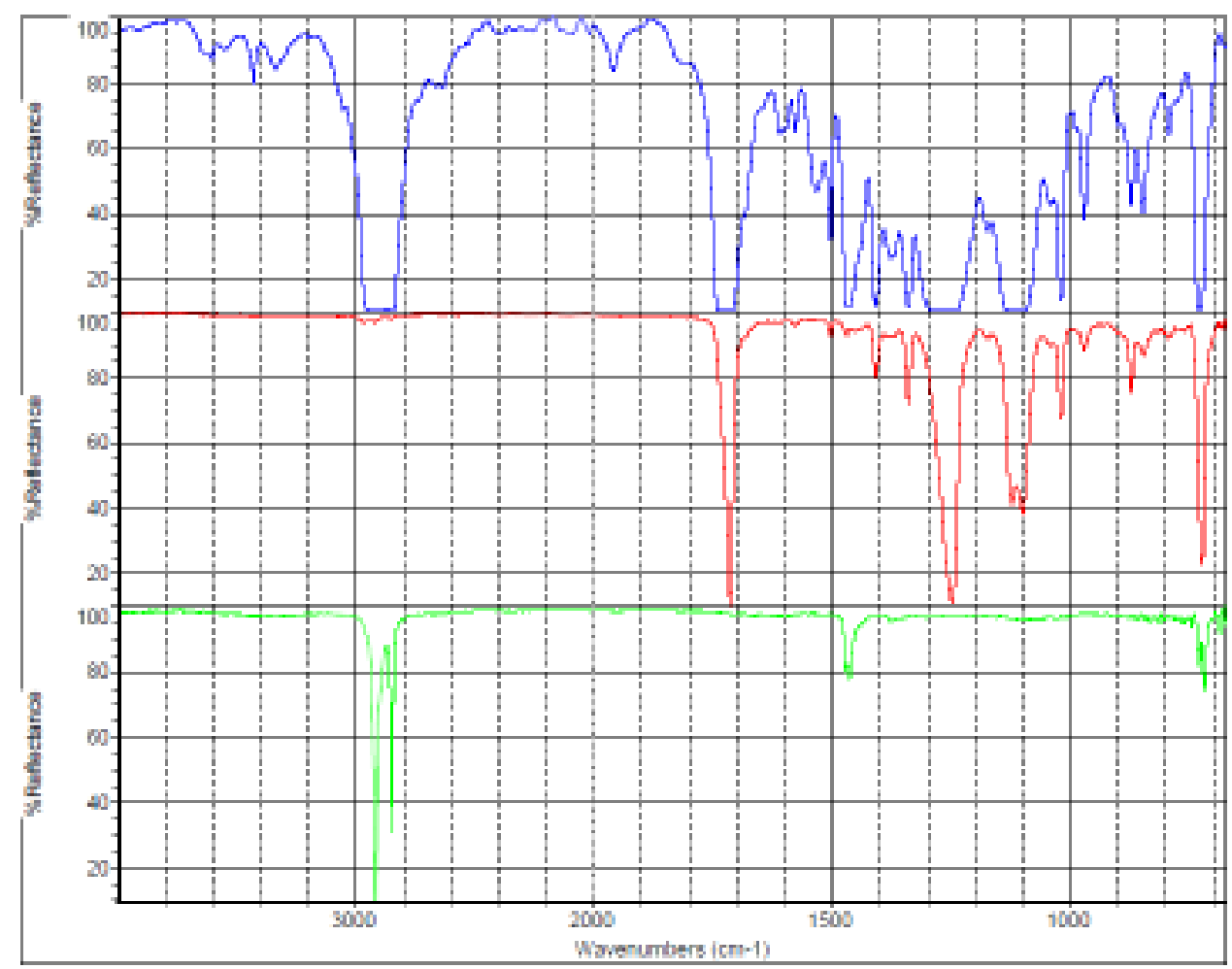

Figura 25 - Comparação do espectro total (a) do filme plástico laminado da Amostra 1 com os espectros da frente (b) e do verso (c) 
(a)

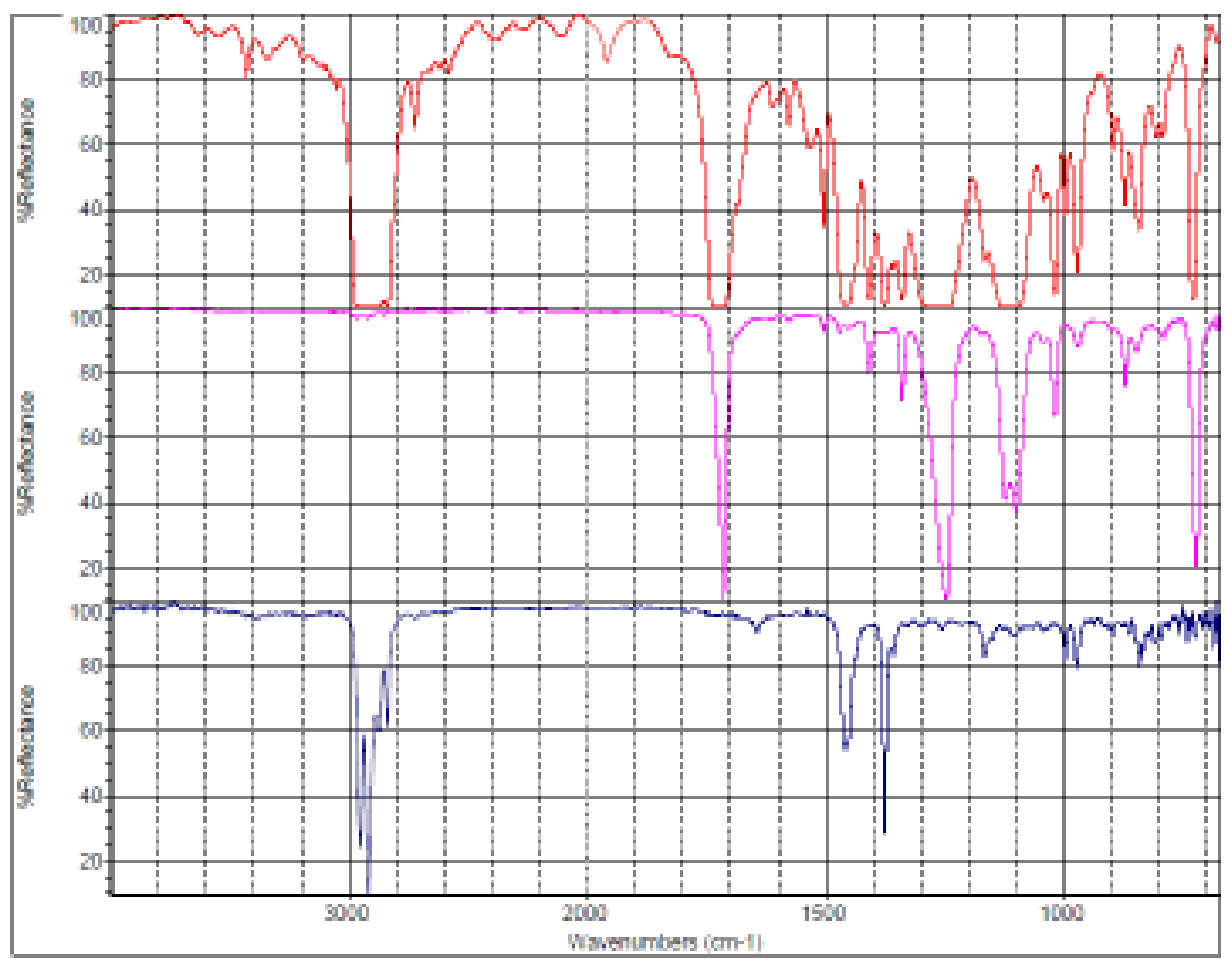

Figura 26 - Comparação do espectro total (a) do filme plástico laminado da Amostra 2 com os espectros da frente (b) e do verso (c)

\subsection{Irradiação das amostras com dose de 25 kGy}

Para analisar a influência da radiação ionizante sob as duas amostras de embalagem comercial utilizadas neste estudo e seus materiais papel e filme plástico multicamada, são apresentadas, a seguir, em etapas distintas, as análises dos resultados obtidos para os parâmetros selecionados para ambas as amostras, antes e após serem submetidas ao processo de irradiação com 25 kGy. Foram consideradas como influências significativas as diferenças acima de $5 \%$ entre os valores determinados para os parâmetros selecionados para as análises das amostras não irradiadas e irradiadas.

\subsubsection{Análise dos resultados obtidos para os parâmetros relacionados aos papéis das Amostras 1 e 2}

Os resultados obtidos para os parâmetros selecionados para analisar a influência da irradiação com 25 kGy sobre os papéis das amostras aqui tratadas estão apresentados na TAB. 5. 
Tabela 5 - Efeitos da radiação (25 kGy) nas propriedades dos papéis das amostras de embalagem 1 e 2

\begin{tabular}{|c|c|c|c|c|c|}
\hline \multicolumn{6}{|c|}{ PAPEL } \\
\hline \multirow{2}{*}{\multicolumn{2}{|c|}{ Ensaios }} & \multicolumn{2}{|c|}{ Amostra 1} & \multicolumn{2}{|c|}{ Amostra 2} \\
\hline & & $\begin{array}{c}\text { Não } \\
\text { irradiada }\end{array}$ & Irradiada & $\begin{array}{l}\text { Não } \\
\text { irradiada }\end{array}$ & Irradiada \\
\hline \multicolumn{2}{|l|}{ Gramatura, $g / \mathrm{m}^{2}$} & $62,9(0,2)$ & $63,3(0,4)$ & $69,9(1,0)$ & $70,4(0,7)$ \\
\hline \multicolumn{2}{|l|}{ Espessura, mm } & $0,089(0,000)$ & $0,090(0,001)$ & $0,104(0,004)$ & $0,101(0,002)$ \\
\hline \multicolumn{2}{|c|}{$\begin{array}{l}\text { Resistência ao arrebentamento, } \mathrm{kPa} \\
\text { Lado A } \\
\text { Lado B }\end{array}$} & $\begin{array}{l}358,1(37,8) \\
384,4(17,4) \\
\end{array}$ & $\begin{array}{l}319,0(26,3) \\
330,0(16,1)\end{array}$ & $\begin{array}{l}448,8(35,7) \\
389,4(67,0) \\
\end{array}$ & $\begin{array}{l}367,1(43,6) \\
318,8(27,6) \\
\end{array}$ \\
\hline \multicolumn{2}{|c|}{$\begin{array}{l}\text { Resistência à tração, } \mathrm{kN} / \mathrm{m} \\
\text { - direção de fabricação } \\
\text { - direção transversal }\end{array}$} & $\begin{array}{l}7,28(0,44) \\
3,79(0,12)\end{array}$ & $\begin{array}{l}6,66(0,30) \\
3,38(0,14)\end{array}$ & $\begin{array}{l}7,77(0,24) \\
4,02(0,20)\end{array}$ & $\begin{array}{l}6,88(0,43) \\
3,55(0,13)\end{array}$ \\
\hline \multicolumn{2}{|c|}{$\begin{array}{l}\text { Resistência ao rasgo, } \mathrm{mN} \\
\text { - direção de fabricação } \\
\text { - direção transversal }\end{array}$} & $\begin{array}{l}601,7(20,3) \\
686,7(32,8)\end{array}$ & $\begin{array}{l}484,0(40,5) \\
555,9(29,5)\end{array}$ & $\begin{array}{l}673,6(29,5) \\
797,9(32,0)\end{array}$ & $\begin{array}{l}549,4(0,00) \\
627,8(0,00)\end{array}$ \\
\hline \multicolumn{2}{|c|}{$\begin{array}{l}\text { Permeância ao ar - Método Bendtsen, } \\
\mu \mathrm{m} / \text { Pa.s }\end{array}$} & $10,41(0,34)$ & $10,72(0,14)$ & $9,53(0,44)$ & $9,53(0,63)$ \\
\hline \multicolumn{2}{|c|}{ Diâmetro dos poros, $\mu \mathrm{m}$} & $28,2(3,0)$ & $27,6(3,1)$ & $22,8(3,3)$ & $22,6(4,1)$ \\
\hline \multicolumn{2}{|c|}{ Residual de corantes } & ausente & ausente & ausente & ausente \\
\hline \multicolumn{2}{|c|}{$\mathrm{pH}$ do extrato aquoso, a quente } & $6,25(0,04)$ & $5,68(0,02)$ & $6,08(0,01)$ & $5,40(0,03)$ \\
\hline \multirow{2}{*}{$\begin{array}{l}\text { Fator de } \\
\text { refletância difusa } \\
\text { no azul (alvura), \% }\end{array}$} & UV calibrado & $86,04(0,11)$ & $79,77(0,09)$ & $85,36(0,04)$ & $80,11(0,05)$ \\
\hline & UV excluído & $85,68(0,11)$ & $79,42(0,09)$ & $85,09(0,04)$ & $79,82(0,05)$ \\
\hline \multirow[t]{2}{*}{ Fluorescência } & $\begin{array}{l}\text { diferença entre UV } \\
\text { calibrado e UV } \\
\text { excluído, em \% }\end{array}$ & 0,36 & 0,35 & 0,27 & 0,29 \\
\hline & $\begin{array}{l}\text { pontos } \\
\text { fluorescentes }\end{array}$ & ausentes & ausentes & ausentes & ausentes \\
\hline
\end{tabular}

a. Considerou-se como lado A, o lado interno da embalagem o qual entra em contato direto com o produto e, como lado B o lado externo da embalagem;

b. O líquido usado no ensaio de diâmetro dos poros foi o álcool etílico $99,5 \%$.

c. Os números entre parênteses referem-se ao desvio padrão das determinações paralelas.

d. Para o ensaio do fator de reflectância difusa no azul (alvura), UV calibrado significa a medida de alvura realizada com a presença do filtro UV e UV excluído, a medida sem a presença do filtro.

Os números de determinações para se obter a média dos resultados apresentados na TAB. 5 foram:

- dez determinações para os ensaios de alvura e fluorescência;

- dez corpos de prova para o ensaio de diâmetro dos poros, sendo três leituras efetuadas em cada um deles;

- nove determinações para o ensaio de resistência à tração;

- seis determinações para os ensaios de resistência ao rasgo e permeância ao ar; 
- cinco determinações para os ensaios de: resistência ao arrebentamento, gramatura e espessura;

- três determinações para os ensaios de pH e residual de corantes.

Observando os resultados obtidos para os ensaios realizados no papel grau cirúrgico, apresentados na TAB. 5, para ambas as amostras após serem irradiadas com dose de 25 kGy, verificou-se que os parâmetros gramatura, espessura, permeância ao ar e diâmetro dos poros são muito pouco alterados pela radiação enquanto que os parâmetros $\mathrm{pH}$, resistência ao arrebentamento, resistência ao rasgo e resistência à tração sofreram uma diminuição significativa após o tratamento. Através das FIG. 27, 28, 29, 30 e 31, pode-se verificar as variações em porcentagem dos valores determinados para os parâmetros nos quais o efeito da radiação foi maior e para os considerados essenciais para os papéis deste tipo de embalagem.

A resistência ao rasgo é uma propriedade que depende essencialmente da integridade da fibra, enquanto que a resistência à tração depende mais do arranjo fibroso do papel. Visto que a variação da resistência ao rasgo para ambas às amostras foi maior (FIG. 27) do que a da resistência à tração (FIG. 28) é possível deduzir que o processo de esterilização por radiação gama aplicado afete especialmente a fibra celulósica.
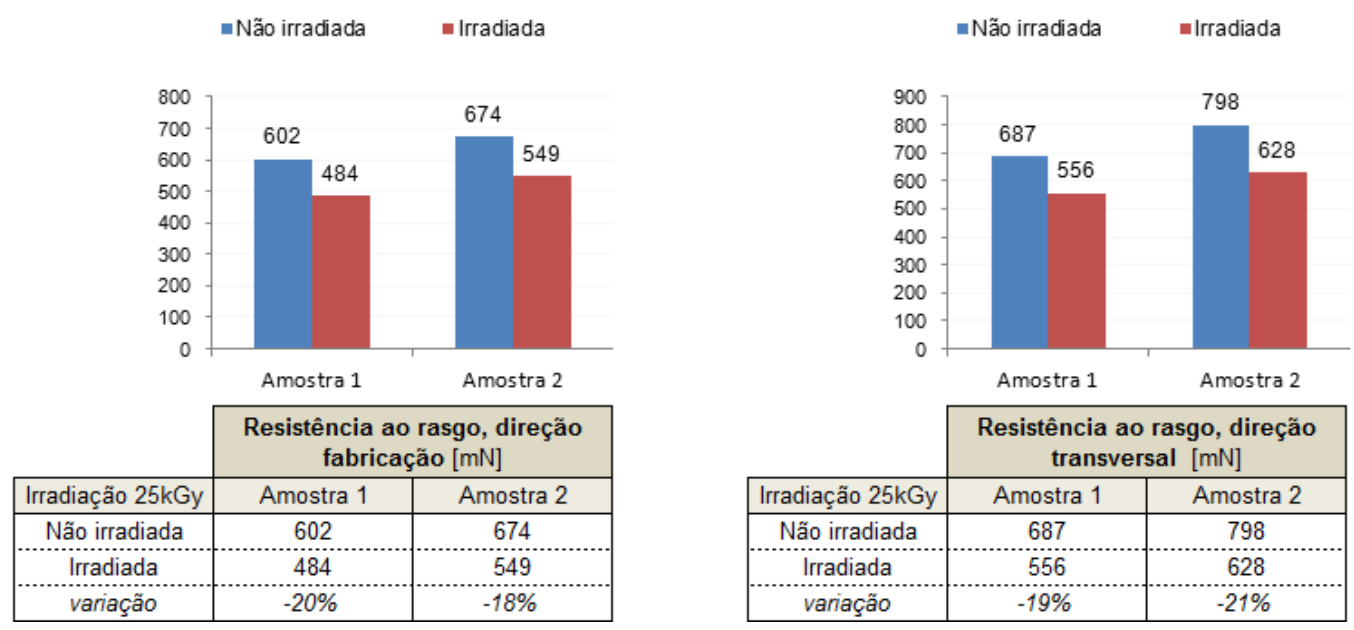

Figura 27 - Variações em porcentagem dos valores obtidos para o parâmetro de resistência ao rasgo nos papéis das amostras 1 e 2 não irradiadas e irradiadas com 25 kGy 


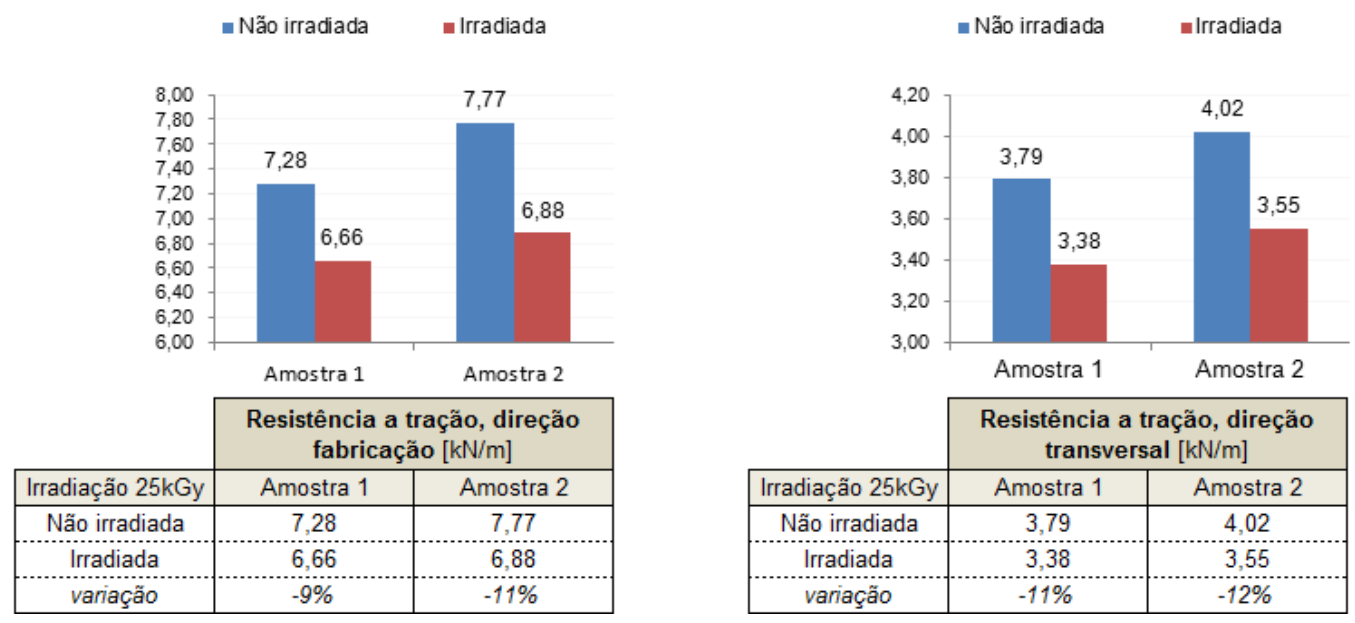

Figura 28 - Variações em porcentagem dos valores obtidos para o parâmetro de resistência à tração nos papéis das amostras 1 e 2 não irradiadas e irradiadas com 25 kGy

A resistência ao arrebentamento é uma característica tanto da integridade da fibra quanto do arranjo fibroso do papel e também foi uma característica que sofreu uma variação considerável de $11 \%$ e $14 \%$ para a Amostra 1 e $18 \%$ para a Amostra 2 (FIG. 29). Para ambas as amostras, a pequena variação obtida para os valores de permeância ao ar e diâmetro dos poros (FIG. 30), propriedades que dependem do arranjo fibroso do papel, confirma o fato do arranjo fibroso ser menos afetado pela radiação do que a estrutura da fibra.
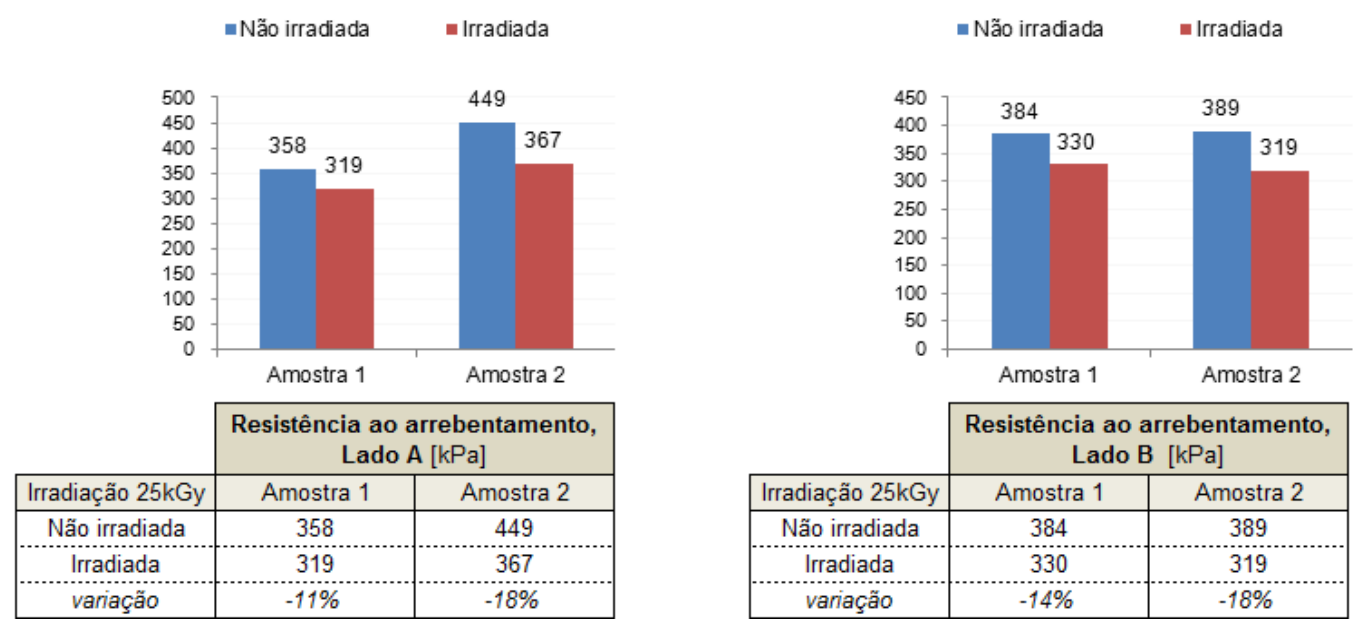

Figura 29 - Variações em porcentagem dos valores obtidos para o parâmetro de resistência ao arrebentamento nos papéis das amostras 1 e 2 não irradiadas e irradiadas com 25 kGy 

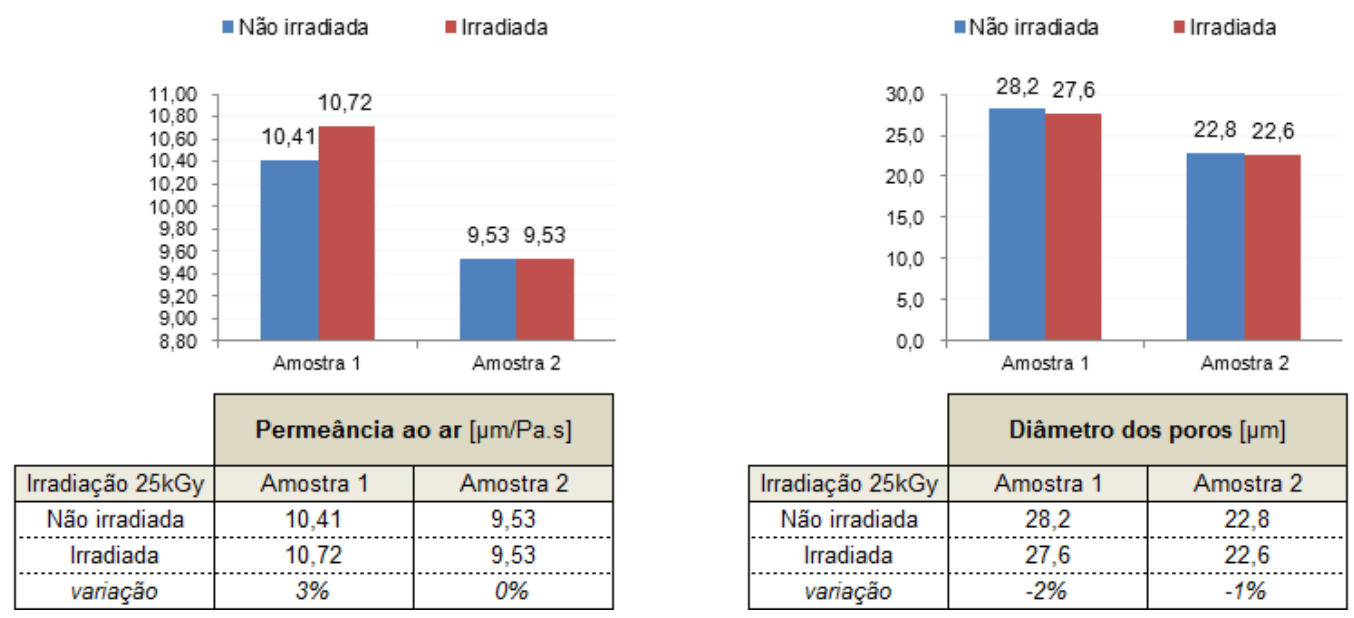

Figura 30 - Variações em porcentagem dos valores obtidos para os parâmetros de permeância ao ar e diâmetro dos poros nos papéis das amostras 1 e 2 não irradiadas e irradiadas com $25 \mathrm{kGy}$

Os resultados obtidos por D'Almeida et al. (2009), quando analisados os fatores resistência à tração e zero span em folhas de papel formadas em laboratório mostraram um decréscimo nesses parâmetros a partir de uma irradiação com 9 kGy. Segundo este estudo, a resistência da fibra foi mais afetada que a resistência da folha de papel, provavelmente devido à clivagem da molécula de celulose. Gonzalez et al. (2002) estudaram nove tipos de papéis diferentes contaminados com fungos e avaliaram os efeitos da radiação gama (14,4 kGy) sobre propriedades mecânicas sendo uma delas a resistência à tração. Os resultados mostraram que apenas uma das amostras de papel contaminado (revista) sofreu uma redução significativa nestas propriedades após a irradiação. Segundo Gonzalez et al. (2002), a deterioração causada por irradiação nestes papéis não foi significativa e nenhuma amostra foi danificada a ponto de ser inutilizada. Também não observaram mudanças na cor dos papéis, nem nas estruturas das fibras analisadas por microscopia óptica e microscopia eletrônica de varredura. Para eles, os resultados obtidos podem ser explicados devido à dose aplicada ter sido relativamente baixa para produzir rupturas na cadeia dos polímeros de celulose a ponto de afetar substancialmente as propriedades mecânicas dos papéis.

Estudos realizados por Magaudda (2004) demonstraram não haver efeito prejudicial significativo sobre as propriedades mecânicas e físicas de celulose pura e de papel utilizando doses de 0,2 a $8 \mathrm{kGy}$. Alguns autores, como 
Flores (1975-1976), por exemplo, indicam que as propriedades de resistência mecânica de base do papel não são significativamente modificadas em doses até 10 kGy; outros obtiveram resultados diferentes (Butterfield, 1987). Segundo Magaudda (2004), estas diferenças entre os resultados poderiam ser explicadas pelas diferenças nas "taxas de dose" (a intensidade da dose de radiação absorvida em função do tempo, ou seja, com a mesma dose, o tempo necessário para realizar o tratamento de acordo com a atividade da fonte de radiação disponível no equipamento utilizado).

Para Magaudda (2004), o efeito direto das ondas eletromagnéticas nas propriedades físicas de polímeros como a celulose é a depolimerização (divisão das ligações intermolares, portanto, redução de seu tamanho), mas, há também outro efeito químico indireto causado por radicais livres que, sob a sua ou outras formas (formação de peróxido de hidrogénio), podem reagir com outras moléculas, causando, assim, uma modificação química. Nesta ação indireta induzida pelos radicais livres, o oxigênio presente no ar durante a irradiação desempenha um importante papel. Quanto mais longo for o período de irradiação maior a possibilidade do oxigênio interagir e tanto maior será o efeito indireto. Magaudda (2004) acredita que os resultados negativos de deterioração da celulose e do papel acontecem apenas em altas doses de radiação.

Segundo Ershov (1998), o principal resultado da ação da radiação ionizante sobre a celulose (assim como em outros polissacarídeos) é a cisão da cadeia polimérica, isto é, a degradação alterando as propriedades físicoquímicas do polímero (estado estrutural, a resistência mecânica, a solubilidade em meios diferentes, a reatividade, etc.). Ele mostra por meio de seu estudo que o processo de degradação em uma macromolécula por cisão aleatória sem ligações cruzadas é predominante quando a celulose e outros polissacarídeos são tratados por radiação ionizante.

A diminuição nos graus de polimerização do papel e da celulose determinados após a irradiação leva a concluir que a radiação realmente provoca ruptura na cadeia do polímero de celulose (Phillips e Arthur, 1985; Stepanik et al., 1998; Majali et al., 1998). Este efeito poderia diminuir as propriedades mecânicas da celulose, porém, segundo alguns pesquisadores as diminuições encontradas para o grau de polimerização não altera sensivelmente as propriedades mecânicas do papel. Resultados obtidos por Calvini e Santucci (1978-1979), 
através de um experimento realizado em papel Whatman $\mathrm{N}^{\circ} 1$, mostram uma significativa depolimerização da celulose com dose de 5 kGy (diminuição de 58 \% do grau de polimerização), porém, não detectaram alterações relevantes nas propriedades mecânicas.

Phillips e Arthur (1985), com uma diminuição de 76 \% no grau de polimerização, não detectaram modificações nas propriedades mecânicas do papel. Para Magaudda (2004), o fato do grau de polimerização diminuir e não afetar as propriedades mecânicas do papel e da celulose pode ser explicado devido às diferenças de taxas de doses com a mesma dose absorvida.

A queda considerável encontrada para o ensaio de $\mathrm{pH}$ do papel grau cirúrgico, para ambas as amostras tratadas com 25 kGy apresentada na FIG. 31 está relacionada com a formação de grupos ácidos pela modificação dos aditivos presentes na formação do papel ou da própria molécula da celulose. Alguns estudos mostram que o papel se deteriora mais rapidamente quando o $\mathrm{pH}$ de seu extrato é ácido, caso dos papéis das amostras estudadas (Dixson e Nelson, 1960; Lyne, 1995; Laamanen, 1999). A reação química principal que ocorre na degradação do papel é a hidrólise ácida, sendo que as hemiceluloses presentes no papel hidrolisam mais rapidamente do que a celulose. A hidrólise pode levar a uma perda de resistência da fibra como também de ligações entre elas, afetando as propriedades mecânicas do papel negativamente (Luner, 1969).
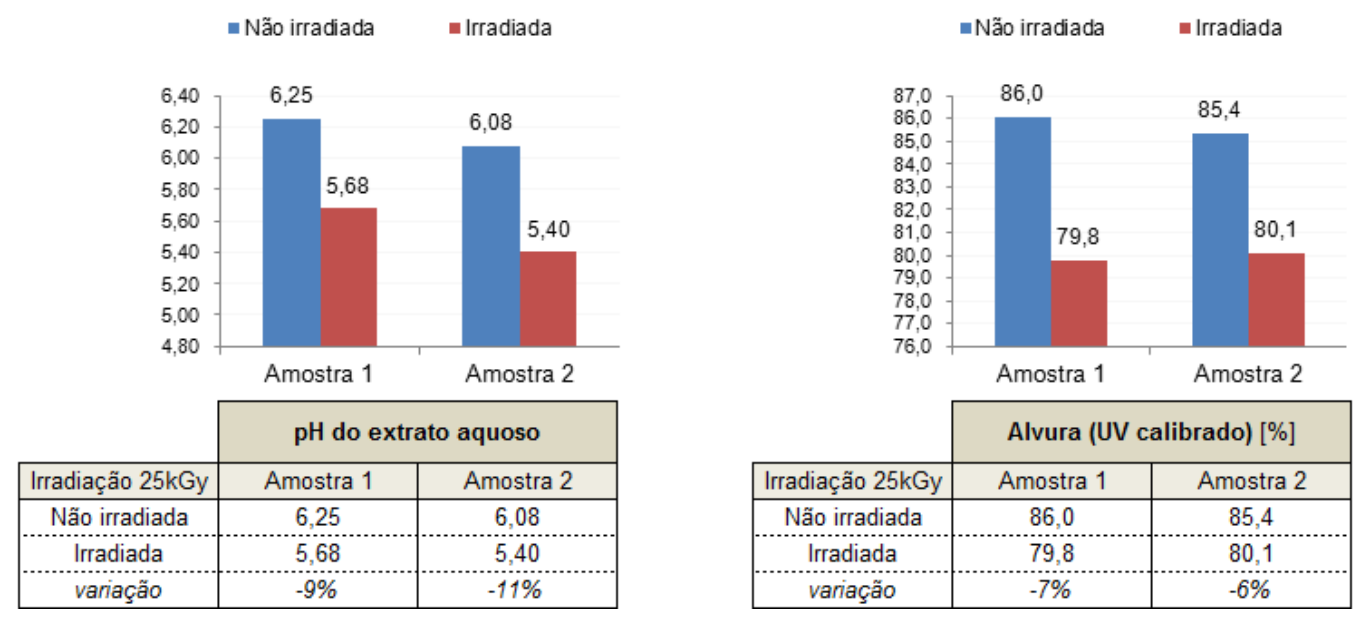

Figura 31 - Variações em porcentagem dos valores obtidos para os parâmetros de pH e alvura nos papéis das amostras 1 e 2 não irradiadas e irradiadas com 25 kGy

A partir do parâmetro fator de refletância difusa no azul (alvura), consegue-se analisar a cor do papel, a qual foi afetada pelo tratamento por radiação 
causando um amarelecimento no papel das amostras de embalagem. Isto ocorreu provavelmente devido à formação de grupos cromóforos ou centros de cor na celulose (D’Almeida et al., 2009). Apesar das variações encontradas para o ensaio de alvura dos papéis das amostras não irradiadas e irradiadas (FIG. 31) não terem sido muito altas (7\% para a Amostra 1 e $6 \%$ para a Amostra 2), o amarelecimento do papel de ambas as amostras foi observado a olho nu.

Para uma análise mais completa dos efeitos da radiação com 25 kGy nos papéis das Amostras 1 e 2, foram realizados espectros de infravermelho dos papéis não irradiados e irradiados. Os espectros estão apresentados nas FIG. 32 e 33.
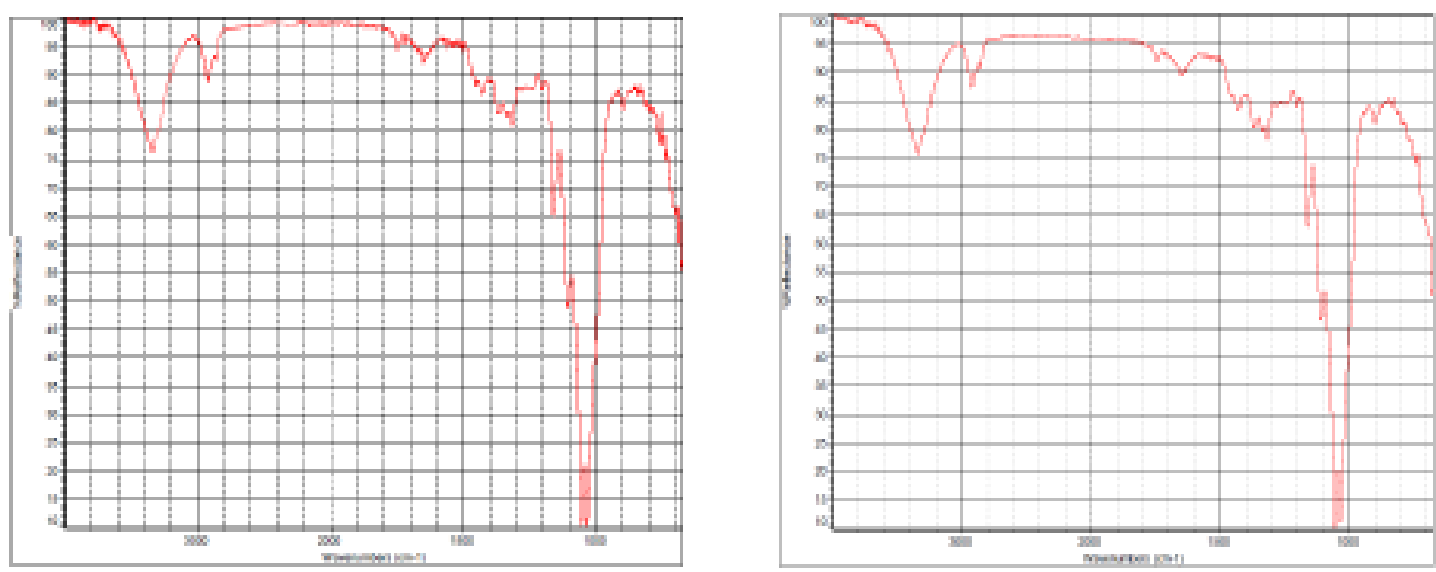

Figura 32 - Espectros de infravermelho do papel da Amostra 1 não irradiada e irradiada com 25 kGy, respectivamente
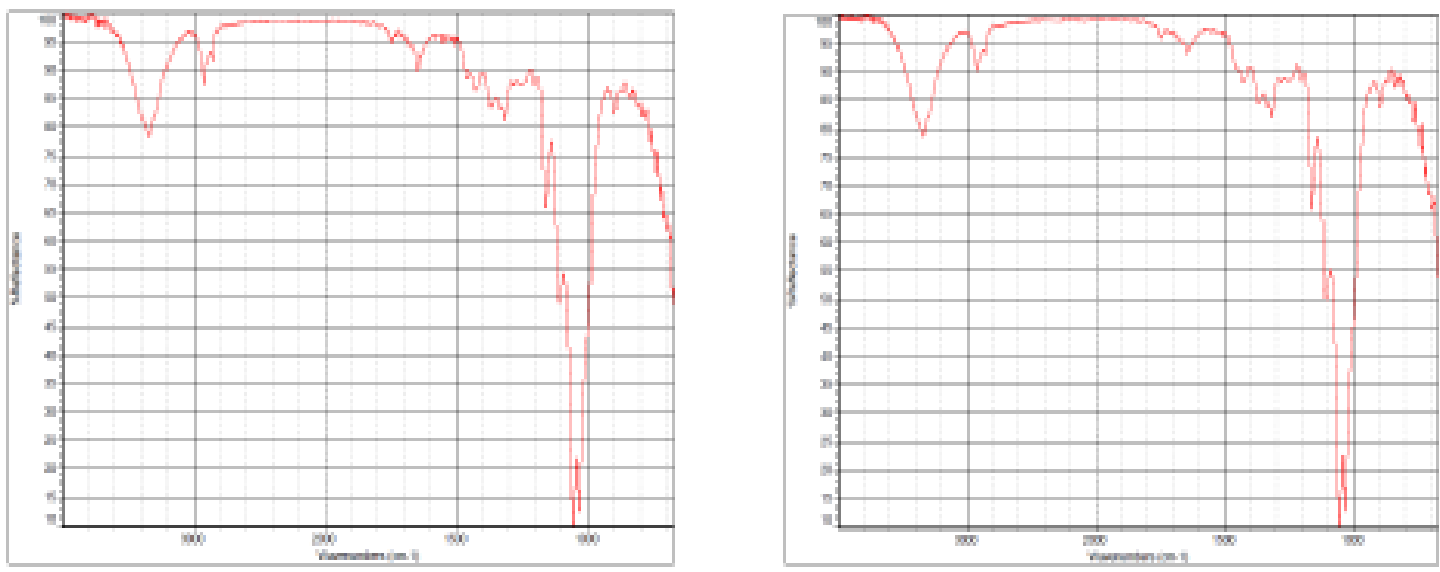

Figura 33 - Espectros de infravermelho do papel da Amostra 2 não irradiada e irradiada com 25 kGy, respectivamente 
Analisando os espectros de infravermelho dos papéis das duas amostras apresentados nas FIG. 32 e 33, verifica-se que não houve alteração como mudanças e deslocamentos dos picos devido à irradiação, ou seja, a irradiação com 25 kGy não causou modificações nos papéis que possam ser detectadas por esta técnica.

A celulose ocorre na natureza em forma de arranjo fibroso com regiões amorfas e cristalinas (Sànchez e Cardona, 2008), as regiões cristalinas são formadas por cadeias de celulose altamente ordenadas e a amorfa constituída por cadeias menos ordenadas. Estas regiões não possuem fronteiras bem definidas e a razão entre elas é chamada de grau de cristalinidade $\left(I_{c}\right)$ e varia conforme a origem e pré-tratamento da celulose. A compreensão das relações entre o grau de cristalinidade da celulose (razão entre a quantidade de regiões cristalinas e amorfas presentes na celulose) e as propriedades físico-químicas deste biopolímero nos auxilia na compreensão de sua reatividade. Nas celuloses de madeira a porcentagem de regiões cristalinas fica na faixa de 50 a $70 \%$ (D'Almeida, 1988).

O grau de cristalinidade dos papéis das duas amostras em estudo foi calculado a partir dos difratogramas obtidos pela técnica de difração de raios $X$. Os difratogramas dos papéis das Amostras 1 e 2 não irradiadas e irradiadas com 25 kGy, estão apresentados nas FIG. 34 e 35, respectivamente. Foi confirmado que os difratogramas obtidos para as duas amostras são típicos da celulose (Almeida, 2009).

Muitos métodos foram desenvolvidos para calcular 0 índice de cristalinidade da celulose a partir dos espectros de difração de raios $\mathrm{X}$, porém, neste estudo, foi escolhido o método proposto por Bansal et al. (2010) um dos mais difundidos. O grau de cristalinidade foi calculado utilizando a equação:

$$
\left.I_{C}=100 \times\left(I_{\text {máxima }}-I_{\text {mínima }}\right) / I_{\text {máxima }}\right) \quad \text { Equação } 1
$$

em que:

$I_{\text {mínima }}=$ mínimo da intensidade acima da linha base em $2 \theta=19,005^{\circ}$;

$I_{\text {máxima }}=$ máximo de intensidade acima da linha base em $2 \theta$ variável entre $22^{\circ} \mathrm{e}$ $23^{\circ}$. 
A intensidade mínima representa a parte amorfa da celulose e a intensidade máxima a parte cristalina. Este cálculo foi feito apenas para o pico principal, ou seja, de maior intensidade que é característico de celulose. O método é útil para a comparação relativa e os resultados devem ser interpretados com cautela. Este método foi utilizado por Bansal et al. (2010) para calcular o grau de cristalinidade de uma celulose microcristalina e não de um papel formado como é o caso; por isto, os valores de $2 \theta$ de $I_{\text {mínima }}$ e $I_{\text {máxima }}$ considerado foi um pouco diferente do utilizado por Bansal et al. (2010).
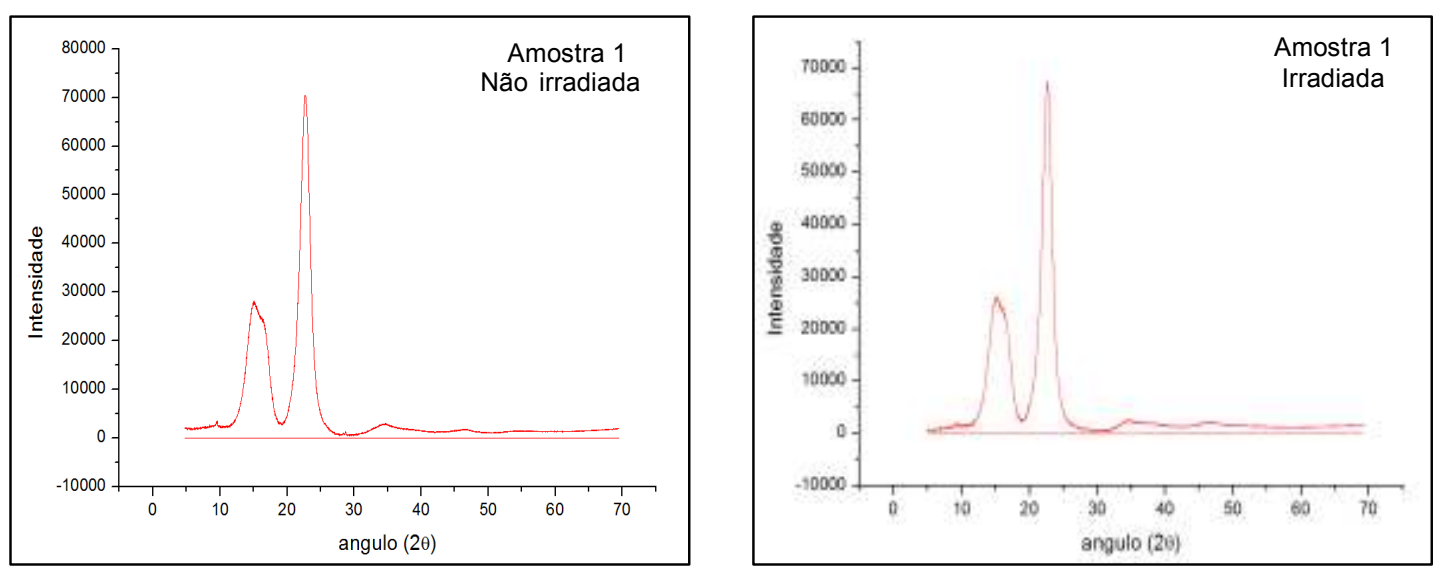

Figura 34 - Difratogramas do papel da Amostra 1 não irradiada e irradiada com 25 kGy
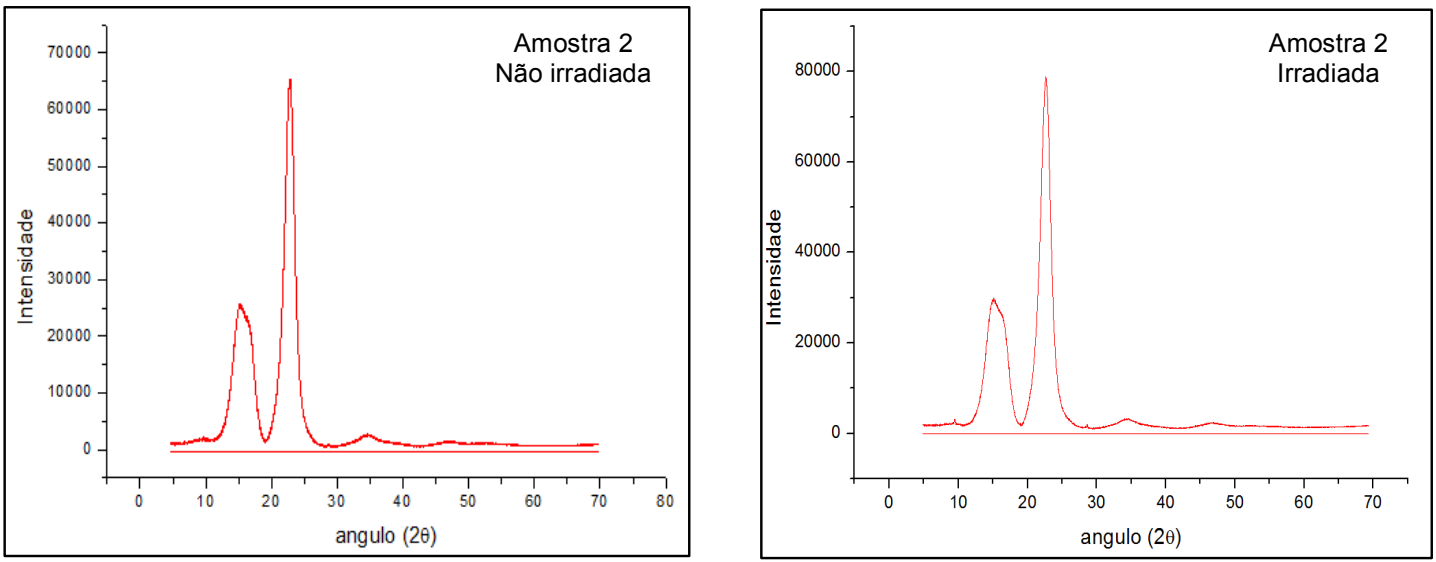

Figura 35 - Difratogramas do papel da Amostra 2 não irradiada e irradiada com 25 kGy 
Os valores determinados para os graus de cristalinidade calculados a partir dos difratogramas empregando-se a Equação 1 estão apresentados na TAB. 6. Os valores de $I_{\text {máxima }}$ e $I_{\text {mínima }}$ utilizados para o cálculo do grau de cristalinidade foram:

Para a Amostra 1

não irradiada: $I_{\text {mínima }}=2968,34434$ e $I_{\text {máxima }}=70457,31910$;

irradiada: $I_{\text {mínima }}=2693,99207$ e $I_{\text {máxima }}=67216,38510$.

\section{Para a Amostra 2}

não irradiada: $I_{\text {mínima }}=1899,48313$ e $I_{\text {máxima }}=65613,45390$;

irradiada: $I_{\text {mínima }}=1882,32119$ e $I_{\text {máxima }}=78846,05340$.

Tabela 6 - Grau de cristalinidade do papel da Amostra 1 e da Amostra 2 não irradiadas e irradiadas com $25 \mathrm{kGy}$

\begin{tabular}{c|c|c|c|c}
\hline \multirow{2}{*}{ Ensaio } & \multicolumn{2}{|c|}{ Amostra 1 } & \multicolumn{2}{c}{ Amostra 2 } \\
\cline { 2 - 5 } & Não irradiada & Irradiada & Não irradiada & Irradiada \\
\hline Grau de cristalinidade, em \% & 96 & 96 & 97 & 98 \\
\hline
\end{tabular}

Comparando-se os valores obtidos de grau de cristalinidade para os papéis das duas amostras antes e após passarem pelo processo de irradiação com 25 kGy, verificou-se que praticamente não houve mudança na estrutura cristalina do papel; com isto, é possível concluir que a parte cristalina da fibra não é afetada pela radiação. Segundo Kumakura e Kaetsu (1978 e 1979), a radiação provoca clivagem mais facilmente da região amorfa da celulose do que da região cristalina.

Estudos mostraram que a radiação ionizante reduz a cristalinidade da celulose em doses de 100 kGy e 200 kGy (Kasprzyk et al., 2004; Alberti et al., 2005). Outros autores relataram a degradação das fibras de celulose a partir dos estudos do grau de polimerização da celulose do algodão após serem irradiadas com doses de 10 kGy e 3 kGy (Takács et al., 1999; Tóth et al., 2003). Driscoll et al. (2009) mostraram que a celulose microcristalina após irradiada com feixe de elétrons com doses de 10 kGy, 100 kGy e 1000 kGy sofre, de forma crescente, com o aumento das doses aplicadas, uma redução considerável de sua massa molar, fator analisado por cromatografia líquida (HPLC), uma redução de sua cristalinidade o que foi analisado por difração de raios $\mathrm{X}$ e um decréscimo de sua área superficial. 
A partir dos dados aqui apresentados, observou-se que o papel da Amostra 1 foi menos degradado pela irradiação a 25 kGy quando comparado ao papel da Amostra 2. Isto provavelmente aconteceu devido ao papel da Amostra 1 ser formado por fibras longas advindas de coníferas (árvores de pinus).

\subsubsection{Análise dos resultados obtidos para os parâmetros relacionados aos filmes plásticos das Amostras 1 e 2}

Os resultados obtidos para os parâmetros selecionados para analisar a influência da irradiação com 25 kGy sobre os filmes plásticos das Amostras 1 e 2 aqui tratadas estão apresentados na TAB. 7.

Os números de determinações para se obter a média dos resultados apresentados na TAB. 7 para os filmes plásticos das duas amostras de embalagem foram: seis determinações para o ensaio de resistência à tração e cinco determinações para os ensaios de microfuros, gramatura e espessura.

Tabela 7 - Efeitos da radiação (25 kGy) nas propriedades dos filmes plásticos das amostras de embalagem 1 e 2

\section{FILME PLÁSTICO LAMINADO}

\begin{tabular}{l|c|c|c|c}
\hline \multirow{2}{*}{ Ensaios } & \multicolumn{2}{|c|}{ Amostra 1 } & \multicolumn{2}{c}{ Amostra 2 } \\
\cline { 2 - 5 } & Não irradiada & Irradiada & Não irradiada & Irradiada \\
\hline Gramatura, g/m² & $56,3(0,5)$ & $56,1(0,6)$ & $52,8(0,5)$ & $53,2(0,5)$ \\
\hline Espessura, mm & $0,058(0,002)$ & $0,058(0,002)$ & $0,055(0,002)$ & $0,056(0,001)$ \\
\hline Microfuros & ausentes & ausentes & ausentes & ausentes \\
\hline $\begin{array}{l}\text { Resistência à tração, N } \\
\text { - direção de fabricação } \\
\text { - direção transversal }\end{array}$ & $\begin{array}{c}49,99(1,21) \\
37,78(1,19)\end{array}$ & $\begin{array}{c}49,74(2,30) \\
39,92(2,03)\end{array}$ & $\begin{array}{c}36,63(2,52) \\
41,68(2,18)\end{array}$ & $\begin{array}{c}37,97(2,19) \\
41,89(2,09)\end{array}$ \\
\hline
\end{tabular}

Nota: Os números entre parênteses referem-se ao desvio padrão das determinações paralelas.

Os resultados dos parâmetros gramatura, espessura e microfuros, obtidos para o filme plástico laminado de ambas as amostras, não foram alterados pela irradiação com $25 \mathrm{kGy}$, como se observa analisando os valores apresentados na TAB. 7. O parâmetro resistência à tração apresentou uma leve variação nas amostras irradiadas. Na FIG. 36, estão apresentadas as variações do ensaio de resistência à tração dos filmes plásticos para ambas as amostras. 


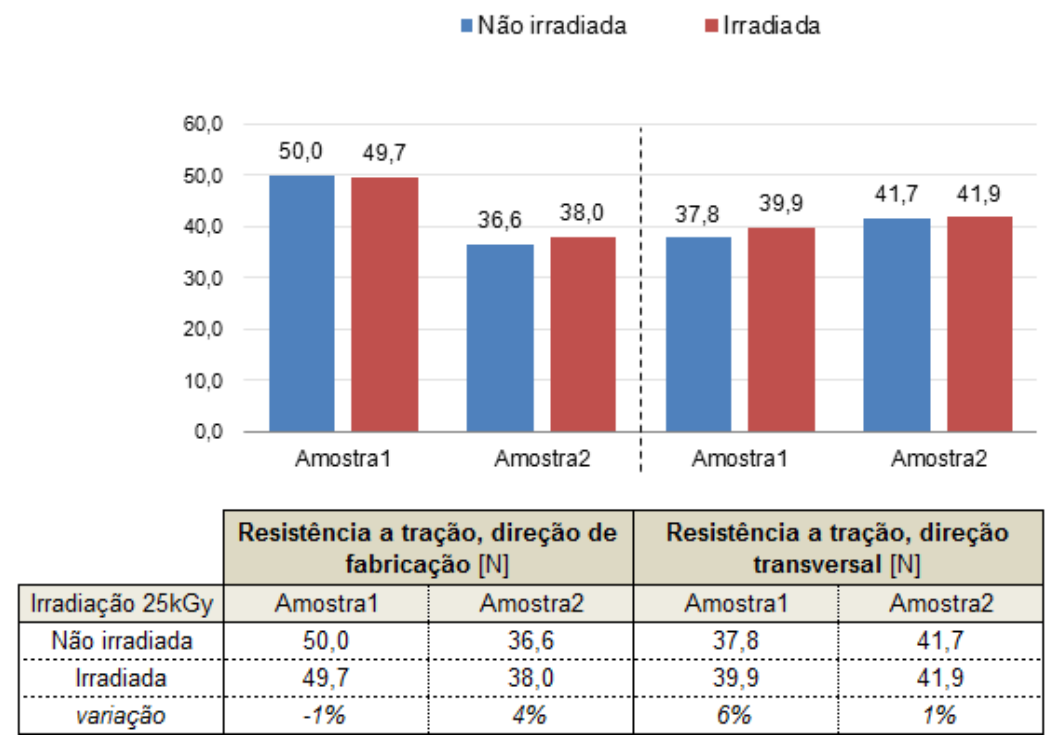

Figura 36 - Variações em porcentagem dos valores obtidos para o parâmetro de resistência à tração dos filmes plásticos das amostras 1 e 2 não irradiadas e irradiadas com 25 kGy

Utilizando doses de 5 e 10 kGy, Goulas et al. (2003) mostraram que não houve diferença estatística significativa em propriedades mecânicas nos filmes multicamadas irradiados quando comparados aos não irradiados. Porém, a irradiação com 30 kGy resultou numa diminuição da resistência à tração dos filmes polietileno de baixa densidade/etileno vinil álcool/ polietileno de baixa densidade (LDPE/EVOH/LDPE); poliamida/polietileno de baixa densidade (PA/LDPE) e polietileno de baixa densidade/poliamida/ionômero (LDPE/PA/ Ionômero) de 21,9 \%,38,0 \% e 10,5 \%, respectivamente.

Fengmei et al. (2000) estudaram os efeitos da radiação gama em propriedades mecânicas nas doses de 5 kGy, 10 kGy e 25 kGy do nylon/cloreto de polivinilideno/polietileno e observaram que não houve diferença significativa na resistência à tração e alongamento após irradiação com uma dose de 5 kGy, enquanto doses de irradiação de 10 e 25 kGy reduziram ligeiramente as propriedades mecânicas. George et al. (2006) não obtiveram mudanças significativas nas propriedades mecânicas (resistência à tração e alongamento) do polímero polipropileno (PP) e outros em doses de 2,5 kGy até 10 kGy. 
Segundo Demertzis et al. (1999), o polietileno (PE) é um polímero mais estável à irradiação gama que o polipropileno por causa do carácter mais ramificado das cadeias do polímero de polipropileno. Para o polipropileno, são produzidos radicais terciários, com uma vida útil mais longa e, portanto, mais tempo para reagir com o oxigênio e produzir produtos de decomposição que contêm oxigênio. Por outro lado, os polímeros aromáticos como o poli(tereftalato de etileno) - poliéster (PET) ou poliestireno (PS) são muito mais estáveis à radiação gama se comparados a poliolefinas (PE e PP).

Oliveira et al. (2009) mostraram que o alongamento de PET/PP melhorou após a irradiação com feixes de elétrons, enquanto para o PET/LDPE/EVOH/LDPE piorou, o que indicou uma moderada a grave degradação nesta estrutura. Segundo Oliveira et al. (2009), o aumento do alongamento na ruptura do filme irradiado PET/PP indicou um possível domínio da reticulação na degradação desta estrutura. Neste estudo, o alongamento foi mais afetado pela irradiação que a resistência à tração. Goulas et al. (2004) e Wilsky (1987) também relataram que o alongamento é a propriedade mais sensível à radiação que a resistência à tração dos polímeros.

Mizani et al. (2009) relataram que a resistência à tração e alongamento do filme plástico multicamada formado por poli(tereftalado de etileno)/poli (tereftalado de etileno)/polietileno linear de baixa densidade (PET/PET/LLDPE), tratado com 15 kGy, diminuiu $21 \%$ e 59 \%, respectivamente, em relação ao não irradiado. Os autores atribuíram a diminuição das propriedades mecânicas deste filme ao efeito da radiação não na estrutura principal dos polímeros, mas sobre os aditivos utilizados nos filmes plásticos. Realmente, muitos pesquisadores vêm relatando a degradação de diferentes aditivos durante a irradiação (Riganakos et al., 1999; Welle et al., 2002). Jeon et al. (2007) demonstraram a destruição de diferentes tipos de compostos fenólicos antioxidantes, utilizados em filmes de 
polietileno linear de baixa densidade (LLDPE) tratados por radiação gama e observou decréscimo de 34,9\% na concentração de Irganox 1076 a 10 kGy. Antioxidantes desempenham um importante papel na estabilização de poliolefinas e a sua presença pode reduzir a perda de propriedades mecânicas (Kawamura, 2004; Ekman et al., 1993). Eles funcionam tanto como reagentes, reagindo prontamente com os radicais livres gerados pela irradiação no polímero, ou como absorvedores de energia primária, impedindo a interação da radiação com o polímero (Hemmerich, 2000).

Alguns pesquisadores afirmam que o poli(tereftalato de etileno) (PET) é um polímero relativamente resistente à radiação devido à presença de um anel aromático, na sua estrutura, especialmente em doses baixas. Tem sido demonstrado que cadeias aromáticas têm uma maior resistência à radiação do que cadeias alifáticas, porque os anéis fenil proporcionam um efeito protetor tanto intra quanto intermolar (Moura et al., 2004; Ravasio et al., 2007; Pentimalli et al., 2000; Hemmerich, 2000). Do outro lado, Jeon et al. (2004) relataram um pequeno aumento em ambas as propriedades de tensão de filme PET após a irradiação com 5 e 10 kGy.

Nas FIG. 37 e 38, estão apresentados os espectros de infravermelho dos filmes plásticos das Amostras 1 e 2 não irradiadas e irradiadas com 25 kGy. Observando estes espectros, verifica-se que não tiveram nenhuma alteração devido à irradiação. Deschênes et al. (1995) e Riganakos et al. (1999) também concluíram que independente da dose de radiação (5, 20 e 100 kGy) os espectros de infravermelho dos filmes multicamadas poliamida/poli(cloreto de vinilideno)/etileno vinil acetato (PA/PVDC/EVA) e PET/PE/EVOH/PE e dos filmes monocamada polietileno de baixa densidade (LDPE) e copolímero de etileno vinil acetato (EVA) não foram significativamente alterados pela irradiação, mesmo em doses tão elevadas quanto 100 kGy. 


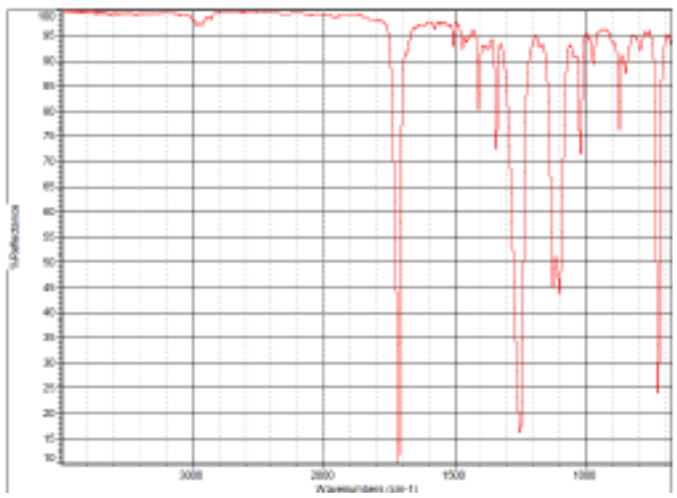

(a)
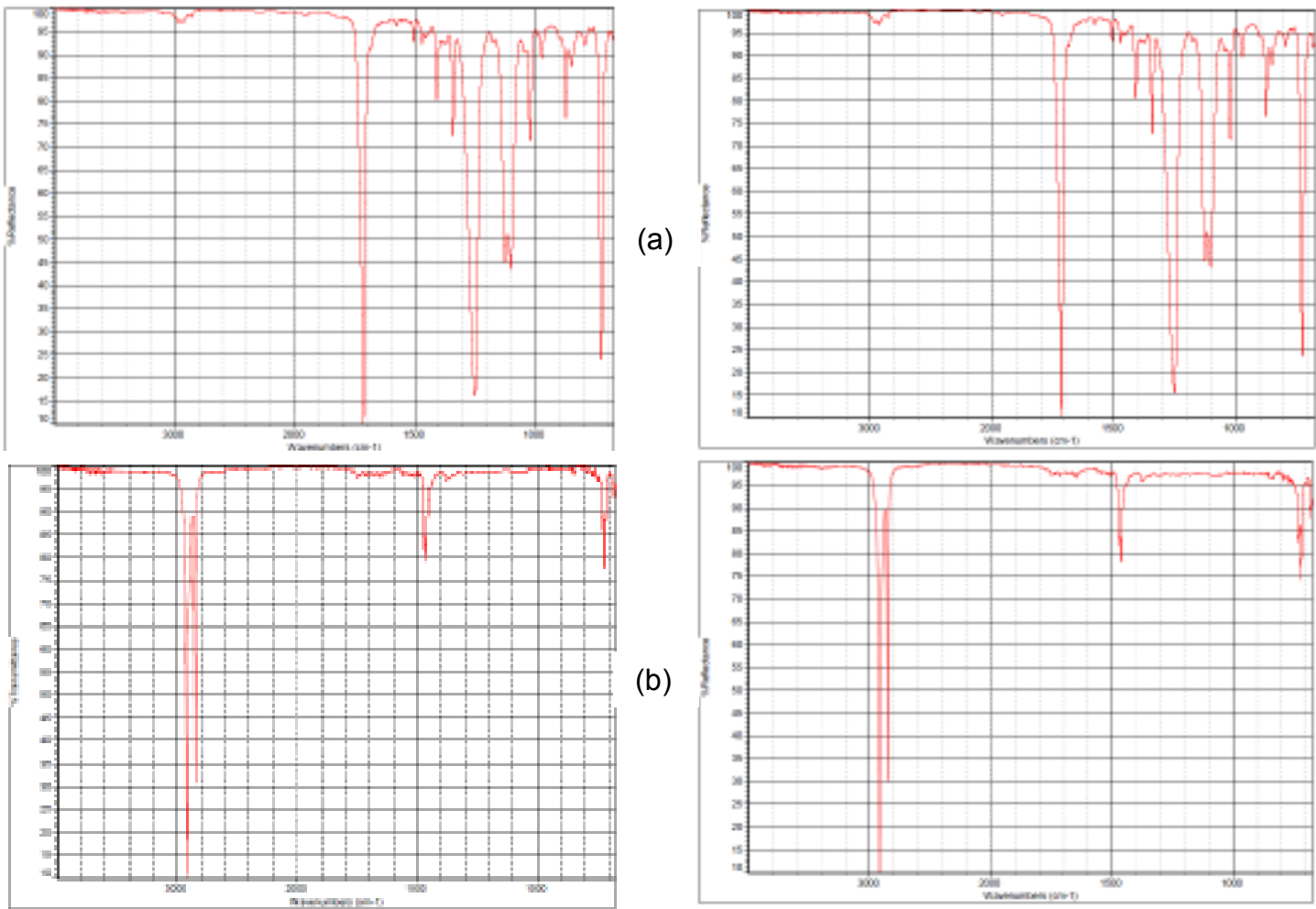

Figura 37 - Espectros de infravermelho da frente (a) e do verso (b) do filme plástico da Amostra 1 não irradiada e irradiada com 25 kGy, respectivamente

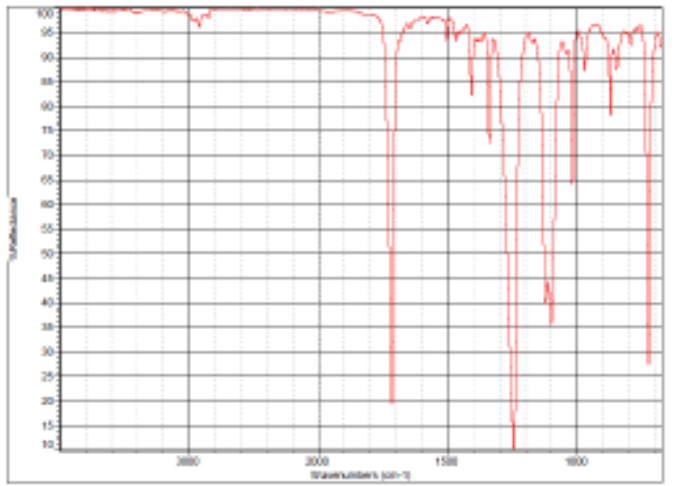

(a)
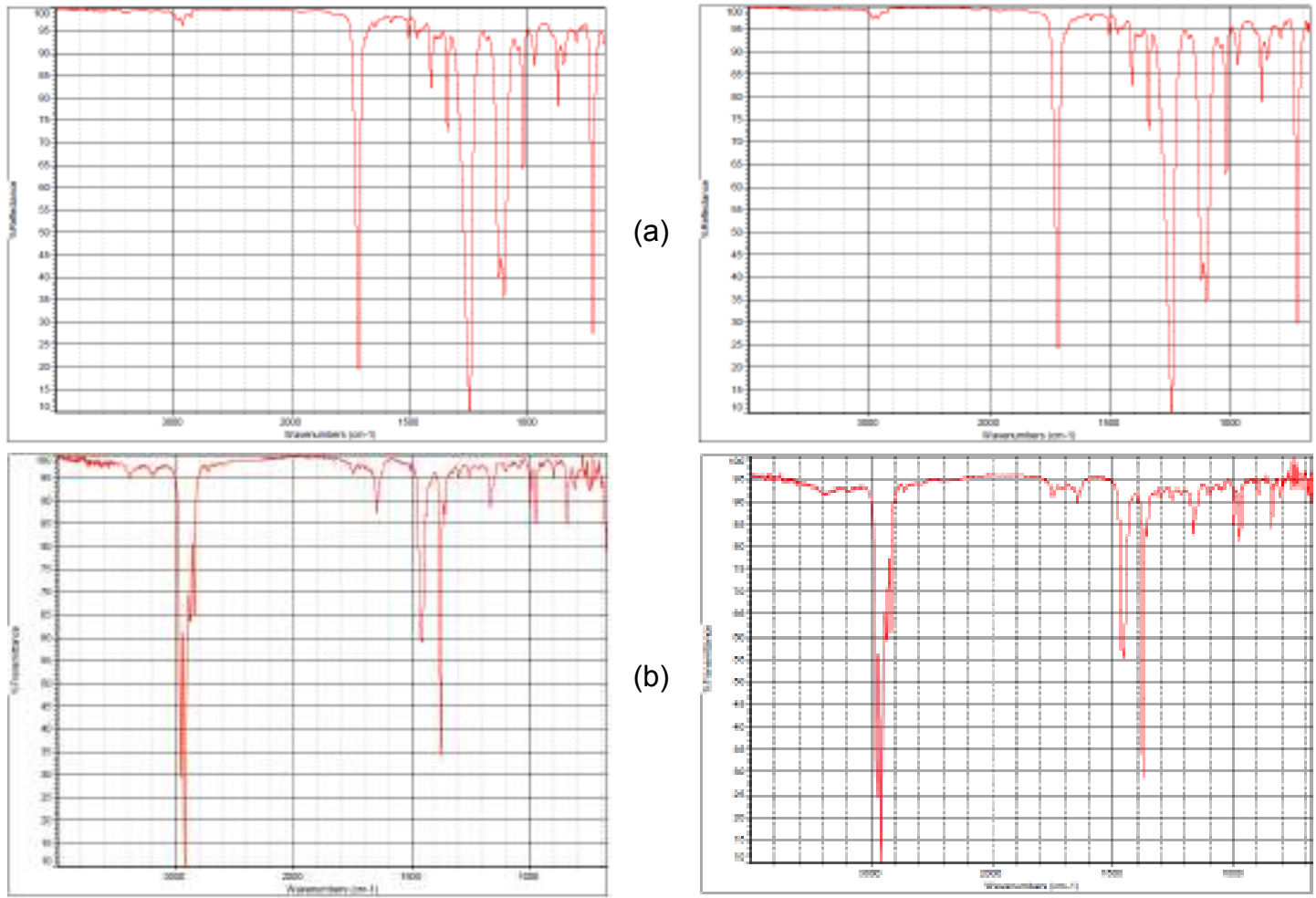

Figura 38 - Espectros de infravermelho da frente (a) e do verso (b) do filme plástico da Amostra 2 não irradiada e irradiada com 25 kGy, respectivamente 
Para George et al. (2006), as mudanças nas intensidades dos picos encontrados para PP, PET e Nylon 6 após irradiações com 2,5 kGy até 10 kGy foram mínimas. Jipa et al. (2012), utilizando esta mesma técnica, relataram para poli vinil álcool e celulose bacteriana variações consideráveis quando comparados os produtos antes e após o tratamento com radiação.

Para Goulas et al. (2003), as diferenças encontradas entre diferentes estudos podem ser relacionadas com a estrutura química das camadas individuais dos filmes plásticos, espessura das amostras de embalagem, aditivos adicionados, a taxa de dose aplicada durante a irradiação, bem como parâmetros como temperatura e umidade relativa. Portanto, os resultados encontrados são apenas indicativos e não se deve generalizar para todos os filmes plásticos multicamadas.

Hemmerich (2000) relata que a radiação normalmente afeta os polímeros de duas formas básicas, ambas resultantes da excitação ou ionização de átomos. Os dois mecanismos são: a) cisão de cadeia, ou seja, uma ruptura aleatória de ligações, o que reduz a massa molar, isto é, a força do polímero; e b) ligação cruzada ou reticulação de moléculas de polímero, o que resulta na formação de grandes redes tridimensionais molares. Na maioria das vezes, ambos os mecanismos ocorrem nos materiais poliméricos quando submetidos à radiação ionizante, mas frequentemente um deles predomina. Como resultado da cisão da cadeia, fragmentos de baixa massa molar, evolução de gás, e ligações insaturadas podem aparecer. A reticulação geralmente resulta em um aumento inicial da resistência à tração, ao passo que diminui a força de impacto e o polímero torna-se mais quebradiço com aumento da dose.

Para Yaghoubi et al. (1999), a irradiação com 25 kGy pode diminuir a cristalinidade do polipropileno de 1,1\%, devido à cisão das cadeias macromolares. Segundo Ekman et al. (1993), no polietileno e em borrachas ocorrem predominantemente ligações cruzadas após a exposição à radiação enquanto a cisão da cadeia predomina em polipropileno. Para polímeros com cadeias de carbono-carbono, a reticulação, geralmente, irá ocorrer se os átomos de carbono possuem um ou mais átomos de hidrogênio ligados, ao passo que a cisão ocorre em carbonos tetra substituídos (Hemmerich, 2000). 


\subsubsection{Análise dos resultados obtidos para os parâmetros relacionados às Amostras de Embalagem 1 e 2}

Os resultados obtidos para os parâmetros selecionados para analisar a influência da irradiação com 25 kGy nas amostras de embalagem 1 e 2 aqui tratadas estão apresentados na TAB. 8.

Os números de determinações para obter a média dos resultados apresentados na TAB. 8 foram:

- dez determinações para o ensaio de impurezas;

- nove determinações para o ensaio de resistência da selagem do topo da embalagem;

- seis determinações para o ensaio de resistência da selagem dos lados direito e esquerdo da embalagem;

- cinco determinações para o ensaio de integridade da selagem.

Os lados denominados de esquerdo e direito nos resultados do ensaio de resistência da selagem referem-se à embalagem com o filme plástico voltado para cima e com o sentido de abertura da embalagem, do topo da embalagem para o fundo da embalagem (FIG. 39).
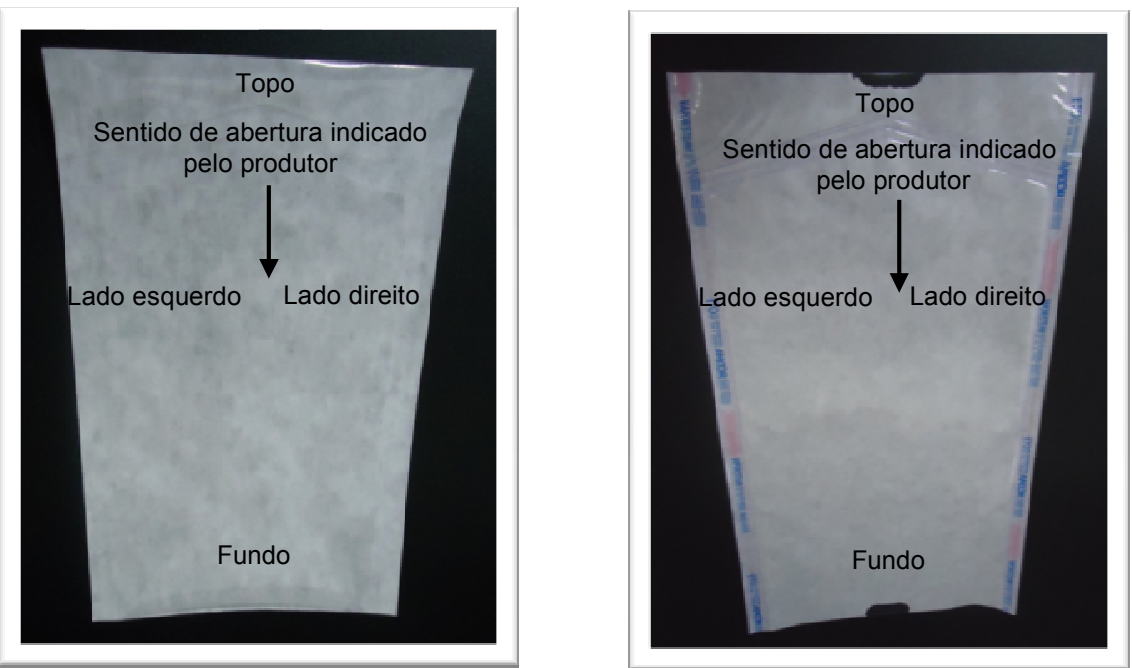

Figura 39 - Fotos e identificação dos lados das amostras de embalagem 1 e 2 utilizadas para o estudo 
Tabela 8 - Efeitos da irradiação (25 kGy) nas propriedades das amostras de embalagem (envelope) 1 e 2

\begin{tabular}{l|l|c|c|c|c}
\hline \multicolumn{5}{c}{ EMBALAGEM } \\
\hline \multirow{2}{*}{ Ensaios } & \multicolumn{2}{c}{ Amostra 1 } & \multicolumn{2}{c}{ Amostra 2 } \\
\cline { 2 - 6 } & Não irradiada & Irradiada & Não irradiada & Irradiada \\
\hline \multirow{2}{*}{$\begin{array}{l}\text { Resistência } \\
\text { da selagem, } \\
N\end{array}$} & Topo & $7,59(0,70)$ & $7,43(0,96)$ & $8,00(0,23)$ & $6,39(0,35)$ \\
\cline { 2 - 6 } & Lado direito & $5,01(0,38)$ & $4,82(0,23)$ & $6,85(1,00)$ & $5,54(0,66)$ \\
\cline { 2 - 6 } & $\begin{array}{l}\text { Lado } \\
\text { esquerdo }\end{array}$ & $5,09(0,50)$ & $4,92(0,53)$ & $5,80(0,37)$ & $5,15(0,32)$ \\
\hline \begin{tabular}{l} 
Impurezas, $\mathrm{mm}^{2} / \mathrm{m}^{2}$ \\
\hline Integridade da selagem
\end{tabular} & ausentes & ausentes & ausentes & ausente \\
\hline
\end{tabular}

Nota: Os números entre parênteses referem-se ao desvio padrão das determinações paralelas.

Dos parâmetros utilizados para a análise da embalagem de ambas as amostras, observou-se que os ensaios de impureza e integridade da selagem não foram modificados pela radiação, porém, a resistência da selagem sofreu uma redução da força da selagem considerável para a Amostra 2, cujo papel é uma mistura de fibras longas e curtas e cujo filme plástico é formado pelos polímeros polipropileno e poliéster. Para a Amostra 1 não irradiada e irradiada, a variação com $25 \mathrm{kGy}$ foi de 2 a $4 \%$ dependendo do lado da selagem, enquanto para a Amostra 2, foi de 11 a 20 \% (FIG. 40). A Amostra 1 tem em sua composição, do lado em que o filme é selado ao papel, o polímero polietileno (lado interno) e papel formado por fibras longas. Talvez estas diferenças entre as amostras tenham causado menor degradação na selagem da Amostra 1 após ser submetida ao processo de irradiação. 


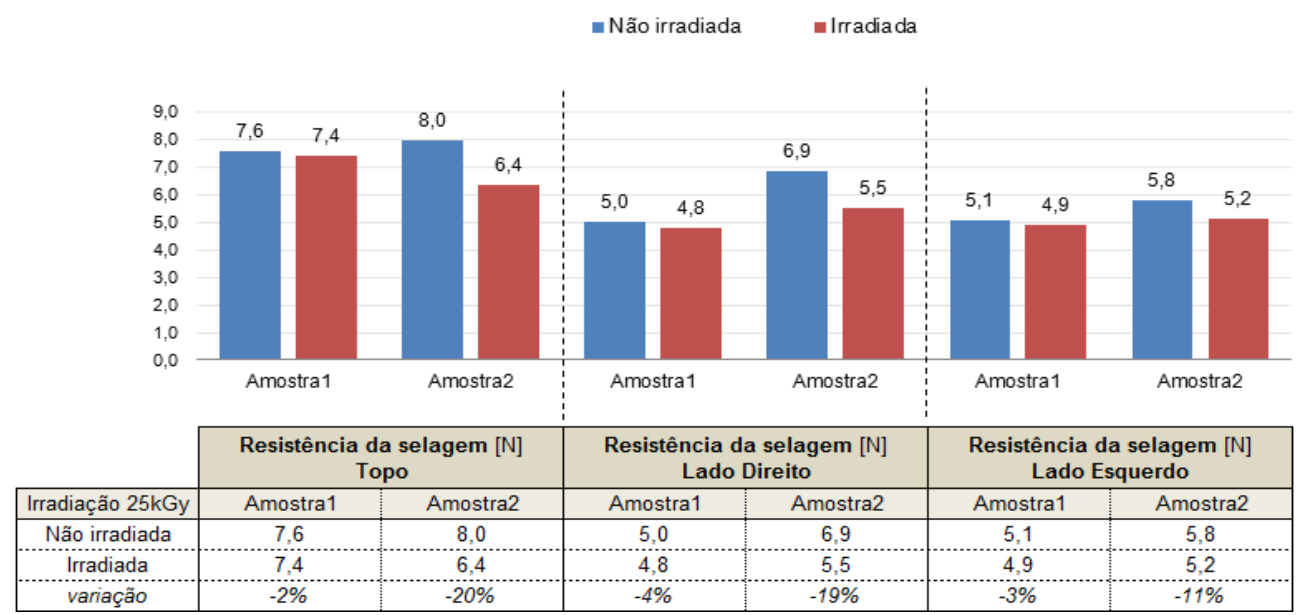

Figura 40 - Variações em porcentagem dos valores obtidos para o parâmetro de resistência da selagem das amostras 1 e 2 não irradiadas e irradiadas com 25 kGy

Segundo Goulas et al. (2003), muitos filmes multicamadas coextrusados são baseados em poliolefinas, polietileno (PE) e polipropileno (PP). Polietileno de baixa densidade (LDPE) e polietileno linear de baixa densidade (LLDPE) são valorizados pela sua tenacidade e propriedades de selagem. Oliveira et al. (2009) mostraram que a resistência à selagem do polímero multicamada PET/PP foi mais afetada pela irradiação do que para o polímero $\mathrm{PET} / \mathrm{LDPE} / \mathrm{EVOH} / \mathrm{LDPE}$. A perda da resistência à selagem do PET/PP em doses até 25 kGy foi em torno de 65-92\% oito dias após a irradiação, e de 43-88\% seis meses após a irradiação em doses de até 15 kGy.

Killoran (1972) investigou o efeito da radiação gama (60-67 kGy) nas propriedades mecânicas de cinco laminados multicamadas: de poli(tereftalato de etileno) (PET) como camada externa, folha de alumínio como camada intermediária e uma mistura de PE-poliisobutileno, polietileno de alta densidade (HDPE), PET, poli(iminocaproila), policarbonato como camadas internas em contato com o alimento e não foram observadas diferenças significativas nos parâmetros resistência à tração e resistência à selagem das amostras irradiadas. Keay (1968) examinou os efeitos da radiação gama nas doses de 10, 20, 30, 50, 80 e 160 kGy em filmes laminados constituídos por poliéster/polietileno de média densidade (MDPE) e polipropileno/polietileno de média densidade (PP/MDPE) e também não observou diferenças significativas em propriedades mecânicas (fragilidade e delaminação). 


\subsection{Irradiação das amostras com dose de 50 kGy}

A influência do tratamento por irradiação com 50 kGy foi estudada nas duas amostras de embalagem comercial consideradas neste estudo e nos seus materiais (papel e filme plástico multicamada), a partir dos resultados obtidos para os parâmetros selecionados para cada um dos materiais que compõem estas embalagens. Estas análises serão apresentadas a seguir, em etapas distintas. Foram consideradas como influências significativas as diferenças acima de $5 \%$ entre os valores determinados para os parâmetros selecionados para as análises das amostras não irradiadas e irradiadas.

\subsubsection{Análise dos resultados obtidos para os parâmetros relacionados aos papéis das Amostras 1 e 2}

Os ensaios realizados e os resultados obtidos para analisar a influência da irradiação com 50 kGy nos papéis das duas amostras de embalagem comercial estudadas estão apresentados na TAB. 9.

Os números de determinações para se obter a média dos resultados apresentados na TAB. 9 foram:

- dez determinações para os ensaios de: alvura; fluorescência; permeância ao ar e resistência à tração;

- dez corpos de prova para o ensaio de diâmetro dos poros, sendo três leituras efetuadas em cada um deles;

- cinco determinações para os ensaios de resistência ao arrebentamento e resistência ao rasgo;

- três determinações para os ensaios de pH e residual de corantes. 
Tabela 9 - Efeitos da radiação (50 kGy) nas propriedades dos papéis das amostras de embalagem 1 e 2

\begin{tabular}{|c|c|c|c|c|c|}
\hline \multicolumn{6}{|c|}{ PAPEL } \\
\hline \multirow{2}{*}{\multicolumn{2}{|c|}{ Ensaios }} & \multicolumn{2}{|c|}{ Amostra 1} & \multicolumn{2}{|c|}{ Amostra 2} \\
\hline & & Não irradiada & Irradiada & $\begin{array}{c}\text { Não } \\
\text { irradiada }\end{array}$ & Irradiada \\
\hline \multicolumn{2}{|c|}{$\begin{array}{l}\text { Resistência ao arrebentamento, } \\
\text { kPa } \\
\text { - Lado A } \\
\text { - Lado B }\end{array}$} & $\begin{array}{l}356,29(38,73) \\
374,69(32,80)\end{array}$ & $\begin{array}{l}270,20(14,44) \\
278,09(22,56)\end{array}$ & $\begin{array}{l}306,57(33,70) \\
305,91(21,47)\end{array}$ & $\begin{array}{l}214,13(17,42) \\
199,67(26,12)\end{array}$ \\
\hline \multicolumn{2}{|c|}{$\begin{array}{l}\text { Resistência à tração, kN/m } \\
\text { - direção de fabricação } \\
\text { - direção transversal }\end{array}$} & $\begin{array}{l}8,03(0,40) \\
3,52(0,20)\end{array}$ & $\begin{array}{l}6,57(0,25) \\
2,96(0,12)\end{array}$ & $\begin{array}{l}7,00(0,32) \\
3,01(0,15)\end{array}$ & $\begin{array}{l}5,53(0,26) \\
2,61(0,08)\end{array}$ \\
\hline \multicolumn{2}{|c|}{$\begin{array}{l}\text { Resistência ao rasgo, mN } \\
\text { - direção de fabricação } \\
\text { - direção transversal }\end{array}$} & $\begin{array}{l}543,5(22,05) \\
678,9(22,05)\end{array}$ & $\begin{array}{l}373,37(16,18) \\
419,78(16,18)\end{array}$ & $\begin{array}{l}628,63(23,68) \\
725,31(19,34)\end{array}$ & $\begin{array}{l}446,85(17,30) \\
446,85(10,59)\end{array}$ \\
\hline \multicolumn{2}{|c|}{$\begin{array}{l}\text { Permeância ao ar - Método } \\
\text { Bendtsen, } \mu \mathrm{m} / \mathrm{Pa} \text {.s }\end{array}$} & $11,08(0,67)$ & $10,77(0,55)$ & $8,65(0,44)$ & $8,65(0,61)$ \\
\hline \multicolumn{2}{|c|}{ Diâmetro dos poros, $\mu \mathrm{m}$} & $37,4(3,8)$ & $41,5(5,7)$ & $23,2(2,1)$ & $25,1(2,2)$ \\
\hline \multicolumn{2}{|c|}{ Residual de corantes } & ausente & $\begin{array}{c}\text { coloração } \\
\text { amarela }\end{array}$ & ausente & $\begin{array}{l}\text { coloração } \\
\text { amarela }\end{array}$ \\
\hline \multicolumn{2}{|c|}{$\mathrm{pH}$ do extrato aquoso, à quente } & $6,34(0,09)$ & $4,76(0,10)$ & $6,21(0,04)$ & $5,05(0,11)$ \\
\hline \multirow{2}{*}{$\begin{array}{l}\text { Fator de } \\
\text { refletância } \\
\text { difusa no azul } \\
\text { (alvura), \% }\end{array}$} & UV calibrado & $83,96(0,05)$ & $76,02(0,08)$ & $83,37(0,16)$ & $79,32(0,11)$ \\
\hline & UV excluído & $83,59(0,05)$ & $75,70(0,09)$ & $83,18(0,16)$ & $79,22(0,12)$ \\
\hline \multirow[t]{2}{*}{ Fluorescência } & $\begin{array}{l}\text { diferença entre UV } \\
\text { calibrado e UV } \\
\text { excluído, em \% }\end{array}$ & 0,37 & 0,32 & 0,19 & 0,10 \\
\hline & $\begin{array}{l}\text { pontos } \\
\text { fluorescentes }\end{array}$ & ausentes & ausentes & ausentes & ausentes \\
\hline
\end{tabular}

Notas:

a. Considerou-se como lado A, o lado interno da embalagem o qual entra em contato direto com o produto e como lado B o lado externo da embalagem.

b. O líquido usado no ensaio de diâmetro dos poros foi o álcool etílico 99,5\%.

c. Os números entre parênteses referem-se ao desvio padrão das determinações paralelas.

d. Para o ensaio do fator de reflectância difusa no azul (alvura), UV calibrado significa a medida de alvura realizada com a presença do filtro UV, e UV excluído, a medida sem a presença do filtro.

Como os parâmetros gramatura e espessura dos papéis de ambas as amostras não sofreram modificações devido à irradiação com 25 kGy (TAB. 5 do item 5.2.1), estes não foram considerados na análise da amostra irradiada com 50 kGy. Os parâmetros permeância ao ar e diâmetro de poros, apesar de terem sido muito pouco alterados pela irradiação com $25 \mathrm{kGy}$, foram considerados na amostra irradiada com $50 \mathrm{kGy}$ por serem propriedades estruturais importantes para o papel grau cirúrgico.

Os resultados obtidos dos ensaios realizados no papel grau cirúrgico de ambas as amostras de embalagem não irradiadas e irradiadas com 50 kGy mostram que a permeância ao ar continua sendo muito pouco afetado pela radiação, enquanto que os parâmetros resistência ao arrebentamento, resistência 
ao rasgo, resistência à tração, $\mathrm{pH}$ e alvura resultaram em uma diminuição após dose de $50 \mathrm{kGy}$ da mesma forma que foi observado nos resultados obtidos após irradiação com 25 kGy apresentados na TAB. 5 do item 5.2.1. Para o parâmetro diâmetro dos poros, observou-se que este foi modificado, apresentando um aumento com a dose de 50 kGy, o que não ocorreu para 25 kGy.

Após a irradiação dos papéis das amostras com 50 kGy, observou-se para o ensaio de residual de corantes uma coloração amarelada no extrato aquoso, obtido a quente.

Nas FIG. 41, 42, 43, 44 e 45, estão apresentadas as variações em porcentagem dos valores determinados para os parâmetros nos quais o efeito da radiação foi maior e para os considerados essenciais para os papéis deste tipo de embalagem.

As variações encontradas para a resistência ao rasgo dos papéis de ambas às amostras foram maiores (FIG. 41) do que as da resistência à tração (FIG. 42) assim como observado para dose de 25 kGy. Por este motivo, pode-se inferir que o processo de esterilização por radiação gama nas condições deste estudo causaram alterações especialmente nas fibras celulósicas.
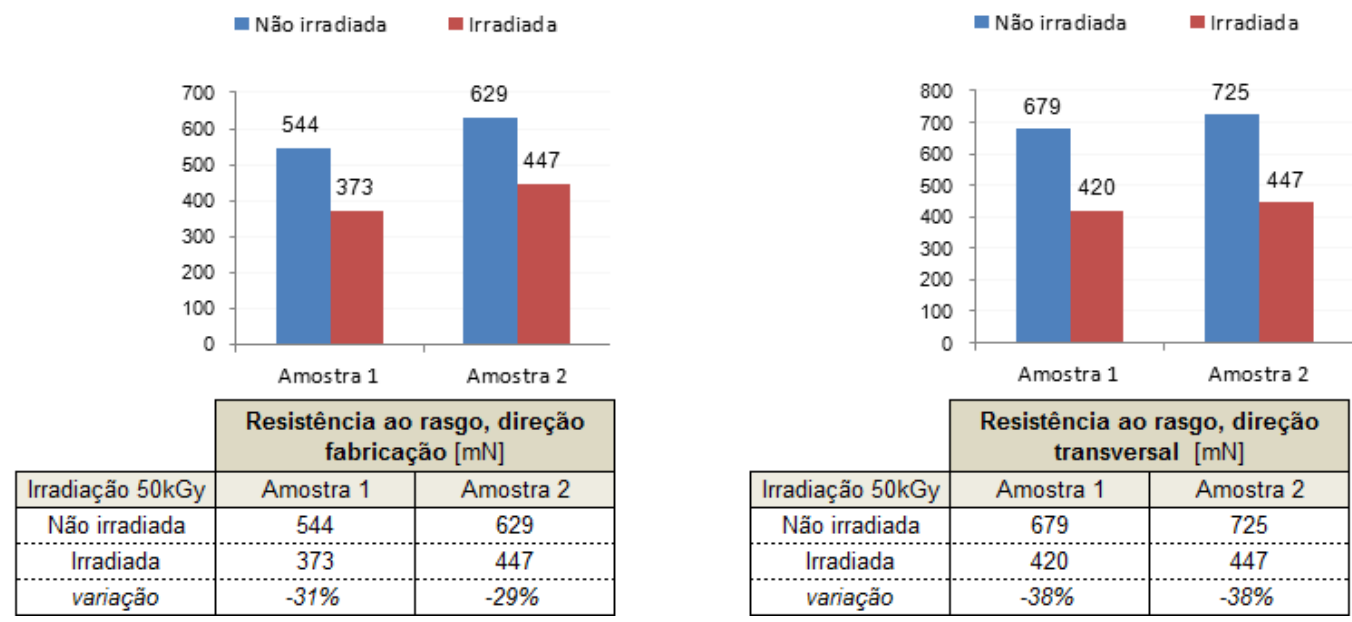

Figura 41 - Variações em porcentagem dos valores obtidos para o parâmetro de resistência ao rasgo nos papéis das amostras 1 e 2 não irradiadas e irradiadas com 50 kGy 

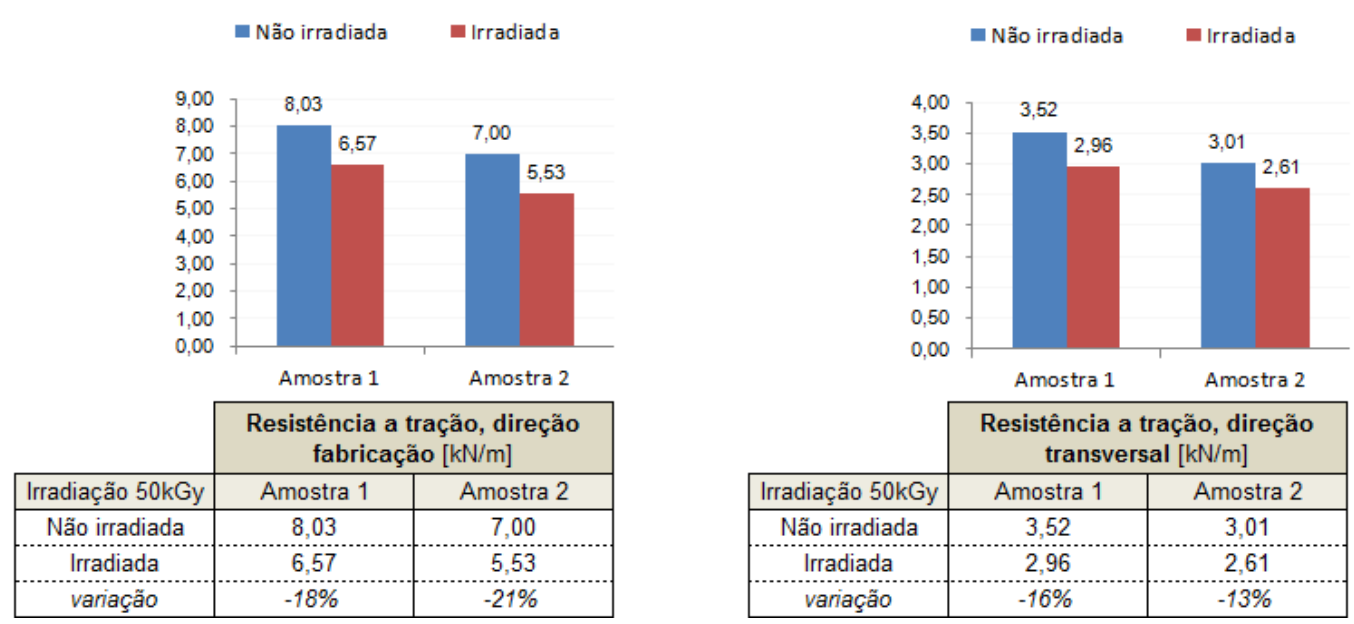

Figura 42 - Variações em porcentagem dos valores obtidos para o parâmetro de resistência à tração nos papéis das amostras 1 e 2 não irradiadas e irradiadas com 50 kGy

As variações obtidas para a resistência ao arrebentamento (FIG. 43) foram significativas, $24 \%$ e $26 \%$ para a Amostra 1 e, $30 \%$ e 35\% para a Amostra 2. Para a Amostra 1, o parâmetro de permeância ao ar não teve uma variação significativa e para a Amostra 2 não teve nenhuma variação. No caso do diâmetro dos poros (FIG. 44), diferente do que ocorreu na dose de 25 kGy, foi obtida uma variação de $11 \%$ para a Amostra 1 e 8 \% para a Amostra 2. Esta variação corresponde a um aumento nos valores encontrados para os tamanhos dos poros do papel, o que representa um fato negativo no caso do papel grau cirúrgico, pois quanto maior o tamanho dos poros maiores são as possibilidades de contaminação por microrganismos do produto embalado.
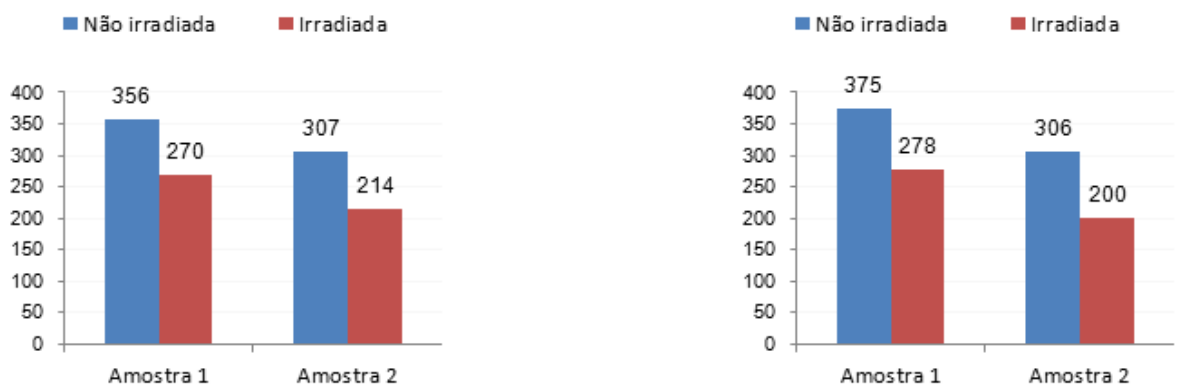

\begin{tabular}{|c|c|c|}
\cline { 2 - 3 } \multicolumn{1}{c|}{} & \multicolumn{2}{c|}{$\begin{array}{c}\text { Resistência ao arrebentamento, } \\
\text { Lado A [kPa] }\end{array}$} \\
\hline Irradiação 50kGy & Amostra 1 & Amostra 2 \\
\hline Não irradiada & 356 & 307 \\
\hline Irradiada & 270 & 214 \\
\hline variação & $-24 \%$ & $-30 \%$ \\
\hline
\end{tabular}

\begin{tabular}{|c|c|c|}
\cline { 2 - 3 } \multicolumn{1}{c|}{} & \multicolumn{2}{c|}{$\begin{array}{c}\text { Resistência ao arrebentamento, } \\
\text { Lado B [kPa] }\end{array}$} \\
\hline Irradiação 50kGy & Amostra 1 & Amostra 2 \\
\hline Não irradiada & 375 & 306 \\
\hline Irradiada & 278 & 200 \\
\hline variação & $-26 \%$ & $-35 \%$ \\
\hline
\end{tabular}

Figura 43 - Variações em porcentagem dos valores obtidos para o parâmetro de resistência ao arrebentamento nos papéis das amostras 1 e 2 não irradiadas e irradiadas com 50 kGy 


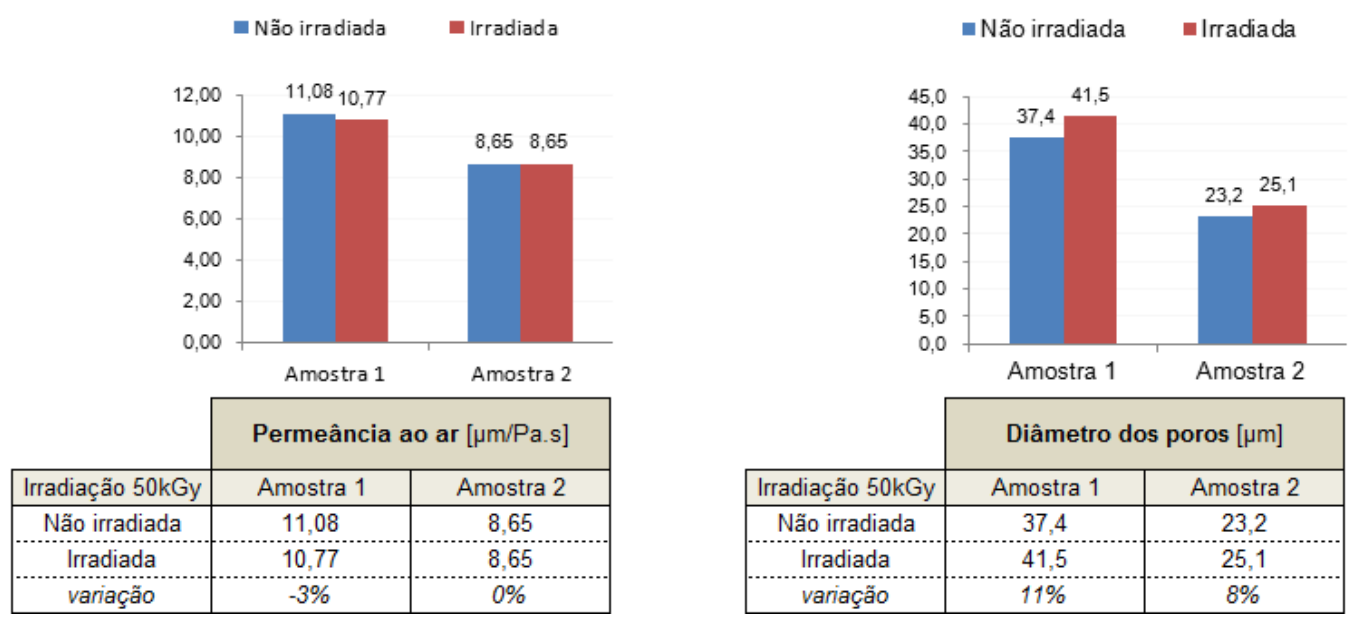

Figura 44 - Variações em porcentagem dos valores obtidos para os parâmetros de permeância ao ar e diâmetro dos poros nos papéis das amostras 1 e 2 não irradiadas e irradiadas com $50 \mathrm{kGy}$

Os valores de $\mathrm{pH}$ do papel grau cirúrgico foram reduzidos consideravelmente para ambas as amostras irradiadas com 50 kGy (FIG. 45) o que também foi observado com 25 kGy e vale aqui as explicações dadas no item 5.2.1.

O parâmetro fator de refletância difusa no azul (alvura) também sofreu redução com variações de $9 \%$ para a Amostra 1 e $5 \%$ para a Amostra 2 (FIG. 45) causando um amarelecimento nos papéis de ambas as amostras, assim como foi observado com 25 kGy.
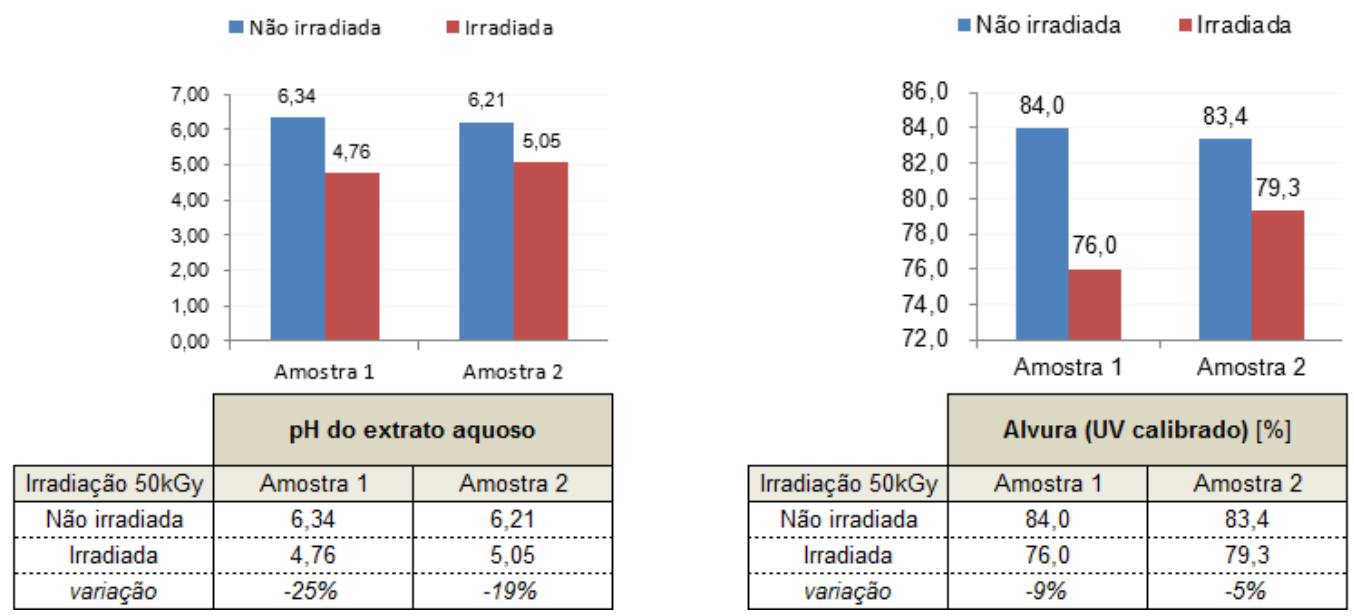

Figura 45 - Variações em porcentagem dos valores obtidos para os parâmetros de $\mathrm{pH}$ e alvura nos papéis das amostras 1 e 2 não irradiadas e irradiadas com 50 kGy 
Foram obtidos espectros de infravermelho (FIG. 46 e 47) para os papéis das amostras de embalagem não irradiadas e irradiadas com 50 kGy e, assim como para dose de 25 kGy (item 5.2.1, FIG. 32 e 33), não foram observadas modificações nos picos presentes nos espectros. Com isto, verifica-se que a irradiação com 50 kGy não causou modificações nos papéis que possam ser detectadas através da espectroscopia no infravermelho.
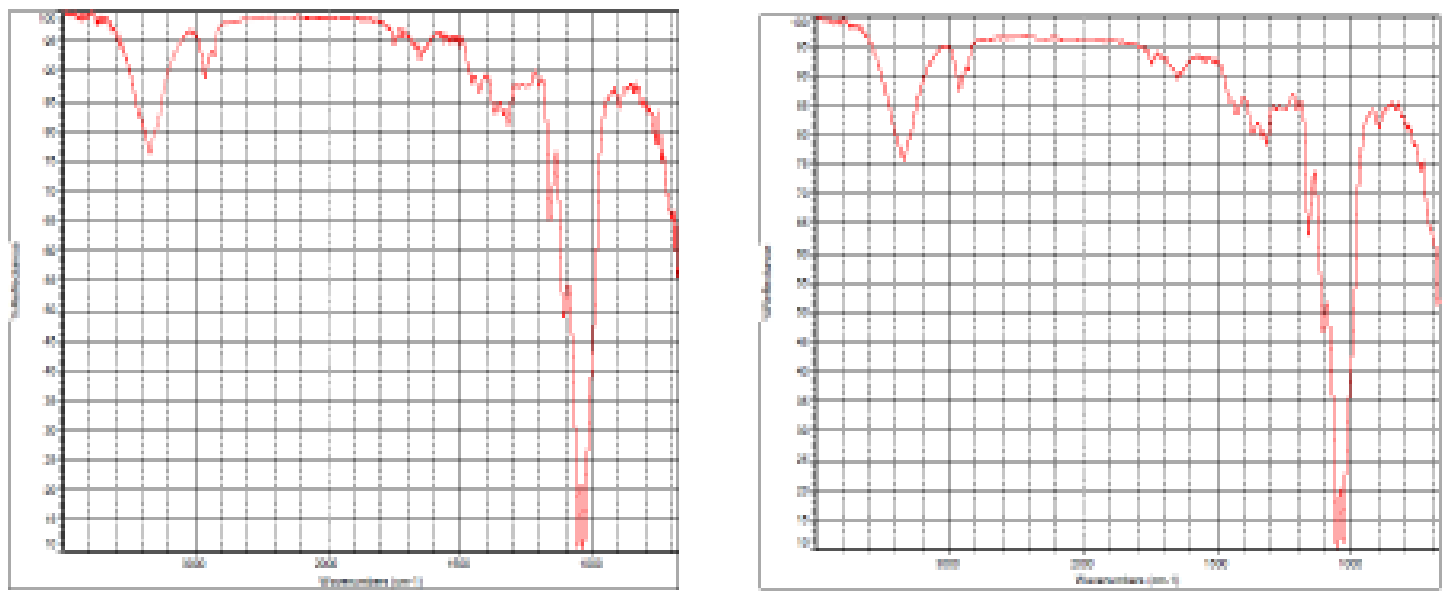

Figura 46 - Espectros de infravermelho do papel da Amostra 1 não irradiada e irradiada com 50 kGy, respectivamente
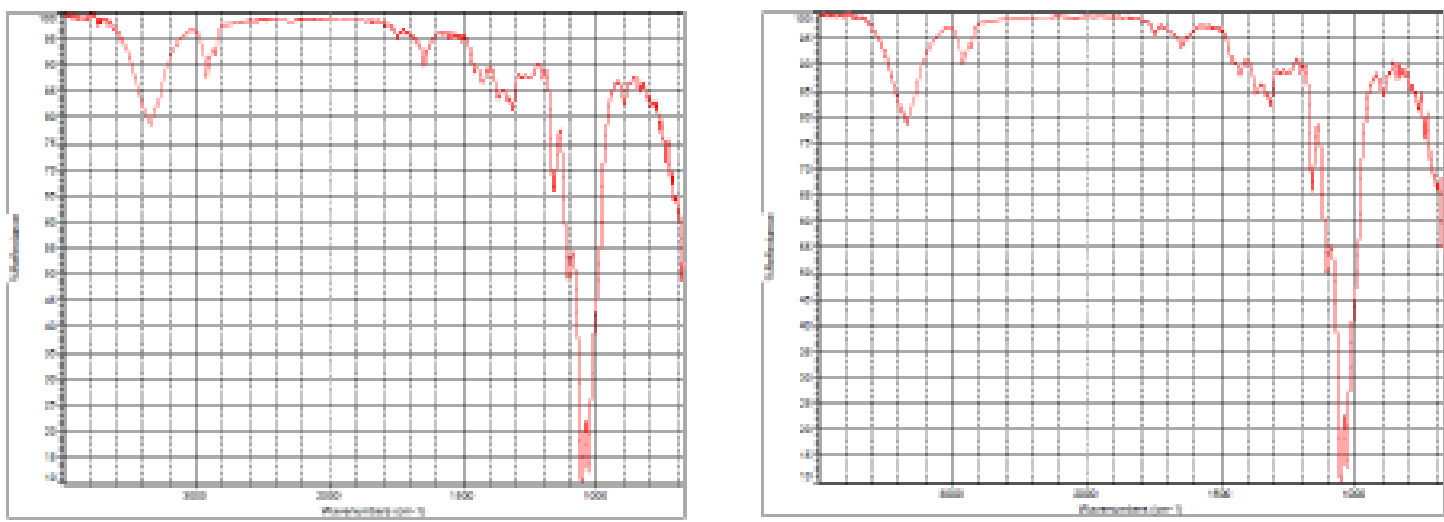

Figura 47 - Espectros de infravermelho do papel da Amostra 2 não irradiada e irradiada com 50 kGy, respectivamente

Para a análise dos efeitos da radiação sobre o grau de cristalinidade dos papéis das Amostras 1 e 2, foi realizada a difração de raios $X$ dos papéis das amostras não irradiadas e irradiadas com $50 \mathrm{kGy}$. Os difratogramas dos papéis das duas amostras estão apresentados nas FIG. 48 e 49, respectivamente. 

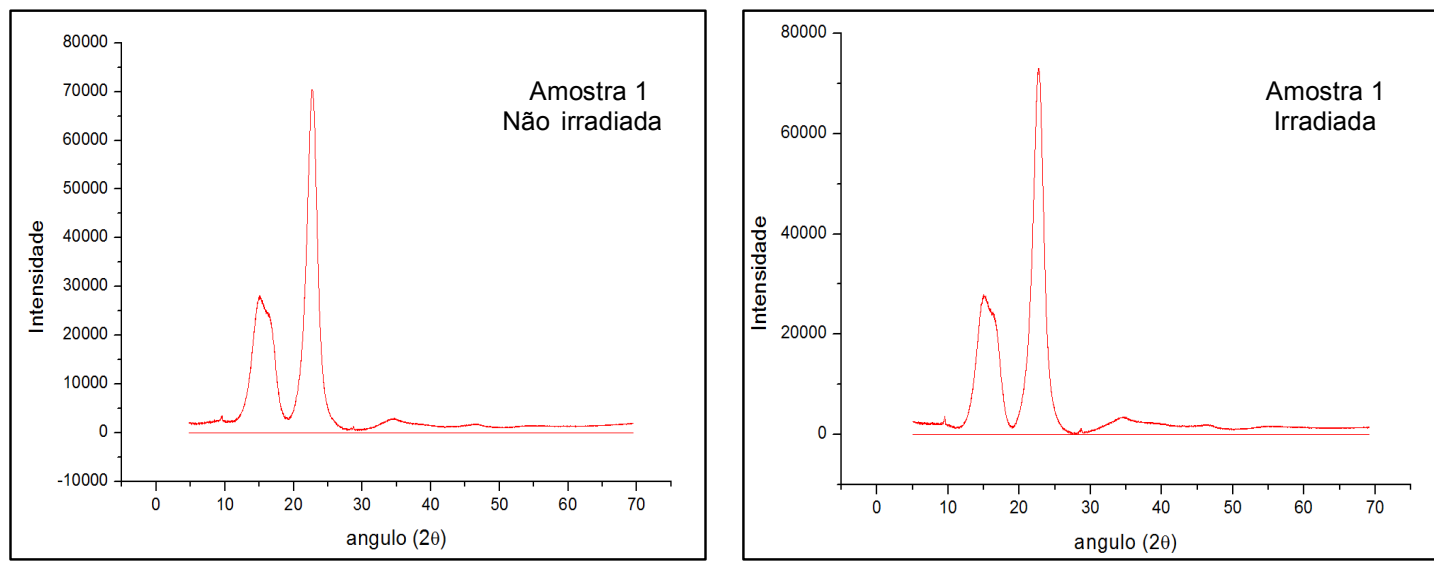

Figura 48 - Difratogramas do papel da Amostra 1 não irradiada e irradiada com 50 kGy
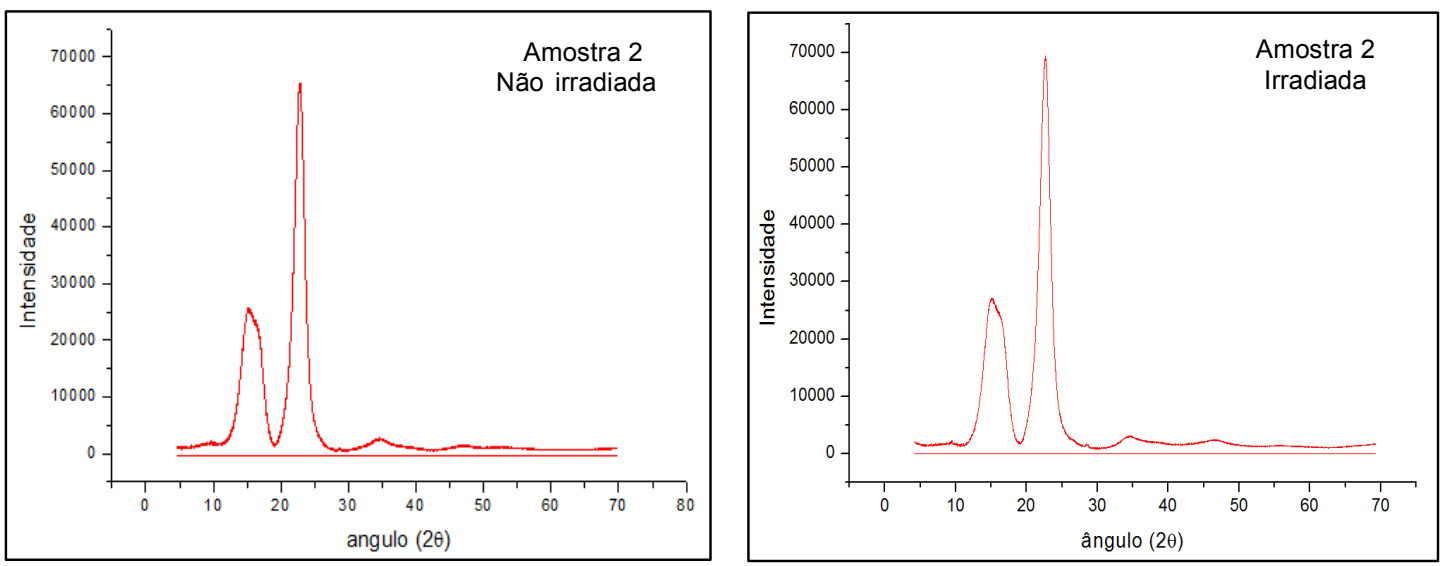

Figura 49 - Difratogramas do papel da Amostra 2 não irradiada e irradiada com 50 kGy

Os valores determinados para os graus de cristalinidade, calculados a partir dos difratogramas empregando-se a Equação 1 estão apresentados na TAB. 10. Os valores de $I_{\text {máxima }}$ e $I_{\text {mínima }}$ utilizados para o cálculo do grau de cristalinidade foram:

\section{Para a Amostra 1}

não irradiada: $I_{\text {mínima }}=2968,34434$ e $I_{\text {máxima }}=70457,31910$;

irradiada: $I_{\text {mínima }}=1400,28042$ e $I_{\text {máxima }}=72969,24980$.

\section{Para a Amostra 2}

não irradiada: $I_{\text {mínima }}=1899,48313$ e $I_{\text {máxima }}=65613,45390$;

irradiada: $I_{\text {mínima }}=1966,49588$ e $I_{\text {máxima }}=69425,22890$. 
Tabela 10 - Grau de cristalinidade do papel das amostras 1 e 2 não irradiadas e irradiadas com 50 kGy

\begin{tabular}{c|c|c|c|c}
\hline \multirow{2}{*}{ Ensaio } & \multicolumn{2}{|c|}{ Amostra 1 } & \multicolumn{2}{c}{ Amostra 2 } \\
\cline { 2 - 5 } & Não irradiada & Irradiada & Não irradiada & Irradiada \\
\hline Grau de cristalinidade, em \% & 96 & 98 & 97 & 97 \\
\hline
\end{tabular}

Analisando os valores obtidos de grau de cristalinidade para os papéis de ambas as amostras de embalagem (TAB. 10), verificou-se que ocorreu uma pequena mudança na estrutura cristalina apenas do papel da Amostra 1, porém, não foi considerada significativa; portanto, concluiu-se que a parte cristalina da fibra não foi afetada pela radiação assim como discutido para os papéis das amostras de embalagem irradiados com 25 kGy.

\subsubsection{Análise dos resultados obtidos para os parâmetros relacionados aos filmes plásticos das Amostras 1 e 2}

Na TAB. 11, estão apresentados os resultados obtidos dos parâmetros selecionados para analisar a influência da irradiação com 50 kGy sobre os filmes plásticos das Amostras 1 e 2 aqui tratadas.

Os números de determinações para obter a média dos resultados apresentados na TAB. 11 foram: dez determinações para o ensaio de resistência à tração e cinco determinações para o ensaio de microfuros.

Tabela 11 - Efeitos da radiação (50 kGy) nas propriedades dos filmes plásticos das amostras de embalagem 1 e 2

\begin{tabular}{l|c|c|c|c}
\hline \multirow{2}{*}{\multicolumn{1}{c}{ Ensaios }} & \multicolumn{2}{c}{ Amostra 1 } & \multicolumn{2}{c}{ Amostra 2 } \\
\cline { 2 - 5 } & Não irradiada & Irradiada & Não irradiada & Irradiada \\
\hline Microfuros & ausentes & ausentes & ausentes & ausentes \\
\hline Tração do filme plástico, N & & & & \\
- direção de fabricação & $40,05(1,54)$ & $38,93(1,44)$ & $37,83(1,20)$ & $38,84(1,09)$ \\
- direção transversal & $37,95(1,16)$ & $37,02(1,61)$ & $33,10(0,77)$ & $33,49(1,09)$ \\
\hline
\end{tabular}

Nota: Os números entre parênteses referem-se ao desvio padrão das determinações paralelas. 
Como os parâmetros gramatura e espessura dos filmes plásticos de ambas as amostras não foram modificados pela irradiação com 25 kGy (TAB. 7 do item 5.2.2), eles não foram considerados na análise da amostra irradiada com 50 kGy.

Analisando os valores apresentados na TAB. 11, obtidos para os parâmetros microfuros e resistência à tração dos filmes plásticos das duas Amostras 1 e 2, conclui-se que estes não foram alterados após a irradiação com $50 \mathrm{kGy}$, assim como aconteceu para dose de $25 \mathrm{kGy}$, como apresentado no item 5.2.2 TAB. 7.

Na FIG. 50 foram apresentadas as variações obtidas para o ensaio de resistência à tração dos filmes plásticos para ambas as amostras. Analisando esta figura, verificou-se que tanto a Amostra 1 quanto a Amostra 2 não sofreram variação após irradiadas com 50 kGy como também aconteceu para dose de 25 kGy (item 5.2.2, FIG. 36).

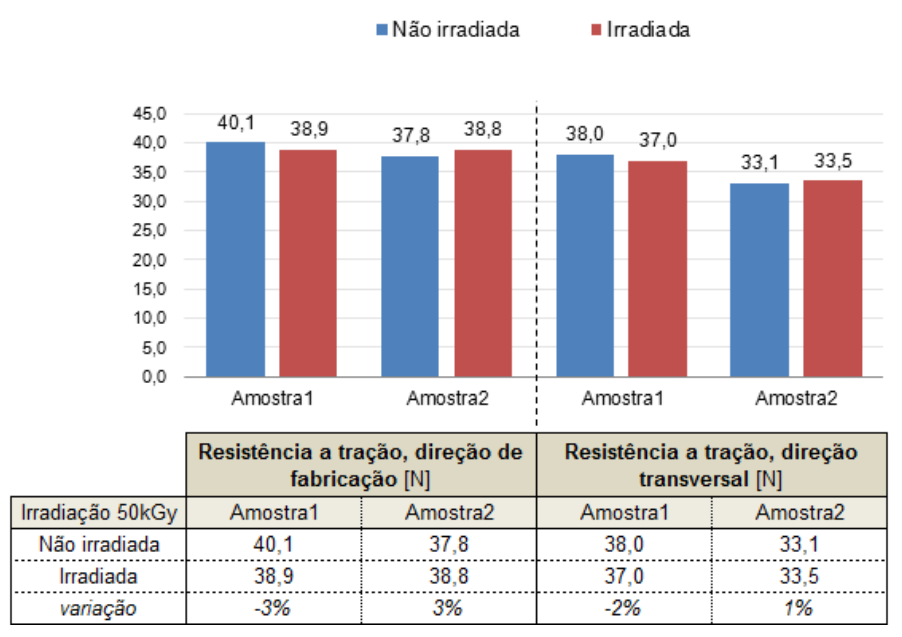

Figura 50 - Variações em porcentagem dos valores obtidos para o parâmetro de resistência à tração dos filmes plásticos das amostras 1 e 2 não irradiadas e irradiadas com 50 kGy

Nas FIG. 51 e 52, estão apresentados os espectros de infravermelho dos filmes plásticos das Amostras 1 e 2 não irradiadas e irradiadas com 50 kGy. Observando estes espectros, verifica-se que não houve alterações nos filmes plásticos de ambas as amostras após tratamento com $50 \mathrm{kGy}$ possíveis de serem detectadas pela técnica de espectroscopia no infravermelho. 


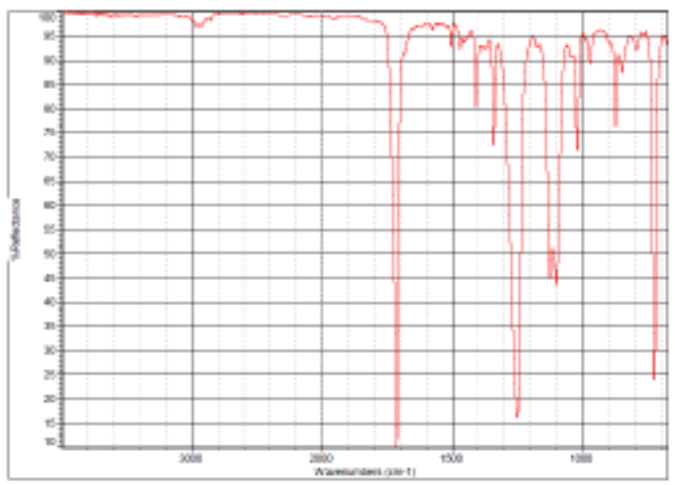

(a)
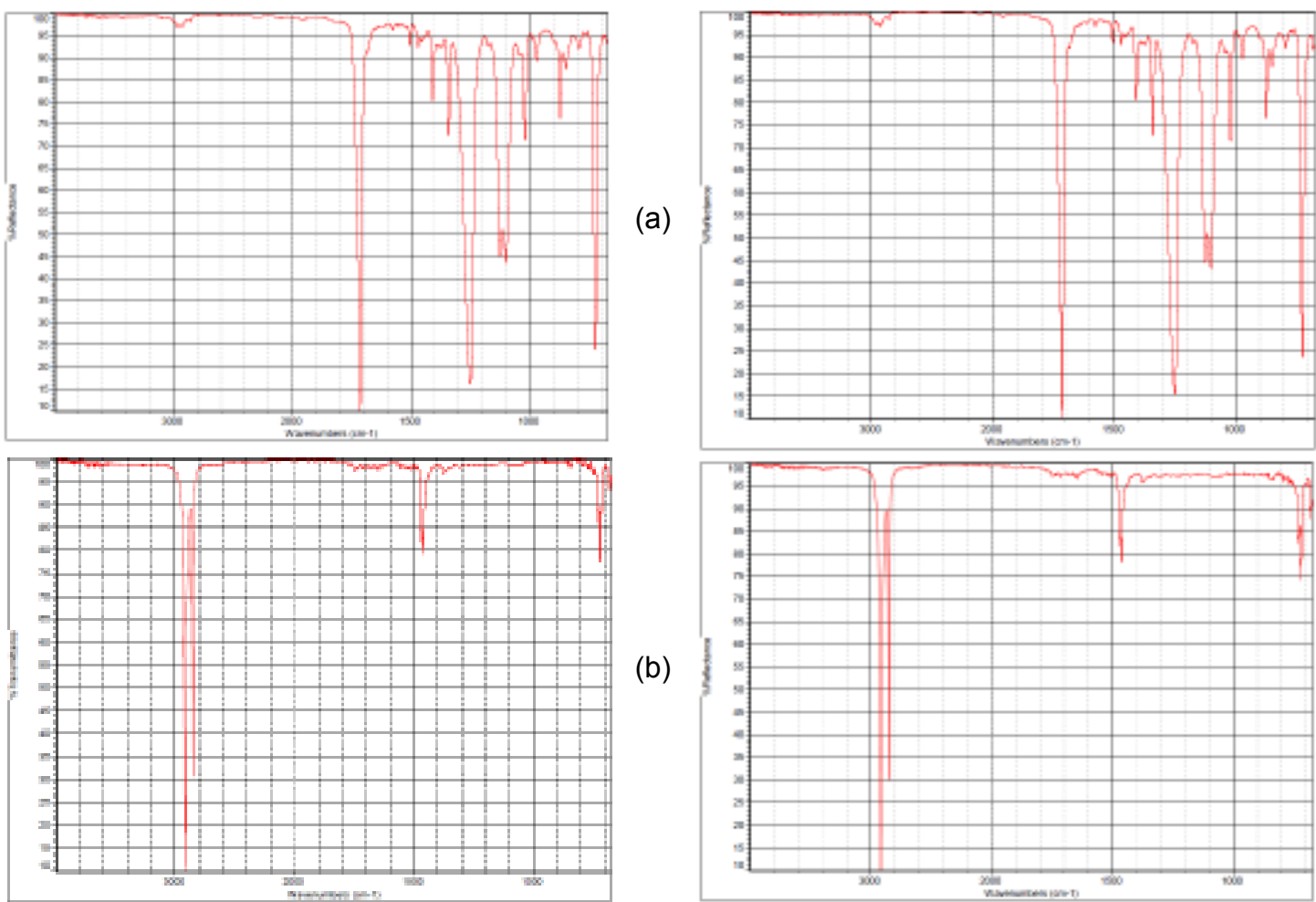

Figura 51 - Espectros de infravermelho da frente (a) e do verso (b) do filme plástico da Amostra 1 não irradiada e irradiada com 50 kGy, respectivamente

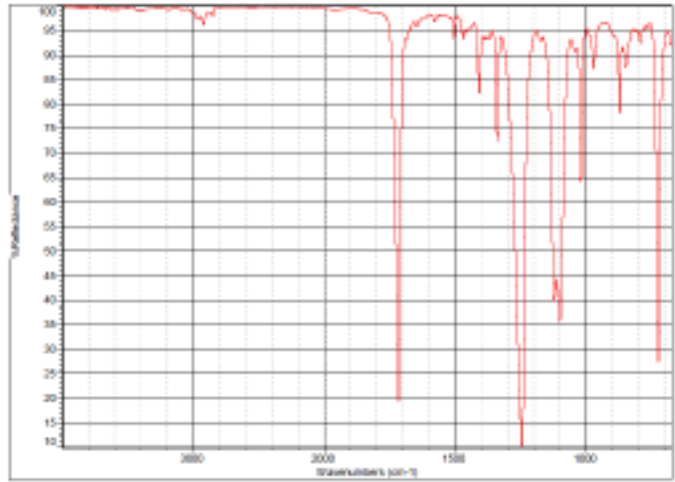

(a)
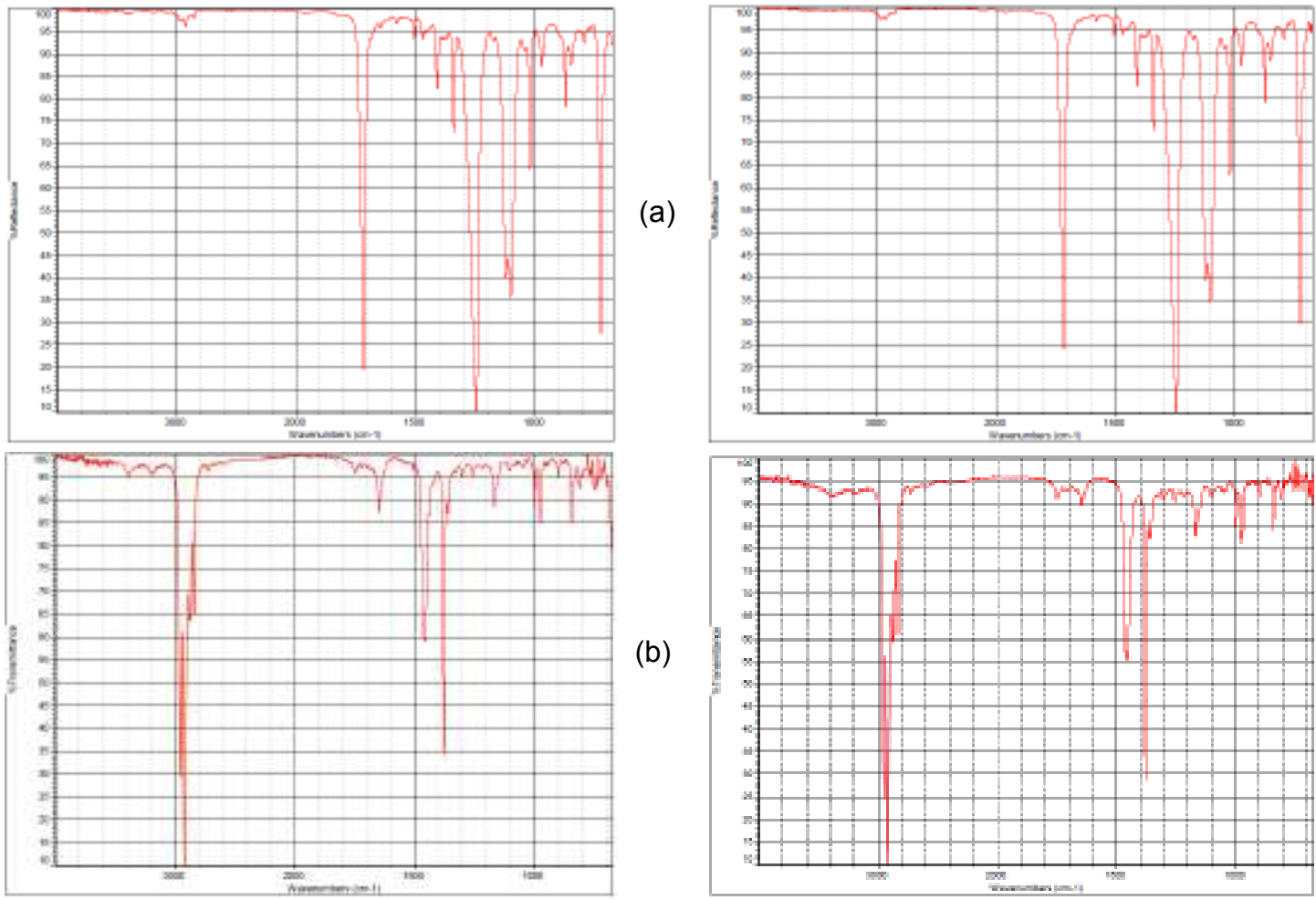

(b)

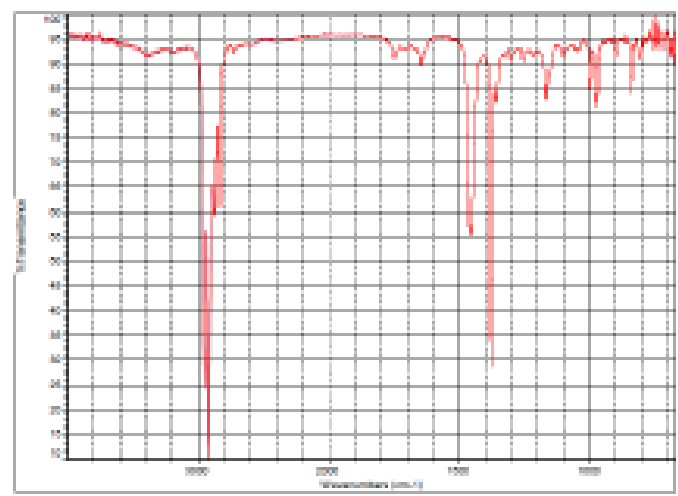

Figura 52 - Espectros de infravermelho da frente (a) e do verso (b) do filme plástico da Amostra 2 não irradiada e irradiada com 50 kGy, respectivamente 


\subsubsection{Análise dos resultados obtidos para os parâmetros relacionados às Amostras de Embalagem 1 e 2}

Os resultados para os parâmetros selecionados na análise da influência da irradiação com 50 kGy nas amostras de embalagem estudadas estão apresentados na TAB. 12.

Os números de determinações para obter a média dos resultados apresentados na TAB. 12 foram:

- dez determinações para os ensaios de impurezas e resistência a selagem do topo e dos lados direito e esquerdo da embalagem;

- cinco determinações para o ensaio de integridade da selagem;

Tabela 12 - Efeitos da radiação (50 kGy) nas propriedades das amostras de embalagem (envelope) 1 e 2

\begin{tabular}{l|l|c|c|c|c}
\hline \multicolumn{5}{c}{ EMBALAGEM } \\
\hline \multirow{2}{*}{ Ensaios } & \multicolumn{2}{c}{ Amostra 1 } & \multicolumn{2}{c}{ Amostra 2 } \\
\cline { 3 - 6 } & Não irradiada & Irradiada & Não irradiada & Irradiada \\
\hline \multirow{2}{*}{$\begin{array}{l}\text { Resistência } \\
\text { da selagem, }\end{array}$} & Topo & $6,69(0,17)$ & $6,80(0,24)$ & $5,43(0,44)$ & $4,21(0,33)$ \\
\cline { 2 - 6 } & Lado direito & $5,17(0,41)$ & $4,79(0,50)$ & $3,77(0,12)$ & $2,98(0,19)$ \\
\cline { 2 - 5 } & Lado esquerdo & $5,21(0,52)$ & $4,74(0,44)$ & $4,71(0,26)$ & $3,34(0,23)$ \\
\hline \multirow{2}{*}{$\begin{array}{l}\text { Impurezas, } \mathrm{mm}^{2} / \mathrm{m}^{2} \\
\text { Integridade da selagem }\end{array}$} & ausentes & ausentes & ausentes & ausente \\
\hline
\end{tabular}

Notas:

a. Os números entre parênteses referem-se ao desvio padrão das determinações paralelas.

b. Para identificação dos lados das amostras de embalagens, ver FIG. 39 do item 5.2.3.

Visto que os parâmetros de impurezas e integridade da selagem não sofreram alteração após irradiação com 50 kGy, o parâmetro utilizado para a análise das amostras de embalagem foi o de resistência da selagem o qual sofreu uma maior diminuição da força da selagem principalmente para a Amostra 2, após ser submetida à irradiação com 50 kGy.

Na FIG. 53, são apresentadas as variações obtidas para o parâmetro resistência da selagem de todos os lados de ambas as amostras. Analisando os resultados, verifica-se que a Amostra 1 sofreu uma variação muito pequena após irradiada com 50 kGy em todos os lados da embalagem. Porém, a Amostra 2 sofreu uma variação considerável em todos os lados da selagem assim como ocorreu com 25 kGy (item 5.2.3, FIG. 40). Entretanto, essas variações foram maiores com $50 \mathrm{kGy}$. 


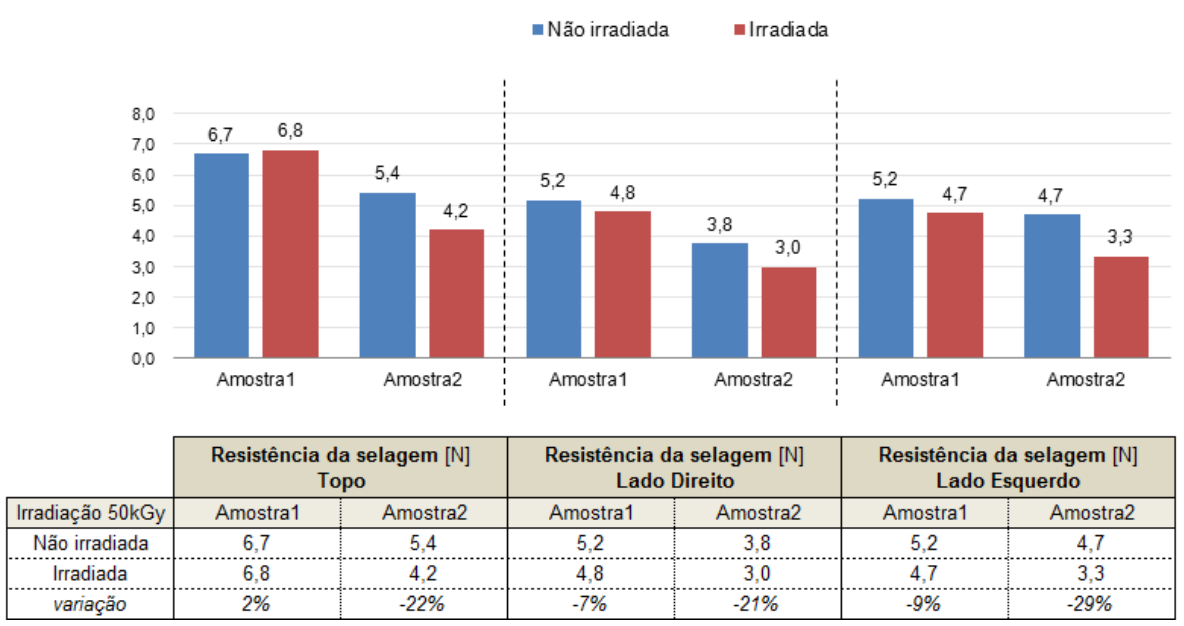

Figura 53 - Variações em porcentagem dos valores obtidos para o parâmetro de resistência da selagem das amostras 1 e 2 não irradiadas e irradiadas com 50 kGy

Após a irradiação com 50 kGy, ambas as amostras apresentaram odor forte, que desapareceu aproximadamente quinze dias após a irradiação. Como as embalagens foram irradiadas como um todo, o odor pode provir tanto do papel como do plástico. A causa deste odor não foi pesquisada por não ser escopo deste estudo; entretanto, o problema de odor já foi observado por outros pesquisadores.

Alguns pesquisadores acreditam que a presença de odores provenientes dos materiais de embalagens irradiadas pode resultar dos compostos produzidos por radiólise (Feazel et al., 1960; Azuma et al., 1983 e 1984a e b; Buchalla et al., 1993 e 1997). Riganakos et al. (1999) analisaram filmes plásticos (LDPE, EVA, PET/PE/EVOH/PE) e mostraram que um grande número de compostos voláteis foram produzidos após irradiação das embalagens com 5 kGy, 20 kGy e 100 kGy, associando-os à oxidação primária e secundária. Verificaram, ainda, que as concentrações destes compostos aumentaram com o aumento da dose de radiação. A maioria destes compostos foram hidrocarbonetos (saturados e insaturados), álcoois, aldeídos, cetonas, ácidos carboxílicos, etc. Uma parte destes compostos, principalmente ácidos carboxílicos, aldeídos e cetonas foram os responsáveis pelo indesejável odor e manchas. Keay (1968) relatou a presença de odor com dois materiais laminados (PET/PE e PP/MDPE) após irradiação com diferentes doses absorvidas (10 kGy a 160 kGy). Azuma et al.(1984b) observaram que a intensidade do odor aumentou com a concentração de oxigênio na atmosfera. Eles também relacionaram a quantidade de produtos voláteis formados pela irradiação com a intensidade de odores produzidos. 
Para melhor visualização e análise dos efeitos mais pronunciados causados pela irradiação ( 25 e 50 kGy) nas propriedades do papel, do filme plástico e da embalagem, foram construídos gráficos que permitiram uma comparação entre as variações obtidas para as diferentes doses (FIG. 54, 55 e 56).
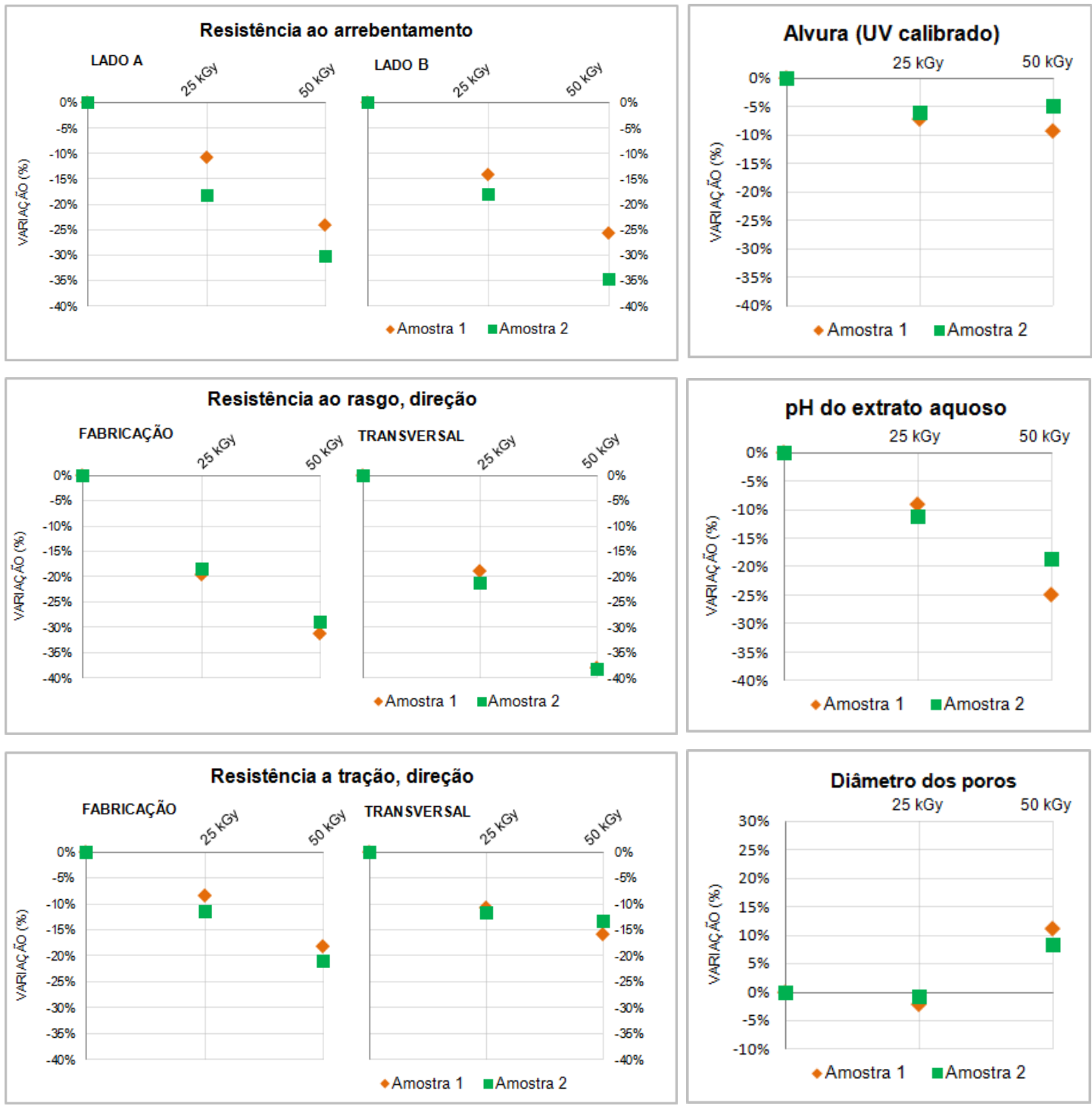

Figura 54 - Comparação entre as variações em porcentagem para os parâmetros mais alterados dos papéis das amostras 1 e 2 não irradiadas e irradiadas com 25 e 50 kGy

Analisando a FIG. 54, observa-se que a dose de 50 kGy produz um efeito negativo da ordem de 10 a 15 pontos percentuais a mais em relação à dose de 25 kGy nos parâmetros relacionados com a resistência mecânica do papel 
(resistência ao rasgo, ao arrebentamento e à tração). As maiores quedas de resistência mecânica acontecem para a Amostra 2. Talvez isto possa ser explicado pelo fato do papel da Amostra 1 ser formado por fibras celulósicas de coníferas, que são longas e levam o papel a uma maior resistência mecânica e, possivelmente, a sentir menos os efeitos da radiação gama em relação ao papel formado por fibras curtas, considerando uma mesma dose de radiação.

Para os ensaios de $\mathrm{pH}$, alvura e diâmetro dos poros, observa-se uma queda maior com 50 kGy especialmente para a Amostra 1. Para o ensaio de diâmetro dos poros, verifica-se que o tamanho dos poros aumentam com 50 kGy; por isto, no gráfico (FIG. 54), a variação é positiva. Porém, para este teste, o aumento é sinal de maior degradação, pois para o papel grau cirúrgico quanto maior o poro maior a possibilidade de entrada de microrganismos causando a contaminação do produto embalado.

$\mathrm{Na}$ análise da FIG. 55, pode-se observar que a tração dos filmes plásticos para as duas amostras de embalagem resultam em pequena variação entre 25 kGy e 50 kGy, porém, um pouco maior para a Amostra 1, formada pelo filme plástico constituído pelos polímeros poli(tereftalato de etileno) PET e polietileno (PE), que, com 25 kGy na direção de fabricação, não variou e com 50 kGy, sofreu um pequeno decréscimo; na direção transversal, sofreu um leve aumento com 25 kGy e uma diminuição com 50 kGy.

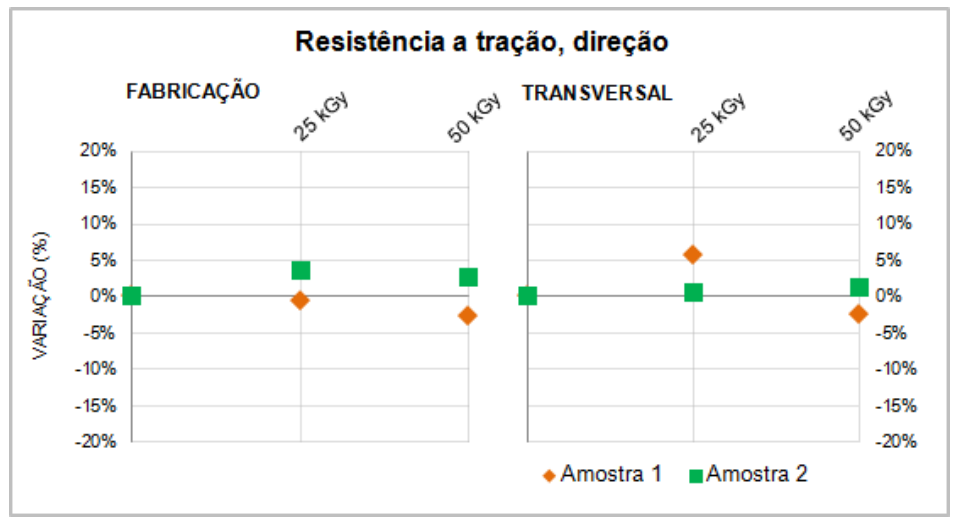

Figura 55 - Comparação entre as variações em porcentagem dos valores obtidos para o parâmetro resistência à tração dos filmes plásticos das amostras 1 e 2 não irradiadas e irradiadas com 25 e 50 kGy 
As variações determinadas entre 25 kGy e 50 kGy para o parâmetro resistência da selagem do topo e do lado direito das embalagens (FIG. 56) foram pouco significativas para ambas as amostras. Para o lado esquerdo, verifica-se uma queda mais acentuada com $50 \mathrm{kGy}$, principalmente para a Amostra 2 que foi de 20 pontos percentuais a mais do que o valor de variação obtido com 25 kGy.

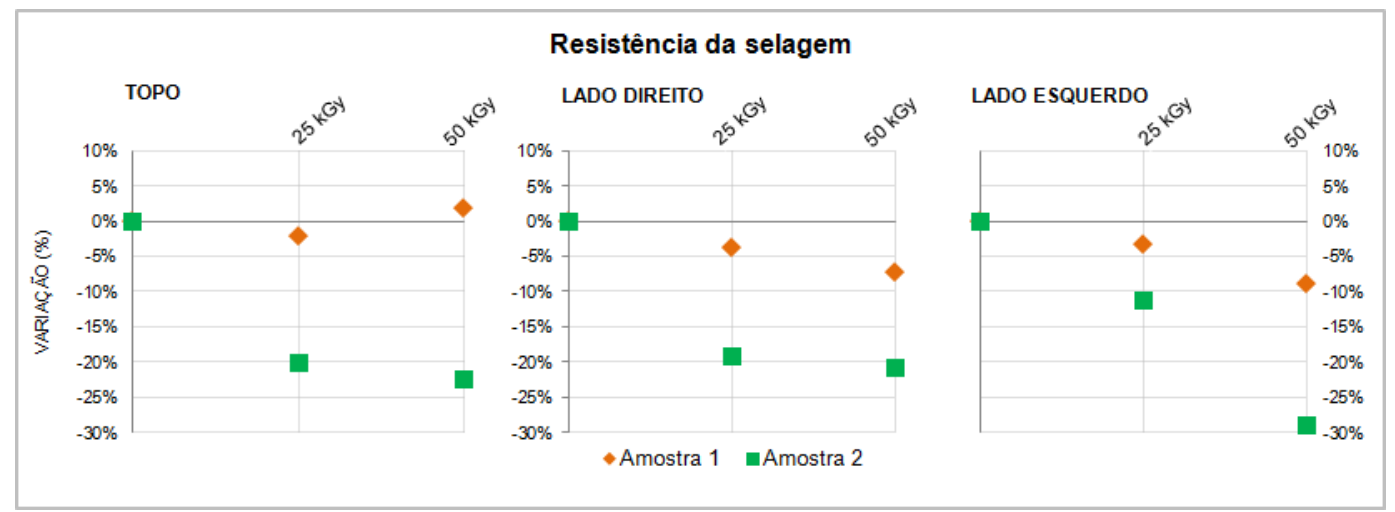

Figura 56 - Comparação entre as variações em porcentagem dos valores obtidos para o parâmetro resistência da selagem das amostras de embalagens 1 e 2 não irradiadas e irradiadas com 25 e 50 kGy

\subsection{Estudo da variação da dose absorvida no material com uso da dosimetria}

Durante este estudo, foi realizada a dosimetria dos materiais irradiados com 25 kGy, 40 kGy e 50 kGy. A partir do certificado de dosimetria obtido (Anexo A), verificou-se que as doses reais obtidas variaram em torno de $20 \%$ para 25 kGy, $10 \%$ para 40 kGy e $30 \%$ para 50 kGy. Isto confirma a preocupação ao submeter produtos embalados ao processo de esterilização por radiação ionizante em relação à dose que o produto irá receber efetivamente, principalmente quando se trata de esterilização de produtos em grande escala, e em irradiadores comerciais. Isto porque se verificou com os estudos feitos até aqui que a dose de radiação influencia muitas das propriedades dos materiais de embalagens que são esterilizadas por radiação ionizante.

A partir das duas amostras utilizadas para o estudo da dosimetria, onde as doses empregadas foram de $25 \mathrm{kGy}, 40 \mathrm{kGy}$ e $50 \mathrm{kGy}$, realizou-se alguns ensaios e fez-se um estudo comparativo entre os resultados obtidos. Estes resultados encontram-se na TAB. 13. 
Os números de determinações para se obter a média dos resultados apresentados na TAB. 13 foram:

- dez determinações para os ensaios de: alvura; fluorescência e resistência à tração;

- cinco determinações para os ensaios de resistência ao arrebentamento e microfuros.

As denominações utilizadas para os corpos de prova das Amostras $1 \mathrm{e}$ 2 na TAB. 13 foram $A, B$ e $C$ e representam as amostras fracionadas antes do tratamento e correspondem ao espelho das frações que foram irradiadas com 25 , 40 e 50 kGy, respectivamente.

Após a análise dos resultados da TAB. 13, construiu-se os gráficos apresentados na FIG. 57, onde foram feitas comparações entre as variações determinadas em porcentagem para as duas amostras de embalagem com e sem a irradiação (25 kGy, 40 kGy e 50 kGy). 
Tabela 13 - Efeitos da radiação (25, 40 e $50 \mathrm{kGy})$ nas propriedades dos materiais das amostras de embalagem 1 e 2 para estudo da dosimetria empregada

\begin{tabular}{|c|c|c|c|c|c|c|c|c|c|c|c|c|c|}
\hline \multicolumn{14}{|c|}{ PAPEL } \\
\hline \multirow{3}{*}{\multicolumn{2}{|c|}{ Ensaios }} & \multicolumn{6}{|c|}{ Amostra 1} & \multicolumn{6}{|c|}{ Amostra 2} \\
\hline & & \multicolumn{3}{|c|}{ Não irradiada } & \multicolumn{3}{|c|}{ Irradiada } & \multicolumn{3}{|c|}{ Não irradiada } & \multicolumn{3}{|c|}{ Irradiada } \\
\hline & & A & B & C & A & B & C & A & B & C & A & B & C \\
\hline \multicolumn{2}{|c|}{ Resistência ao arrebentamento, $\mathrm{kPa}$} & $367,5(49,2)$ & $384,8(18,9)$ & $387,6(40,7)$ & $328,2(34,9)$ & $289,9(38,9)$ & $302,2(39,2)$ & $313,6(10,4)$ & $330,4(23,8)$ & $297,6(30,3)$ & $278.3(14,6)$ & $260,1(8,4)$ & $232,5(15,5)$ \\
\hline \multicolumn{2}{|l|}{$\begin{array}{l}\text { Resistência à tração, } \mathrm{kN} / \mathrm{m} \\
\text { - direção de fabricação } \\
\text { - direção transversal }\end{array}$} & $\begin{array}{l}8,07(0,49) \\
3,78(0,17)\end{array}$ & $\begin{array}{l}7,94(0,27) \\
3,74(0,27)\end{array}$ & $\begin{array}{l}7,50(0,50) \\
3,71(0,21)\end{array}$ & $\begin{array}{l}7,47(0,44) \\
3,50(0,23)\end{array}$ & $\begin{array}{l}6,95(0,66) \\
3,42(0,16)\end{array}$ & $\begin{array}{l}6,61(0,49) \\
3,26(0,20)\end{array}$ & $\begin{array}{l}6,73(0,33) \\
3,31(0,12)\end{array}$ & $\begin{array}{l}6,77(0,28) \\
3,18(0,06)\end{array}$ & $\begin{array}{l}6,74(0,32) \\
3,15(0,10)\end{array}$ & $\begin{array}{l}6,63(0,40) \\
3,18(0,08) \\
\end{array}$ & $\begin{array}{l}6,28(0,22) \\
2,93(0,11)\end{array}$ & $\begin{array}{l}6,04(0,33) \\
2,88(0,15)\end{array}$ \\
\hline \multirow{2}{*}{$\begin{array}{l}\text { Fator de refletância difusa } \\
\text { no azul (alvura), \% }\end{array}$} & $\begin{array}{l}\text { UV } \\
\text { calibrado }\end{array}$ & $83,8(0,1)$ & $83,7(0,1)$ & $83,7(0,1)$ & $79,7(0,1)$ & $79,0(0,3)$ & $77,2(0,1)$ & $84,7(0,1)$ & $84,7(0,1)$ & $84,9(0,1)$ & $82,3(0,1)$ & $81,1(0,1)$ & $79,7(0,1)$ \\
\hline & $\begin{array}{l}\text { UV } \\
\text { excluído }\end{array}$ & $83,5(0,2)$ & $83,4(0,1)$ & $83,4(0,1)$ & $79,4(0,1)$ & $78,7(0,4)$ & $76,8(0,1)$ & $84,4(0,1)$ & $84,4(0,1)$ & $84,6(0,1)$ & $82,0(0,1)$ & $80,8(0,1)$ & $79,5(0,1)$ \\
\hline \multicolumn{2}{|c|}{$\begin{array}{l}\text { Fluorescência, diferença entre UV } \\
\text { calibrado e UV excluído, em \% }\end{array}$} & 0,30 & 0,36 & 0,37 & 0,33 & 0,24 & 0,31 & 0,31 & 0,32 & 0,35 & 0,30 & 0,29 & 0,28 \\
\hline \multicolumn{14}{|c|}{ FILME PLÁSTICO LAMINADO } \\
\hline \multirow{3}{*}{\multicolumn{2}{|c|}{ Ensaios }} & \multicolumn{6}{|c|}{ Amostra 1} & \multicolumn{6}{|c|}{ Amostra 2} \\
\hline & & \multicolumn{3}{|c|}{ Não irradiada } & \multicolumn{3}{|c|}{ Irradiada } & \multicolumn{3}{|c|}{ Não irradiada } & \multicolumn{3}{|c|}{ Irradiada } \\
\hline & & A & B & C & A & B & C & A & B & C & A & B & C \\
\hline Microfuros & & ausente & ausente & ausente & ausente & ausente & ausente & ausente & ausente & ausente & ausente & ausente & ausente \\
\hline
\end{tabular}

\section{Notas:}

a. Os números entre parênteses referem-se ao desvio padrão das determinações paralelas.

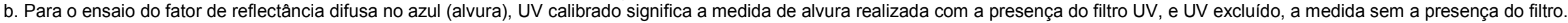

c. $\mathrm{A}=$ corpos de prova não irradiados e irradiados com $25 \mathrm{kGy}$; B = corpos de prova não irradiados e irradiados com $40 \mathrm{kGy}$ e $\mathrm{C}=$ corpos de prova não irradiados e irradiados com $50 \mathrm{kGy}$. 
$\mathrm{Na}$ FIG. 57, estão apresentadas as variações em porcentagem determinadas para a Amostra 1 após ser submetida a 25 kGy, 40 kGy e 50 kGy. Analisando os resultados, verifica-se que houve uma diminuição para quase todos os parâmetros assim como discutido nos itens 5.2 e 5.3 .
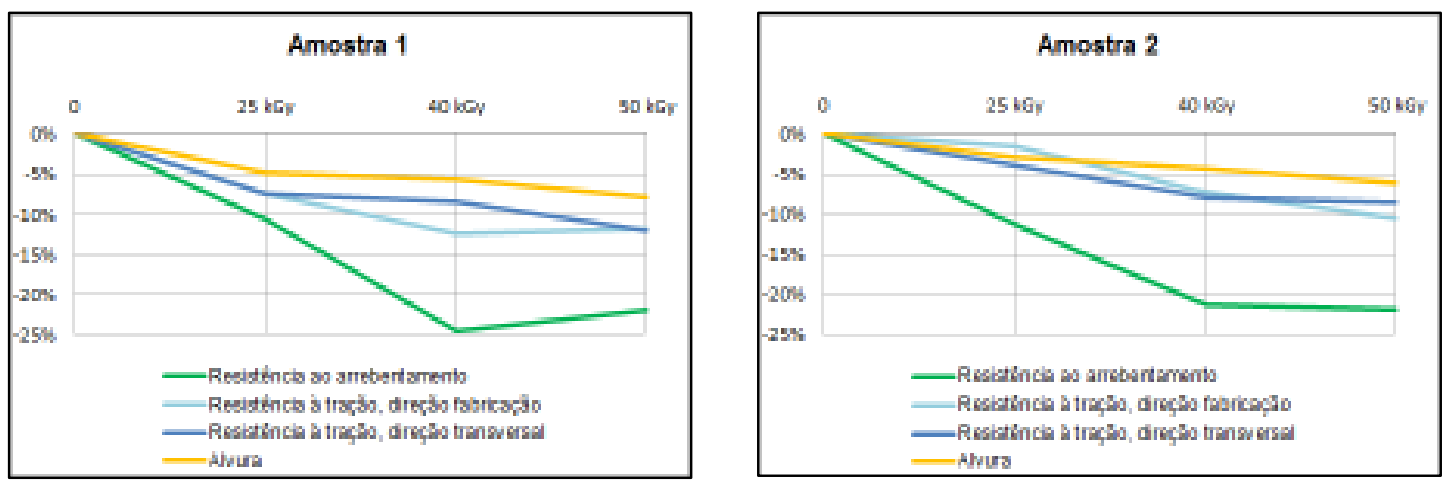

Figura 57 - Variações em porcentagem dos valores obtidos no estudo da dosimetria para as amostras 1 e 2 não irradiadas e irradiadas com 25, 40 e 50 kGy

Analisando a FIG. 57, foi possível constatar que o parâmetro menos afetado pela irradiação, em todas as doses aplicadas foi o de alvura, e o mais afetado foi o de resistência ao arrebentamento, tanto para a Amostra 1 quanto para a Amostra 2. Já o ensaio de resistência à tração apresentou variações semelhantes para as duas direções.

Observa-se também que quanto maior a dose de radiação aplicada maiores as variações para todos os ensaios e a resistência ao arrebentamento foi o parâmetro que mais sofreu com o aumento das doses.

\subsection{Atendimento das amostras aos requisitos da norma ABNT NBR 14990}

Apesar da maioria dos parâmetros analisados terem sido modificados pelas doses de radiação aplicadas, eles ainda estão em conformidade com os requisitos e especificações solicitados nas normas para as embalagens de produtos para saúde consideradas neste estudo, conforme apresentado nas TAB. 1 e 2 do item 4.3 Etapa III, exceto para os parâmetros:

- resistência ao arrebentamento para a Amostra 2, Lado B, após irradiação com 50 kGy; 
- diâmetro de poros, para as Amostras 1 e 2 tanto antes quanto após serem submetidas às irradiações com 25 kGy e 50 kGy;

- pH da Amostra 1 após irradiação com 50 kGy. 


\section{CONCLUSÕES}

As propriedades mais afetadas nos papéis de grau cirúrgico das amostras de embalagem estudadas, após serem irradiadas tanto com $25 \mathrm{kGy}$ quanto com $50 \mathrm{kGy}$ foram: alvura, $\mathrm{pH}$ e propriedades mecânicas de resistência ao arrebentamento, de resistência ao rasgo e de resistência à tração. Os efeitos foram proporcionais à elevação da dose de radiação.

Houve redução de 10 a 15 pontos percentuais nas propriedades de resistência mecânica do papel ao elevar a dose de 25 kGy para 50 kGy. Este efeito foi mais pronunciado para o papel de mistura de fibras de coníferas e de folhosas (Amostra 2) em relação ao papel confeccionado com fibras de coníferas (Amostra 1).

Os parâmetros gramatura, espessura, permeância ao ar e diâmetro dos poros foram muito pouco alterados pela irradiação com $25 \mathrm{kGy}$. Porém, com 50 kGy foram obtidas alterações expressivas no diâmetro dos poros dos papéis.

A irradiação induziu amarelecimento nas duas composições de amostras de papel estudadas e isto foi determinado através do parâmetro fator de refletância difusa no azul (alvura).

A parte cristalina da fibra não foi afetada pela radiação (25 kGy e 50 kGy).

Os espectros de infravermelho dos papéis das duas amostras não apresentaram nenhuma alteração devido às irradiações com 25 kGy e 50 kGy.

A gramatura, a espessura e os microfuros dos filmes plásticos laminados não foram alterados pela irradiação com 25 kGy e 50 kGy. A resistência à tração apresentou uma leve variação em ambas as amostras de embalagem irradiadas. A resistência à tração dos filmes plásticos sofreu pequena variação entre $25 \mathrm{kGy}$ e $50 \mathrm{kGy}$, porém, maior para a Amostra 1, formada pelo filme plástico multicamadas constituído pelos polímeros PET/PE. 
Os espectros de infravermelho obtidos para frente e verso dos filmes plásticos das duas amostras não apresentaram alterações após a irradiação (25 kGy e 50 kGy).

Quanto aos ensaios de impureza e integridade da selagem, a irradiação (25 kGy e 50 kGy) não induziu alterações nas duas embalagens fechadas. No entanto, a resistência da selagem diminuiu para ambas as amostras, sendo mais significativa para a Amostra 2, cujo papel é uma mistura de fibras longas e curtas e cujo filme plástico é formado pelos polímeros PET/PP. A variação do efeito foi proporcional à dose de radiação.

Entre as matrizes estudadas, pode-se concluir que o papel foi o material cujas modificações induzidas pelas radiações foram superiores em relação aos polímeros plásticos e embalagens formadas, principalmente nas propriedades mecânicas do papel de mistura de fibras de coníferas e de folhosas (Amostra 2). Importantes alterações foram obtidas nas fibras celulósicas do papel nas doses aplicadas, sobretudo com 50 kGy.

A dosimetria deste estudo foi realizada nos materiais irradiados com 25 kGy, 40 kGy e 50 kGy. As doses reais obtidas variaram em torno de $20 \%$ para 25 kGy, $10 \%$ para 40 kGy e $30 \%$ para 50 kGy, o que confirmou a preocupação ao submeter produtos embalados ao processo de esterilização por radiação ionizante em relação à dose que o produto irá receber efetivamente, principalmente, quando se trata de esterilização de produtos em grande escala e em irradiadores comerciais. 


\section{TRABALHOS FUTUROS}

As propriedades dos papéis das amostras estudadas foram as mais sensíveis ao processamento por radiação gama. Por este motivo, verificou-se a necessidade de maiores estudos sobre as propriedades e os efeitos da radiação em papéis de diferentes tipos, formados por diferentes fibras e submetidos a doses variadas para análise de uma possível utilização de papéis mais baratos e acessíveis na produção de embalagens destinadas à área da saúde. Isto porque, sabe-se que hoje o Brasil não é um produtor de papel grau cirúrgico; portanto, o país depende de importação.

Diferentes ensaios podem ser realizados para um futuro estudo, devendo incluir pesquisas sobre o efeito da radiação nos materiais que compõem as embalagens. Estes ensaios devem seguir a norma ABNT NBR 14990 - Parte 3 para análise do papel das amostras de embalagem e são eles: determinação de cloretos solúveis em água e de sulfatos solúveis em água, além de outros solicitados pela norma ABNT NBR 14990 - Parte 8 para análise da embalagem fechada, como: resistência ao processo de esterilização; características de selagem dos produtos laminados; orientação das fibras; e manutenção da esterilidade.

Diversas técnicas podem ser empregadas para estudos futuros e análise mais aprofundada sobre os efeitos da irradiação nos materiais das embalagens estudadas, como: técnica de espectroscopia no ultravioleta visível (UV/VIS) para a identificação da possível mudança de cor nos filmes plásticos; cromatografia líquida acoplada à espectrometria de massas para a análise da coloração amarelada do extrato aquoso; e cromatografia gasosa acoplada à espectrometria de massa (CGEM), técnica de "head-space", para a análise qualitativa da natureza química dos compostos orgânicos voláteis, os quais provocam odores fortes nas amostras de embalagens irradiadas. 


\section{ANEXO A \\ CÓPIA DO CERTIFICADO DE DOSIMETRIA}

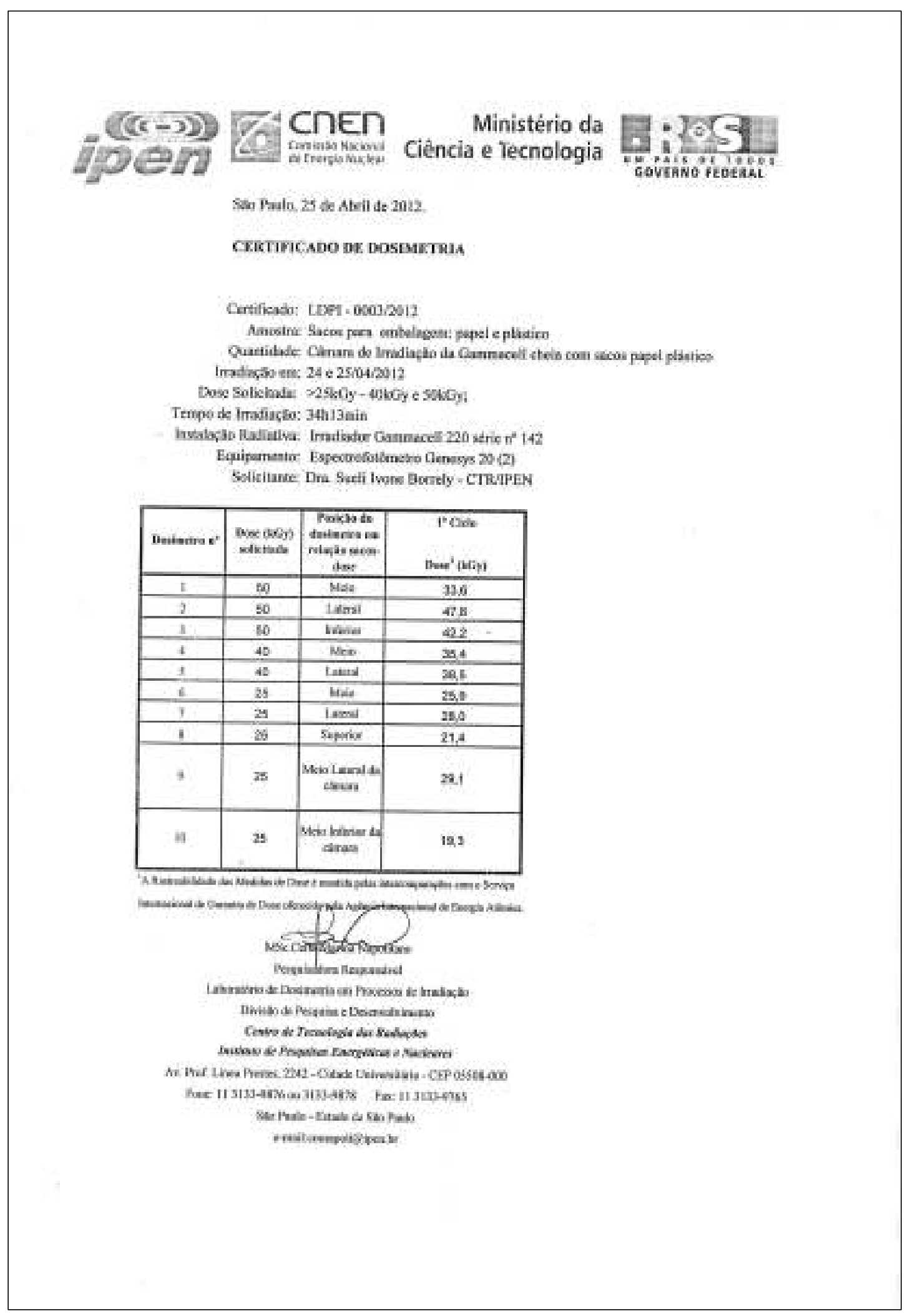




\section{REFERÊNCIAS BIBLIOGRÁFICAS}

ALBERTI, A.; BERTINI, S.; GASTALDI, G.; IANNACCONE, N.; MACCIANTELLI, D.; TORRI, G.; VISMARA, E. Electron beam-irradiated textile cellulose fibers. Eur. Polym.J., v.41, n.8, p.1787-1797, 2005.

ALMEIDA, E.V.R. Valorização da celulose de sisal: uso na preparação de acetatos e de filmes de acetatos de celulose/celulose e quitosana/celulose. 2009. 158p. Tese (Doutorado) - Universidade de São Paulo, São Carlos.

AMERICAN SOCIETY FOR TESTING AND MATERIALS. ASTM D882. Standard test methods for tensile properties of thin plastic sheeting. 1997.

ASSOCIAÇÃO BRASILEIRA DE NORMAS TÉCNICAS - ABNT. NBR 8259. Papel e cartão - Determinação de pintas. 2002.

ASSOCIAÇÃO BRASILEIRA DE NORMAS TÉCNICAS - ABNT. NBR 14129. Papel, cartão e pasta celulósica - Análise de composição fibrosa - Método Geral. 1998.

ASSOCIAÇÃO BRASILEIRA DE NORMAS TÉCNICAS - ABNT. NBR 14255. Papel e cartão - Determinação da permeância ao ar - Método Bendtsen. 1998.

ASSOCIAÇÃO BRASILEIRA DE NORMAS TÉCNICAS - ABNT. NBR 14990. Sistemas e materiais de embalagem para esterilização de produtos para saúde Parte 3: Papel grau cirúrgico para fabricação de embalagens para esterilização por processos de baixa temperatura. 2010.

ASSOCIAÇÃO BRASILEIRA DE NORMAS TÉCNICAS - ABNT. NBR 14990. Sistemas e materiais de embalagem para esterilização de produtos para saúde Parte 8: Envelope e tubular para esterilização por radiação. 2004.

ASSOCIAÇÃO BRASILEIRA DE NORMAS TÉCNICAS - ABNT. NBR NM-ISO 534. Papel e cartão - Determinação da espessura. 1998.

ASSOCIAÇÃO BRASILEIRA DE NORMAS TÉCNICAS - ABNT. NBR NM-ISO 536. Papel e cartão - Determinação da gramatura. 1998.

ASSOCIAÇÃO BRASILEIRA DE NORMAS TÉCNICAS - ABNT. NBR NM-ISO 1924-2. Papel e cartão - Determinação das propriedades de tração - Parte 2: Método da velocidade constante de alongamento. 1998.

ASSOCIAÇÃO BRASILEIRA DE NORMAS TÉCNICAS - ABNT. NBR NM-ISO 1974. Papel - Determinação da resistência ao rasgo - Método Elmendorf. 1998.

ASSOCIAÇÃO BRASILEIRA DE NORMAS TÉCNICAS - ABNT. NBR NM-ISO 2469. Papel, cartão e pasta celulósica - Medição do fator de reflectância difusa. 2004.

ASSOCIAÇÃO BRASILEIRA DE NORMAS TÉCNICAS - ABNT. NBR NM-ISO 2758. Papel - Determinação da resistência ao arrebentamento. 1998. 
ASSOCIAÇÃO BRASILEIRA DE NORMAS TÉCNICAS - ABNT. NBR NM-ISO 6588-2. Papel, cartão e pasta celulósica - Determinação do pH de extratos aquosos - Parte 2: Extração a quente. 2007.

ASSUMPÇÃO, R.M.V.; PINHO, M.R.R.; CAHEN, R.; PHILIPP, P. Polpação química. In: D'ALMEIDA, M.L.O. (Coord.). Celulose e Papel - Tecnologia de fabricação da pasta celulósica. 2.ed. São Paulo : IPT, 1988. v.1, cap.6, p.169319. (IPT - Publicação, 1777).

ATKINS, P.W. Physical chemistry. 6.ed. Oxford University Press, 1998.

AZUMA, K.; HIRATA, T.; TSUNODA, H.; ISHITANI, T.; TANAKA, Y. Identification of the volatiles from low density polyethylene film irradiated with an electron beam. Agric. Biol. Chem., v.47, n.4, p.855, 1983.

AZUMA, K.; TANAKA, Y.; TSUNODA, H.; HIRATA, T.; ISHITANI, T. Effects of film variety on the amounts of carboxylic acids from electron beam irradiated polyethylene film. Agric. Biol. Chem., v.48, n.4, p.2003, 1984a.

AZUMA, K.; TSUNODA, H.; HIRATA, T.; ISHITANI, T.; TANAKA, Y. Effects of the conditions for electron beam irradiation on the amounts of volatiles from irradiated polyethylene film. Agric. Biol. Chem., v.48, n.8, p.2009, 1984b.

BANSAL, P.; HALL, M.; REALFF, M.J.; LEE, J.H.; BOMMARIUS, A.S. Multivariate statistical analysis of $X$-ray data from cellulose: a new method to determine degree of crystalinity and predict hydrolysis rates. Bioresource Technol., Oxon, v.55, p.1-33, 1996.

BEREJKA, A.J.; KALUSKA, I.M. Materials used in medical devices. In: INTERNATIONAL ATOMIC ENERGY AGENCY. Trends in radiation sterilization of health care products. Viena : IAEA, 2008. p.159-174.

BRODY, A.L.; MARSH, K.S., (Eds.). The Wiley Encyclopedia of Packaging Tecnology. 2.ed. New York : Wiley, 1997.

BUCHALLA, R.; BOESS, C.; BÖGL, K.W. Radiolysis products in gammairradiated plastics by thermal desorption-GC-MS. Berlin : Federal Institute for Health Protection of Consumers and Veterinary Medicine (BgVV-Heft), 1997. p.1120.

BUCHALLA, R.; BOESS, C.; BÖGL, K.W. Analysis of volatile radiolysis products in gamma-irradiated LDPE and polypropylene films by thermal desorption-gas chromatography-mass spectrometry. Applied Radiation and Isotopes, v.52, n.2, p.251-269, Feb. 2000.

BUCHALLA, R.; SCHÜTTLER, C.; BÖGL, K.W. Effects of ionizing radiation on plastic food packaging materials: A Review, Part 1. Chemical and physical changes, and the fate of additives. J. Food Prot, v.56, n.11, p.998, 1993.

BUCHALLA, R.; SCHÜTTLER, C.; BÖGL, K.W. Radiation sterilization of medical devices. Effects of ionizing radiation on ultra-high molar-weight polyethylene. Radiation Physics and Chemistry, v.46, n.4-6, Part 1, p.579-585, Oct.-Dec. 1995.

BUTTERFIELD, F.J. The potencial long-term effects of gamma irradiation on paper. Stud. Conserv., v.32, n.4, p.181-191, 1987. 
CALVINI, P.; SANTUCCI, L.; Alcuni dati sugli effetti dell irradiazione gamma sulla carta. Boll. ICPL, v.35, p.55-62, 1978-1979.

CALVO, W.A.P. Desenvolvimento do sistema de irradiação em um irradiador multipropósito de cobalto-60 tipo compacto. 2005. Tese (Doutorado) - Instituto de Pesquisas Energéticas e Nucleares, autarquia associada à Universidade de São Paulo, São Paulo.

CANEVAROLO Jr., S.V. Ciência dos polímeros. São Paulo : Artliber, 2002. 183p.

CHAPIRO, A. Radiation-induced reactions. In: Encyclopedia of Polymer Science and Technology. New York : John Wiley, 1969. v.11, p.702-760, 1969.

CHMIELEWSKI, A.G.; BEREJKA, A.K. Radiation sterilization centres worldwide, In: INTERNATIONAL ATOMIC ENERGY AGENCY. Trends in radiation sterilization of health care products. Viena : IAEA, 2008. p.49-61.

CLEGG, D.W.; COLLYER, A.A. Irradiation effects on polymers. New York : Wiley Interscience, 1964.

CLEGG, D.W.; COLLYER, A.A. Irradiation effects on polymers. New York : Elsevier Science, 1991.

COSTA, L.; LUDA, M.P.; TROSSARELLI, L.; BRACH DEL PREVER, E.M.; CROVA, M.; GALLINARO, P. Oxidation in orthopaedic UHMWPE sterilized by gammaradiation and ethylene oxide. Biomaterials, v.19, n.7-9, p.659-668, Apr. 1998.

COSTA FILHO, P.A. Algorítimo genético na seleção de variáveis em calibração multivariada de dados espectroscópicos. 1998. 122p. Dissertação (Mestrado) - Instituto de Química, Universidade Estadual de Campinas, Campinas, 1998.

D’ALMEIDA, M.L.O. Composição química dos materiais lignocelulósicos. In: D'ALMEIDA, M.L.O. (Coord.). Celulose e Papel - Tecnologia de fabricação da pasta celulósica. 2.ed. São Paulo : IPT, 1988. v.1, cap.3, p.45-106. (IPT Publicação, 1777).

D'ALMEIDA, M.L.O.; BARBOSA, P.S.M.; BOARATTI, M.F.G.; BORRELY, S.I. Radiation effects on the integrity of paper. Radiation Physics and Chemistry, v.78, n.7-8, p.489-492, Jul.-Aug. 2009.

DEMERTZIS, P.G.; FRANZ, R.; WELLE, F. The effects of $r$-irradiation on compositional changes in plastic packaging films. Packaging Technology and Science, v.12, p.119-130, 1999.

DESCHÊNES, L.; ARBOUR, A.; BRUNET, F.; COURT, M.A.; DOYON, G.J.; FORTIN, J.; RODRIGUES, N. Irradiation of a barrier film: Analysis of some mass transfer aspects. Radiation Physics and Chemistry, v.46, n.4-6, p.805, 1995.

DIXSOM, H.P.; NELSON, J.C. Anaccelerated aging study of several writing papers. Tappi, v.45, n.10, p.753-760, Oct., 1962.

DOLE, M. The radiation chemistry of macromolecules. New York : Academic Press, 1972. v.l. 
DRISCOLL, M.; STIPANOVIC, A.; WINTER, W.; CHEGN, K.; MANNING, M.; SPIESE, J.; GALLOWAY, R.A.; CLELAND, M.R. Electron beam irradiation of cellulose. Radiation Physics and Chemistry, v.78, p.539-542, 2009.

DZIEDZIC-GOCLAWSKA, A.; KAMINSKI, A.; UHRYNOWSKA-TYSZKIEWICZ, I.; MICHALIK, J.; STACHOWICZ, W. Radiation sterilization of human tissue grafts. In: INTERNATIONAL ATOMIC ENERGY AGENCY. Trends in radiation sterilization of health care products. Viena : IAEA, 2008. p.231-260.

EKMAN, K.B.; WILÉN, C-E.; NÄSMAN, J.H. Radiation stability of in situ stabilized polypropylene. Polymer Report, v.34, n.17, p.3757-3759, Jan. 1993.

ENCYCLOPEDIA OF POLYMER SCIENCE AND ENGENEERING. New York : Wiley Interscience. 2.ed., 1988. v.13, p.667-707.

ERSHOV, B.G. Radiation-chemical degradation of cellulose and other polysaccharides. Russian Chemical Review, v.67, n.4, p.315-334, 1998.

EUROPEAN COMMITTEE FOR STANDARDIZATION. EN 552:1994. Sterilization of medical devices - Validation and routine control of sterilization by radiation. CEN, Brussels, 1994.

EUROPEAN COMMITTEE FOR STANDARDIZATION. EN 868:2009. Packaging materials and systems for medical devices which are to be sterilized. CEN, Brussels, 2009.

EUROPEAN PHARMACOPOEIA COMMISSION. European Pharmacopoeia. 4.ed. Strasbourg : Council of Europe, 2002.

FEAZEL, C.E.; BURKS, R.E.; MOSES, B.C.; TRIPP, G.E. Testing packages for irradiated foods. Packag. Eng. v.5, n.4, p.43, 1960.

FENGEL, D.; WEGENER, G. Wood: chemistry ultrastructure reactions. New York : Walter de Gruyster - Berlim, 1989. p.513.

FENGMEI, L., YING, W., XIAOGUANG, L., BAOYU, Y. Evaluation of plastic packaging materials used in radiation sterilized medical products and food. Radiation Physics and Chemistry, v.57, n.3-6, p.435-439, Mar. 2000.

FLORES, S.C.P. Gamma irradiation as fungicide and its effects on paper. Bull. AIC, v.16, p.15-44, 1975-1976.

FROHNSDORFF, R.S.M.; PETER, K.H. The control of radiation sterilization facilities. Radiation Physics and Chemistry, v.10, n.1, p.55-60, 1977.

GEORGE, J.; KUMAR, R.; SAJEEVKUMAR, V.A.; SABAPATHY, S.G.; VAIJAPURKAR, S.G.; KUMAR, D.; KACHAWAHHA, A.; BAWA, A.S. Effect of $\gamma$ irradiation on commercial polypropylene based mono and multi-layered retortable food packaging materials. Radiation Physics and Chemistry, v.76, p.1205-1212, 2007.

GOLDMAN, M. et al. The effects of gamma radiation sterilization and ageing on the structure and morphology of medical grade ultra high molar weight polyethylene. Polymer, v.37, n.14, p.2909-2913, Jul. 1996.

GONÇALVES, M.C. Microscopia eletrônica de varredura. In: CANEVAROLO Jr., S. V. Técnicas de caracterização de polímeros. São Paulo : Artliber, 2003. p.165-175. 
GONZALES, M.E.; CALVO, A.M.; KAIRIYAMA, E. Gamma radiation for preservation of biologically damaged paper. Radiation Physics and Chemistry, v.63, n.3-6, p.263-265, 2002.

GOULAS, A.E.; RIGHANAKOS, K.A.; KONTOMINAS, M.G. Effect of ionizing radiation on physicochemical and mechanical properties of commercial multilayer coextruded flexible plastics packaging materials. Radiation Physics and Chemistry, v.68, n.5, p.865-872, 2003.

GOULAS, A.E.; RIGHANAKOS, K.A.; KONTOMINAS, M.G. Effect of ionizing radiation on physicochemical and mechanical properties of commercial monolayer and multilayer semirigid plastics packaging materials. Radiation Physics and Chemistry, v.69, n.5, p.411-417, 2004.

GUISE, B. Sterilized and aseptic-packaging. Manufacturing Chemist, v.57, n.4, p.61, Apr. 1986.

HAJI-SAEID, M.; SAMPA, M.H.O.; CHMIELEWSKI, A.G. Radiation treatment for sterilization of packaging materials. Radiation Physics and Chemistry, v.76, n.89, p.1535-1541, Aug.-Sept. 2007.

HAMA, Y.; HIRADE, T. The effect of irradiation on polyethylene double-laminate by ethylene-vinyl alcohol copolymer. Radiation Physics and Chemistry, v.37, n.1, p.59, 1991.

HAMMAD, A.A. Microbiological aspects of radiation sterilization. In: INTERNATIONAL ATOMIC ENERGY AGENCY. Trends in radiation sterilization of health care products. Viena : IAEA, 2008. p.119-128.

HEMMERICH, K.J. Polymer materials selection for radiation-sterilized products. Medical Device and Diagnostic Industry, v.22, Part 2, p.78-79, 2000.

HUMMEL, D.O.; SCHOOL, F. Atlas of Polymer and Plastics Analysis. v.2, Part. A1 (p.1-456) e A2 (p.457-1035). 2.ed. Munich, Viena : Carl Hanser Verlag, Verlag Chemie., 1990.

INTERNATIONAL ATOMIC ENERGY AGENCY. Guideline for industrial radiation sterilization of disposable medical products ${ }^{60} \mathrm{Co}$, gamma radiation. Viena : IAEA, 1987.

INTERNATIONAL ATOMIC ENERGY AGENCY. Trends in radiation sterilization of health care products. Viena : IAEA, 2008. 261p.

INTERNATIONAL ORGANIZATION FOR STANDARDIZATION. ISO 11607. Packaging for terminally sterilized medical devices - Part 1: Requirements for materials, sterile barrier systems and packaging systems. 2006.

INTERNATIONAL ORGANIZATION FOR STANDARDIZATION. ISO 11607. Packaging for terminally sterilized medical devices - Part 2: Validation requirements for forming, sealing and assembly processes. 2006.

INTERNATIONAL ORGANIZATION FOR STANDARDIZATION. ISO 11137-1. Sterilization of health care products - Radiation - Part 1: Requirements for development, validation and routine control of a sterilization process for medical devices. 2006. 
INTERNATIONAL ORGANIZATION FOR STANDARDIZATION. ISO 11137-2. Sterilization of health care products - Radiation - Part 2: Establishing the sterilization dose. 2007.

JEON, D.H., LEE, K.H., PARK, H.J. The effects of irradiation on physicochemical characteristics of PET packaging film. Radiation Physics and Chemistry, v.71, p.1059-1064, 2004.

JEON, D.H.; PARK, G.Y.; KWAK, I.S.; LEE, K.H.; PARK, H.J. Antioxidants and their migration into food simulants on irradiated LLDPE film. LWT. Food Science and Technology, v.40, n.1, p.151-156, 2007.

JIPA, I.M.; STROESCU, M.; STOICA-GUZUN, A.; DOBRE, T.; JINGA, S.; ZAHARESCU, T. Effect of gamma irradiation on biopolymer composite films of poly(vinyl alcohol) and bacterial cellulose. Nuclear Instruments and Methods in Physics Research B., v.278, p.82-87, 2012.

KASPRZYK, H.; WICHLACZ, K.; BORYSIAK, S. The effect of gamma radiation on the supramolar structure of pine wood cellulose in situ revealed by $X$-ray diffraction. Electron. J. Pol. Agric. Univ., v.7, n.1, 2004.

KAWAMURA, Y. Effects of gamma irradiation on polyethylene, polypropylene and polystyrene. In: KOMOLPRASERT, V.; MOREHOUSE, K. (Eds.). Irradiation of food and packaging: recent developments. Washington : Oxford Press, 2004. p.262-276. (ACS Symposium Series 875).

KAWANO, Y. 2003. Espectroscopia vibracional de absorção no infravermelho. In: CANEVAROLO Jr., S.V. Técnicas de caracterização de polímeros. São Paulo : Artliber, 2003. p.17-39.

KEAY, J.N. The effect of doses of gamma radiation up to 16 Mrad on plastic packaging materials for fish. J. Food Technol, v.3, p.123, 1968.

KILLORAN, J.J. Chemical and physical changes in food packaging materials exposed to ionizing radiation. Radiation Res. Rev., v.3, p.369, 1972.

KILLORAN, J.J. Irradiation of multilayered materials for packaging thermoprocessed foods. In: SWALM, C.M. (Ed.). Chemistry of food packaging. Washington : ACS, 1974. p.87-94.

KOGA, M. Matérias-primas fibrosas. In: D’ALMEIDA, M.L.O. (Coord.). Celulose e Papel - Tecnologia de fabricação da pasta celulósica. 2.ed. São Paulo : IPT, 1988. v.1, cap.2, p.15-44. (IPT - Publicação, 1777).

KOSZINOWSKI, J.; PIRINGER, O. Importance of oxidation products of unsaturated hydrocarbons in the sensorial properties of food packaging. Part 1: Oxygen derivates of 1-alkanes. O. Dtsch. Lebensm. Rundsch, v.79, n.6, p.179, 1983.

KOWALSKI, J.B., HERRING, C., BARYSCKPOLEC, L., REGER, J., PATEL, J., FEENEY, M., TALLENTIRE, A. Field evaluations of the $V_{\max }$ approach for substantiation of a $25 \mathrm{kGy}$ sterilization dose and its application to other preselected doses. Radiation Physics and Chemistry, v.64, p.411-416, Aug.-Nov. 2002.

KUAN, G.S.S.; BENAZZI, R.C.; BERGMAN, S. Matérias-primas. In: D’ALMEIDA, M.L.O. (Coord.). Celulose e Papel - Tecnologia de fabricação do papel. 2.ed. São Paulo : IPT, 1988. v.2. p. 561-581. (IPT - Publicação, 1777). 
KUMAKURA, M.; KAETSU, I. Radiation-induced decomposition and enzymic hydrolysis of cellulose. Biotechnol. Bioeng., v.20, n.8, p.1309-1315, 1978.

KUMAKURA, M.; KAETSU, I. Radiation-induced decomposition and enzymic hydrolysis of cellulose. Int. J. Appl. Radiat. Isot., v.30, p.139-141, 1979.

LAAMANEN, J. Permanent papers. In: LEVLIN, J.; SÖDERBJELM, L. Pulp and Paper Testing. Helsinki : Finish Paper Engineers Association and Tappi, 1999. cap. 12, p.249-255 (Papermaking Science and Technology Series, Book 17).

LI, F.M. et al. Evaluation of plastic packaging materials used in radiation sterilized medical products and food. Radiation Physics and Chemistry, v.57, n.3-6, p.435-439, Mar. 2000.

LUNER, P. Paper permanence. Tappi, v.5, n.5, p.769-805, May 1969.

LUZ, E.R. Predição de propriedades de gasolinas usando espectroscopia FTIR e regressão por mínimos quadrados parciais. 2003. 109p. Dissertação (Mestrado) - Departamento de Química, Pontifícia Universidade Católica, Rio de Janeiro.

LYNE, M.B. The effect of $\mathrm{pH}$ on the permanence of LWC paper and a fine paper made from recycled LWC. Tappi Journal, v.78, n.12, p.138-144, Dec. 1995.

MAGAUDDA, G. The recovery of biodeteriorated books and archive documents through gamma radiation: some considerations on the results achieved. Journal of Cultural Heritage, v.5, p.113-118, 2004.

MAJALI, A.B.; SABHARWAL, S.; DESHPANDE, R.S.; SARMA, K.S.S.; BHARDWAJ, Y.K.; DHANAWADE, B.R. Development of radiation processes for better environment. In: RADIATION Technology for Conservation of the Environment. IAEA RWC-DOC 1023. Vienna, Austria, 1998. p.425-431.

MANO, E.B. Polímeros como materiais de engenharia. São Paulo : Edgard Blücher, 1991. p.197.

MARCINIEC, B.; DETTLAFF, K. Radiation sterilization of drugs. In: INTERNATIONAL ATOMIC ENERGY AGENCY. Trends in radiation sterilization of health care products. Viena : IAEA, 2008. p.187-230.

McLAUGHLIN, W.L.; BOYD, A.W.; CHADWICK, K.H.; McDONALD, J.C.; MILLER, A. Dosimetry for radiation processing. Great Britain : Taylor \& Francis, 1989.

METHA, K. Gamma irradiators for radiation sterilization. In: INTERNATIONAL ATOMIC ENERGY AGENCY. Trends in radiation sterilization of health care products. Viena : IAEA, 2008. p.5-25.

METHA, K.; ABEL-FATTAH, A.A. Dosimetry and the radiation sterilization process. In: INTERNATIONAL ATOMIC ENERGY AGENCY. Trends in radiation sterilization of health care products. Viena : IAEA, 2008. p.91-118.

MIRANDA, L.F. Estudo de parâmetros de processo para a síntese de membranas hidrofílicas a base de poli(n-vinil-2-pirrolidona). 1999. Tese (Doutorado) - Instituto de Pesquisas Energéticas e Nucleares, São Paulo. 
MIZANI, M.; SHEIKH, N.; EBRAHIMI, S. N.; GERAMI, A.; TAVAKOLI, F.A. Effect of gamma irradiation on physico-mechanical properties of spice packaging films. Radiation Physics and Chemistry, v.78, p.806-809, 2009.

MOURA, E.A.B.; ORTIZ, A.V.; WIEBECK, H.; PAULA, A.B.A.; SILVA, A.L.A.; SILVA, L.G.A. Effects of gamma radiation on comercial food packaging films: study of changes in UV/VIS spectra. Radiation Physics and Chemistry, v.71, p.199-202, 2004.

MUKHERJEE, R.N. Radiation: a means of sterilization. IAEA Bulletin, v.17, n.6, p.28-37, 1975.

O'DONNELL, J.H.; SANGSTER, D.F. Principles of radiation chemistry. New York : Arnold E., 1970.

OLIVEIRA, V.M.; ORTIZ, A.V.; MASTRO, N.L.D.; MOURA, E.A.B. The influence of eléctron-beam irradiation on some mechanical properties of comercial multilayer flexible packaging materials. Radiaton Physics and Chemistry, v.78, p.553-555, 2009.

PENTIMALLI, M.; RAGNI, P.; RIGHINI, G.; CAPITANI, D. Polymers and paper as packaging materials of irradiated food: Na NMR study. Radiation Physics and Chemistry, v.57, n.3-6, p.385-388, 2000.

PHILLIPS, G.O.; ARTHUR Jr., J.C. Effects of high-energy radiation on physical and chemical properties of purified fibrous cellulose. In: NEVELL, T.P.; ZERONIAN, S.H. (Eds.). Cellulose chemistry and its applications. Chichester, UK : Ellis Horwood, 1985. p.290-311.

PINTER, M.G.; GABRIELLONI, M.C. Validação de embalagens de algodão duplo e papel grau cirúrgico - Relato de experiência. Acta Paul Enf, São Paulo, v.13, n.especial, Parte II, p.94-95, 2000.

POINTING, S.B.; JONES, E.B.G.; JONES, A.M. Decay prevention in water logged archaeological wood using gamma irradiation. International Biodeterioration \& Biodegradation, v.42, p.17-24, 1998.

RAVASIO, U.; CONSLATI, G.; FAUCITANO, A.; MARIANI, M.; QUASSO, F. Effects of oxygen in gamma irradiated aromatic polyesters in film. European Polymer Journal, v.43, p.2550-2556, 2007.

REINKE, D. Flexible packaging of ground roasted coffee. In: FINLAYSON, K.M. (Ed.). Plastic film technology: high barrier plastic films for packaging. Lancaster PA: Technomic Publ., 1989. v.1, p.70-79.

RIGANAKOS, K.A.; KOLLER, W.D.; EHLERMANN, D.A.E.; BAUER, B.; KONTOMINAS, M.G. Effects of ionizing radiation on properties of monolayer and multilayer flexible food packaging materials. Radiation Physics and Chemistry, v.54, p.527-540, 1999.

RIZZO, M.M.; MACHADO, L.D.B.; BORRELY, S.I.; SAMPA, M.H.O.; RELA, P.R.; FARAH, J.P.S; SCHUMACHER, R.I. Effects of gamma rays on a restored painting from the XVIlth century. Radiation Physics and Chemistry, v.63, p.259-263, 2002.

ROJAS, O.J. Química del papel. Mérida : Universidad de Los Andes, 2003. 266p. (Serie Competencias Laborales, 3). 
SÀNCHEZ, O.J.; CARDONA, C.A. Trends in biotechnological production of fuel etanol from diferente feedstocks. Bioresource Technol., Oxon, v.99, p.52705295, 2008.

SANGSTER, D.F. Early events in high-energy irradiation of polymer. In: O'DONNELL, J.H.; REICHMANIS, E. (Eds). Effects of radiation on high technology polymers. Washington : American Chemical Society, 1989. Cap.2, p.14-26. (ACS, Symposium Series, 381).

SCHNABEL, W. Polymer degradation, principles and practical applications. Munich : Hanser International, 1981.

SCOTT, G. Mechanisms of polymer degradation and stabilization. New York : Elsevier Applied Science, 1990.

SILVA, R.; HARAGUCHI, S.K.; MUNIZ, E.C.; RUBIRA, A. Aplicações de fibras lignocelulósicas na química de polímeros e em compósitos. Química Nova, São Paulo, v.32, p.661-671, 2009.

SINGSON, C.; CARMONA, C.; GUZMAN, Z.D.; BARRUN, W.; LANUZA, L. Radiation sterilization of medical products in the Philippines. Radiation Physics and Chemistry, v.22, n.3-5, p.693-699, 1983.

SKOOG, D.A.; LEARY, J.J. Principles of instrumental analysis. 4.ed. New York : Saunders College Publishing, 1992.

SONNTAG, C. The chemical basis of radiation biology. London : Taylor \& Francis, 1987. 515p.

SPINKS, J.W.T.; WOODS, R.J. An introduction to radiation chemistry. New York : John Wiley e Sons, 1990.

STEPANIK, T.M.; RAJAGOPAL, S.; EWING, D.; WHITEHOUSE, R. Electronprocessing technology: a promising application for the viscose industry. Radiation Physics and Chemistry, v.52, p.505-510, 1998.

TAKÁCS, E.; WOJNÁROVITS, L.; BORSA, J.; FÖLDVRY, Cs.; HARGITTAI, P.; ZÖLD, O. Effect of $\gamma$-irradiation on cotton-cellulose. Radiation Physics and Chemistry, v.55, p.663-666, 1999.

TOMAZELLO, M.G.C. A aplicabilidade da radiação gama no controle de fungos que afetam papéis. 1994. 190p. Tese (Doutorado em Tecnologia Nuclear) - Instituto de Pesquisas Energéticas e Nucleares, São Paulo.

TÓTH, T.; BORSA, J.; TAKÁCS, E. Effect of preswelling on radiation degradation of cotton cellulose. Radiation Physics and Chemistry, v.67, p.513-515.

WEBB, L. Size isn't everything in paper chemical. Pulp and Paper Internacional, p.35-39, Jan. 1998.

WELLE, F.; MAUER, A.; FRANZ, R. Migration and sensory changes of packaging materials caused by ionizing radiation. Radiation Physics and Chemistry, v.63, n.3-6, p.841-844, Mar. 2002.

WILSKY, $\mathrm{H}$. The radiation induced degradation of polymers. Radiation Physics and Chemistry. v.29, n.1, p.1-14, 1987. 
WINPAK. Products. Health Care Packaging. Medical Packaging. Disponível em: <http://www.wipak.com/medical/index.html>. Acesso em: 07/08/2013.

WOO, L.; LING, M.K.; DING, S.Y.; WESTPHAL, S.P. Effect of ionizing radiation on the thermal oxidative stability of medical polymers. Termochim. Acta, v.324, p.179-185, 1988.

YAGHOUBI, N.; PERON, R.; LEGENDRE, B.; GROSSIORD, J. L.; FERRIER, D. Gamma and eléctron beam radiation induced physico-chemical modifications of polypropylene. Nuclear Instruments and Methods in Physics Research B., v.151, p.247-254, 1999.

YASUMURA, P.K. Caracterização de propriedades de papel para impressão por jato de tinta. 2011. Tese (Doutorado) - Escola Politécnica da Universidade de São Paulo, São Paulo. 